\title{
Radiative Aerothermodynamics of Entering Space Vehicles: Toward the Use of State-to-State Approach
}

\author{
S. Surzhikov ${ }^{*}, 1$, P. Reynier ${ }^{2}$, G. Seller ${ }^{3}$ and F. Taccogna ${ }^{3}$ \\ ${ }^{1}$ A. Ishlinsky Institute for Problems in Mechanics Russian Academy of Sciences, Prospect Vernadskogo 101-1, Moscow, \\ Russia \\ ${ }^{2}$ IngénierieetSystèmesAvancés, Pessac, France \\ ${ }^{3}$ IMIP-CNR, via Amendola 122/D, 70126 Bari, Italy
}

\begin{abstract}
Modern problems of radiative aerothermodynamics of entering space vehicles are demonstrated and analyzed in the paper.

New radiative gas dynamic problems concerned to coupling processes of non-equilibrium dissociation with radiation heat transfer in shock layers generated above large scale re-entry space vehicles returning from orbital and super orbital space mission are considered in the first part.

Three-dimensional numerical simulation data on radiative aerothermodynamics of Martian entry probes Pathfinder, Exomars and Mars Science Laboratory (MSL) are presented and analyzed in the second part. It is shown that integral radiative heating of leeward surface of the entry probes exceeds corresponding convective heating.

The third part is dedicated to consideration preliminary numerical simulation results on radiative gas dynamics of Galileo probes. At first, a review of the available results obtained during the mission preparation and post-flight analyses has been undertaken to select a computational matrix. This matrix has been selected by accounting for previous numerical efforts from the literature to crosscheck the results. Then, a model based on previous efforts has been set up for computing the flow-field around the probe at high altitude. Finally the test case matrix has been computed and crosschecked with existing numerical predictions performed.
\end{abstract}

Some possibilities of innovative magneto-hydrodynamic (MHD) technologies being applied to solve problems of re-entry vehicles heat protection are discussed in the fourth part.

All presented data demonstrate necessity of further development of the radiative aerothermodynamics based on state-tostate approaches.

Keywords: Magneto-hydrodynamics, multi-temperature approach, radiation gas dynamics, re-entry space vehicles.

\section{INTRODUCTION}

Modern models of computational aerophysics of space vehicles, entering into atmosphere with orbital and superorbital velocities, are based on gas dynamic models of thermally and chemically non-equilibrium gases. These models use Navier-Stocks (NS) or Reynolds averaged Navier-Stocks (RANS) equations in one-, two-, and three dimensions. Also they take into account radiative and non-equilibrium processes of chemical and physical kinetics, as well as different models of turbulent mixing and radiation transfer. Such models are realized, as a rule, on multi-block in homogeneous grids, or on unstructured grids. Used models of chemical kinetics are conjugated often with heterogeneous chemical processes on solid surfaces, or with kinetics of ablative processes. Electronic data bases on chemical-physical

*Address correspondence to this author at the A. Ishlinsky Institute for Problems in Mechanics Russian Academy of Sciences, Prospect Vernadskogo 101-1, Moscow, Russia; Tel: +7(495) 433-82-98;

Fax: +7(499) 739-95-31; E-mail: surg@ipmnet.ru kinetics, thermodynamic and transport properties, as well as the spectral optical properties are the important components of these computational models. And what is more, there is a common opinion in aerospace community that just in the direction of development of thermo-physical models of nonequilibrium high temperature flows should be concentrated significant efforts of scientists and engineers.

Development of such computational models and codes for description of aerothermodynamics of re-entry into Earth atmosphere apace vehicles or entry probes intended for investigation of planets of the Solar system is the important part of scientific and engineering programs which are currently realized in different space agencies.

This paper is dedicated to review of achievements of different scientific groups involved into project Phys4Entry with has a general goal to introduce into the radiative aerothermodynamic CFD practice state-to-state approaches for description thermal non-equilibrium flow conditions.

The paper contains four parts. The first two parts are dedicated to consideration of general peculiarities of 
aerothermodynamics of Earth (the part 1) and Mars entry (the part 2). The third part is dedicated to the Titan entry. Some possibilities of MHD technologies for flow control around entry bodies are discussed in the fourth part.

\section{RADIATIVE AEROTHERMODYNAMICS OF THE EARTH AND MARS ENTRY}

\subsection{Earth Entry}

Space vehicles of new generation, currently considering in space agencies, are characterized by the large sizes (with midship diameters about 5 meters). For example, the Orion International Space Station Crew Exploration Vehicle (ISS CEV) project considers possibility to use re-entry space vehicles with nose radius more than $400 \mathrm{~cm}$ [1]. This part of the paper contains description of current results of investigation of radiative and convective heating of such space vehicles for orbital trajectory conditions, as well as the urgent problems in the field of physical-chemical kinetics which has to be solved.

Two classes of computational codes are currently used in aerospace community. The first one is the two-dimensional computer codes with different models of chemical and physical kinetics. The computational fluid dynamic codes are based on the following groups of governing equations: (a) the Navier-Stokes and continuity equations, $(b)$ the equations of mass conservation of separate species, $(c)$ the equation of energy conservation, including total and vibrational energy, and $(d)$ radiation heat transfer equation in multi-group spectral approximation. As a rule, calculations are performed with using a multi-block and multi-grid computational technology.

The second one is the three-dimensional computer codes, which realizes the same models of physical and chemical hypersonic gas dynamics, as for the two dimensional case, but allow predict flow field around space vehicles under angles of attack. State of the art of the CFD problems of entry space vehicles is discussed in $[2,3]$.

Spectral optical properties of gases of complex chemical composition are provided by the several computer codes. These are: ASTEROID, HARA, LORAN, NEQAIR, PARADE, SPECAIR, SPRADIAN [4].

Some preliminary quantitative predictions of aerothermodynamics of large scale space vehicles were demonstrated in papers [2,3]. These are:

- $\quad$ The relatively large stand-off distance of bow shock wave front spacecraft surface $(\sim 30-40 \mathrm{~cm})$,

- $\quad$ The large zone of non-equilibrium flow in shock layer behind shock wave front at altitudes $>75 \mathrm{~km}(\sim 5$ $\mathrm{cm}$ ),

- $\quad$ High degree of inhomogeneity of convective heating of space vehicle surface at angle of attack.

It was shown [5] that the use of well known models of chemical kinetics [6-8] together with models of nonequilibrium dissociation drastically change distributions of gas dynamic and heat transfer functions in conditions of super-orbital entry. It was demonstrated also, that the entering velocity higher, the role of non-equilibrium processes increase. So, the question is how the radiative heating of space vehicle is sensitive to possible variation of the models due to some uncertainties in their formulation.

General goal of the part is to demonstrate the significant role of non-equilibrium dissociation processes in condition of orbital entry for space vehicles of large sized on their radiative heating. The Park-Jaffe-Partridge [6] model of chemical kinetics was fixed in these calculations. But it should be mentioned that the use of other models of chemical kinetics will probably demonstrate another quantitative correlations.

The role of vibrational relaxation of diatomic molecules in radiative gas dynamics was studied intensively in literature [9-11]. It was found that the use of multitemperature approach allows describe translational, rotational, vibrational and even electronic relaxation behind leading shock wave with acceptable accuracy for aerospace engineering [11].

Translational and vibrational temperatures being calculated are used for dissociation prediction. Different models of non-equilibrium dissociation are in common use: the Treanor-Marrone [9], the Marrone-Treanor [10], and the Park [11] models. All the models assume possibility to modify dissociation rate constants by multiplying of corresponding one-temperature rate constants on nonequilibrium factor, which is the function of translational and vibrational temperatures $Z\left(T, T_{V}\right)$. This factor, as a rule, less than unit because molecular translational and rotational internal degrees of freedom are excited significantly faster behind shock wave front than vibrational ones.

As it was mentioned above the non-equilibrium radiation heat transfer processes can be significant for large-scale spacecraft of the new generation (with blunt radiuses $\sim 5 \mathrm{~m}$ ) even at orbital entry $\left(V_{\infty} \sim 7 \mathrm{~km} / \mathrm{s}\right)$, at least at high altitudes $(\mathrm{H} \sim 80 \mathrm{~km})$ where intensities of radiative and convective heating are not so much as at region of maximal heating load (at altitudes $\mathrm{H} \sim 60-70 \mathrm{~km}$ ). It was predicted $[12,13]$ and found $[2,3]$ that for high altitudes of such space vehicles the radiative gas dynamic interaction becomes also significant. It means that taking into account radiation heat processes in energy conservation equation results in significant rebuilding of the gas dynamic fields. The role of dissociation processes is demonstrated in the paper just for these conditions.

First of all we will consider results of two-dimensional calculations for axisymmetric case of zero angle of attack. Two-dimensional radiative aerothermodynamics of Orion International Space Station Crew Exploration Vehicle (further, for short, Orion) was investigated for several trajectory points presented in Table $\mathbf{1}$. Note that trajectory points located higher than $\sim 75 \mathrm{~km}$ correspond, as expected, to non-equilibrium conditions inside shock layer above front shield, and large depth of vibrational relaxation zone behind shock wave front can be observed here.

Fig. (1) shows typical distributions of thermal and gas dynamic parameters of flow fields around Orion space vehicle for the first trajectory point. The Treanor-Marrone CVD model [9] was used in the case under consideration. Fig. (2) shows axial distributions of the translational and vibrational temperatures along stagnation line for succession trajectory points. 
Table 1. ISS CEV trajectory parameters [1].

\begin{tabular}{|c|c|c|c|c|c|}
\hline$\#$ & $\boldsymbol{t}, \mathbf{s}$ & $\mathbf{H}, \mathbf{k m}$ & $\boldsymbol{V}_{\infty}, \mathbf{k m} / \mathbf{s}$ & $\boldsymbol{p}_{\infty}, \mathbf{e r g} / \mathbf{c m}^{\mathbf{3}}$ & $\boldsymbol{T}_{\infty}, \mathbf{K}$ \\
\hline \hline 1 & 150 & 83.0 & 7.7 & 3.37 & 187 \\
\hline 2 & 200 & 78.2 & 7.7 & 14.2 & 202 \\
\hline 3 & 300 & 65.6 & 7.0 & 100. & 232 \\
\hline 4 & 400 & 65.6 & 6.2 & 100. & 232 \\
\hline 5 & 500 & 57.1 & 5.2 & 324. & 255 \\
\hline 6 & 600 & 42.8 & 3.0 & 1980. & 258 \\
\hline
\end{tabular}

Axial distributions of translational and vibrational temperatures along forward stagnation line at $\mathrm{t}=150 \mathrm{~s}$ are shown in Fig. (3). Different models of non-equilibrium dissociation were used in these calculations. The use of the Local Thermodynamic Equilibrium (LTE) model leads in the case under consideration to increasing of bow shock wave stand-off distance. In the frame of the LTE model rates of the forward and reverse chemical reactions were calculated with the use of the translational temperature. Vibrational temperatures shown for this calculation case were calculated only for comparison purposes. Translational and vibrational temperatures obtained with the use of different models of non-equilibrium dissociation are also shown in Fig. (3). In the last cases these vibrational temperatures were used for modification rates of forward chemical reactions. Taking into account the non-equilibrium dissociation leads to increasing of the translational temperature, because lesser part of initial kinetic energy is spent on dissociation and ionization.

Shock wave stand-off distance is achieved of $\sim 25 \mathrm{~cm}$ in the case under consideration, while the depth of relaxation zone equal to $\sim 5 \mathrm{~cm}$. Vibrational temperatures of molecules $\mathrm{N}_{2}, \mathrm{O}_{2}$ and $\mathrm{NO}$ increase in this zone from temperature of environment gas up to $T_{V} \sim 10,000 \mathrm{~K}$. Maximal vibrational temperature is achieved for molecules $\mathrm{NO}$, and minimal for molecules $\mathrm{N}_{2}$. Note that the use models of non-equilibrium dissociation follows to overheating of $\mathrm{N}_{2}$ vibrational mode above translational temperature at the end of the relaxation zone.

Fig. (4) show distributions of the species molar fractions along stagnation line in the shock layer above front shield for different mentioned thermodynamic models. Note that the large molar fractions of molecular $\mathrm{N}_{2}$ and $\mathrm{O}_{2}$ and low molar fractions of atomic $\mathrm{N}$ and $\mathrm{O}$ are observed in the vicinity of the space vehicle surface in full agreement with used assumption of the catalytic surface. Observed differences in species concentration distributions in shock layer have their origin in different rates of dissociation provided by the different models of non-equilibrium dissociation. Let us compare, for example, the species concentration distributions predicted by the LTE model, and the Park model of nonequilibrium dissociation [11] (Fig. 4a, b). One can see that in the first case the molecular $\left(\mathrm{N}_{2}, \mathrm{O}_{2}\right)$ and radicals (NO) species significantly less than in the second case due to higher degree of dissociation rate, while the temperature distributions in shock layer are similar. It means that spectral emissivity by vibronic bands of these diatomic molecules should be significantly lower in the first considered case. Just this effect we can observe at analysis of spectral heat fluxes reaching space vehicle surface at critical point, which are shown in Fig. (5). Radiation heat transfer was calculated with the use of 99 multi-group spectral models. Spectral absorption and emission coefficients were averaged inside each of the group. We notice that in the spectral region $\omega=25,000-55,000 \mathrm{~cm}^{-1}$ there is observable difference in the spectral heat fluxes. If now we will analyze cumulative functions of the radiative heat fluxes (see Figs. 5, 6), then we determine that the general difference in the heat fluxes is accumulated in this spectral region. And, as a result, the integral radiation heat fluxes on the space vehicle surface become about three times less than in the cases of taking into account the non-equilibrium dissociation (Fig. 6). Note that one can observe in Fig. (6) also the significant differences between intensity of radiative heating for different models of non-equilibrium dissociation.

Numerical simulation results obtained for ORION ISS CEW at angle of attack $\alpha=25^{\circ}$ in the first trajectory point are shown in Fig. (7). Note that for analysis of aerothermodynamics of space vehicles of large sizes there is a necessity to consider not only flow field above windward surface, but also above leeward surface and wake because radiative heating of the space vehicles has volume nature. Noticeably also that not only temperature distributions should be considered correctly, but also distributions of mass fractions of optically active species.

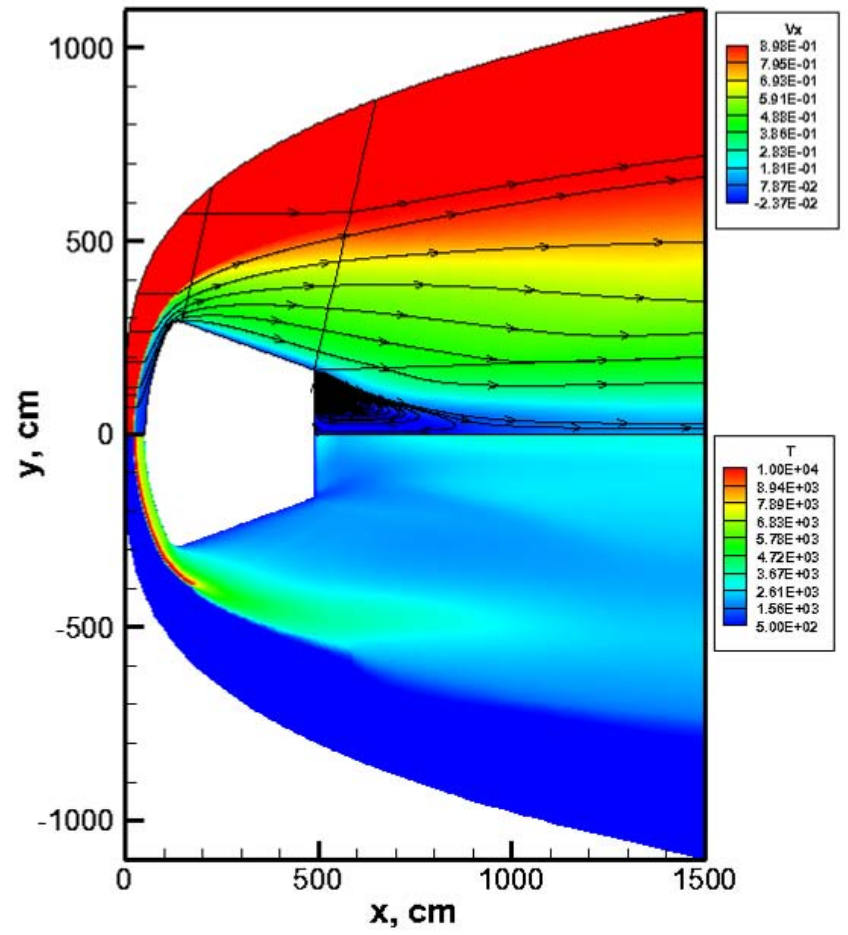

Fig. (1). Fields of longitudinal velocity $V_{x}=u / V_{\infty}$ (at the top) and translational temperature, in $\mathrm{K}$ (at the bottom), at trajectory point $\mathrm{t}=150 \mathrm{~s}$.

Fig. (7) show translational temperatures above leeward surface and in near and far wake, as well as distribution of longitudinal projection of the flow velocity. Densities of convective and radiative heat fluxes along surface for this and another trajectory points are shown in Fig. (8). Model of LTE was used in this case. Surface coordinate $S$ is counted off from the bottom boundary of the first block (see Fig. 9). 


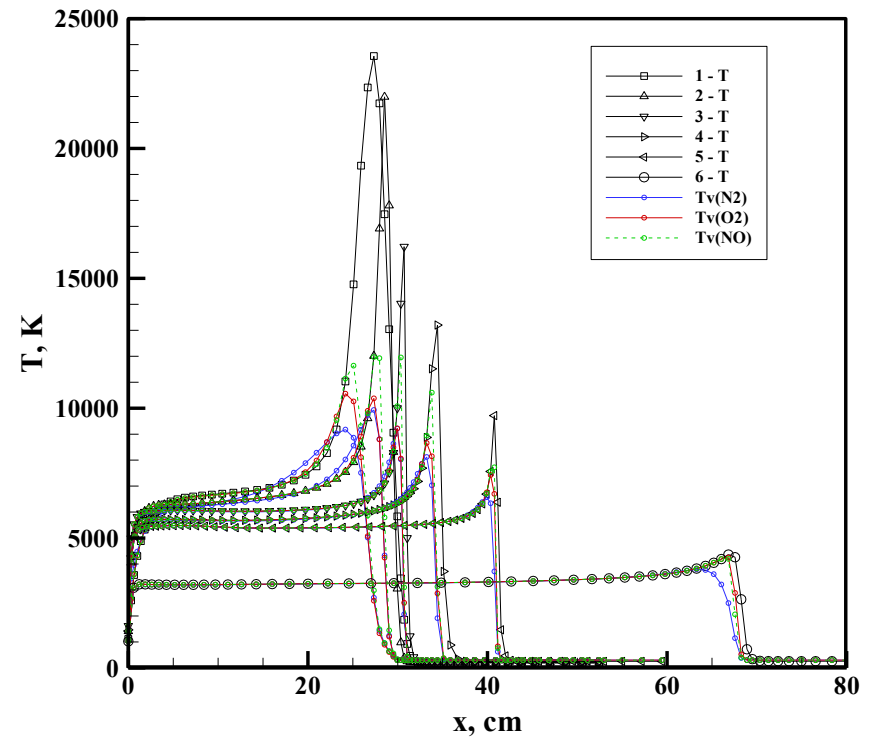

Fig. (2). Translational (solid lines) and vibrational (dashed lines) temperatures in shock layer at consecutive trajectory points. The Treanor-Marrone CVD model [9]; $1-\mathrm{t}=150 \mathrm{~s}, 2-\mathrm{t}=200 \mathrm{~s}$, $3-\mathrm{t}=300 \mathrm{~s}, 4-\mathrm{t}=400 \mathrm{~s}, 5-\mathrm{t}=500 \mathrm{~s}, 6-\mathrm{t}=600 \mathrm{~s}$.

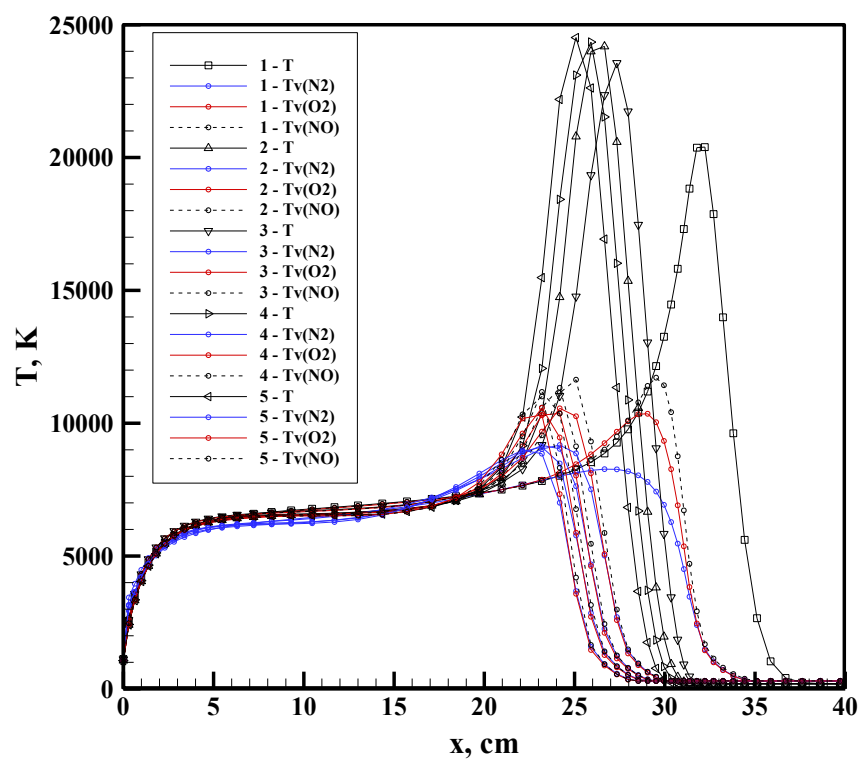

Fig. (3). Translational (solid lines) and vibrational (dashed lines) temperatures in shock layer under conditions of LTE (1), and nonequilibrium dissociation at $t=150 \mathrm{~s}$ : (2) - the Park model of CVD [11], (3) - the Treanor-Marrone model [9], (4) - the MarroneTreanor model [10] with $U=3$; (5) - the Marrone-Treanor model [10] with $U=6$.

Presented distributions show that at non-equilibrium stage of the trajectory the radiative heating can be significant. Also, presented calculated data clearly indicate that CVD models, being applied for solving coupled radiative gas dynamic problems for large space vehicles, exert noticeable effect on radiative heating of its surface at orbital entry on high altitudes $\left(h_{V} \geq 70 \mathrm{~km}\right)$.

\subsection{Partial Conclusion: The Challenging Problems of Earth Entry Aerothermodynamics}

Observed differences in radiative heating of re-entry space vehicle depending on used CVD models are of great practical interest for aerothermodynamic characterisation of the new generation SV. Unfortunately, the common limitation of investigated CVD models is that there is no way to recommend one or other such the model for trustworthy aerothermodynamic prediction, because each the model contains some heuristic parameters or physical assumptions. The state-by-state radiative collisional approach intensively developing last decades shows promise of increasing plausible predictive properties of coupled radiative gas dynamic models.

Observed large volumes of high temperature shock layers with non-equilibrium gas should motivate additional efforts in investigations of nature and models of relaxation of internal degree of freedoms in emitting gases.

\subsection{Martian Entry}

Aerophysics of Martian entry probes has some characteristic properties in comparison with Earth entry. These are: relatively low velocity of atmospheric entry $(\sim 6-7 \mathrm{~km} / \mathrm{s})$, relatively rare atmosphere, and significant role of radiative processes in ultraviolet (UV) spectral region, connected with intensive electronic band $\mathrm{CO}(4+)$, and in infrared (IR) spectral region, connected with vibrational bands of $\mathrm{CO}_{2}$ and $\mathrm{CO}$.

Theoretical basis of the Martian entry gas dynamic models which are in common use at the present have been developing about 50 years [14-25]. Conventionally this period can be divided into three parts. The first investigations were dedicated to experimental measurements of real thermo-physical and optical properties of $\mathrm{CO}_{2}-\mathrm{N}_{2}$ mixtures [15-20]. First theoretical models were also created in 60th-70-th years of last Century [14, 19, 20, 23].

From the beginning of 90 -th large number of investigations were published in AIAA journals which were connected with scientific program of Mars exploration established by NASA [21-35].

A lot of obtained calculation and experimental data [36-42] allow form general representation about aerothermodynamics of Martian entry aerothermodynamics. All these data were undoubtedly used at successfully realized Martian missions.

Development of the Martian radiative gas dynamic models was also the subject of some recently publications. Numerical simulation results on radiative aerothermodynamics of Martian entry probes were presented in [43-50]. These papers contain calculated data obtained with two- and three-dimensional codes. Calculation data for convective heating of front shield and leeward surface of probes [35-37] were used for verification of numerical simulation results of the given paper.

In this part we will show some predictions of conductive and radiative heat fluxes to surface of space vehicles Pathfinder, Exomars and Mars Science Laboratory (MSL) along their entry trajectories. These calculations are complicated by the non-equilibrium character of radiation heat transfer. Attempts to predict radiative heating along the whole surface of space vehicle pose a number of additional problems of radiation heat transfer in shock layer and wake regions. 

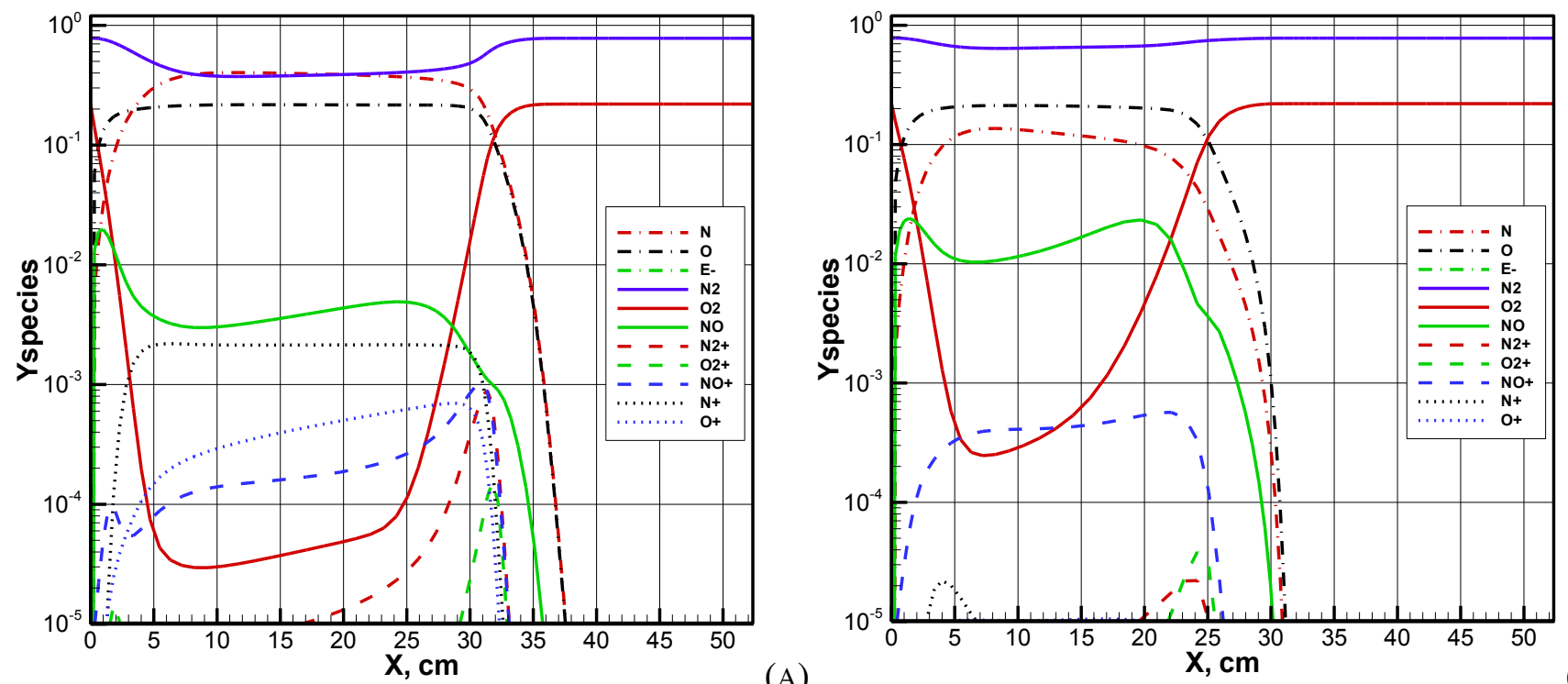

(A)
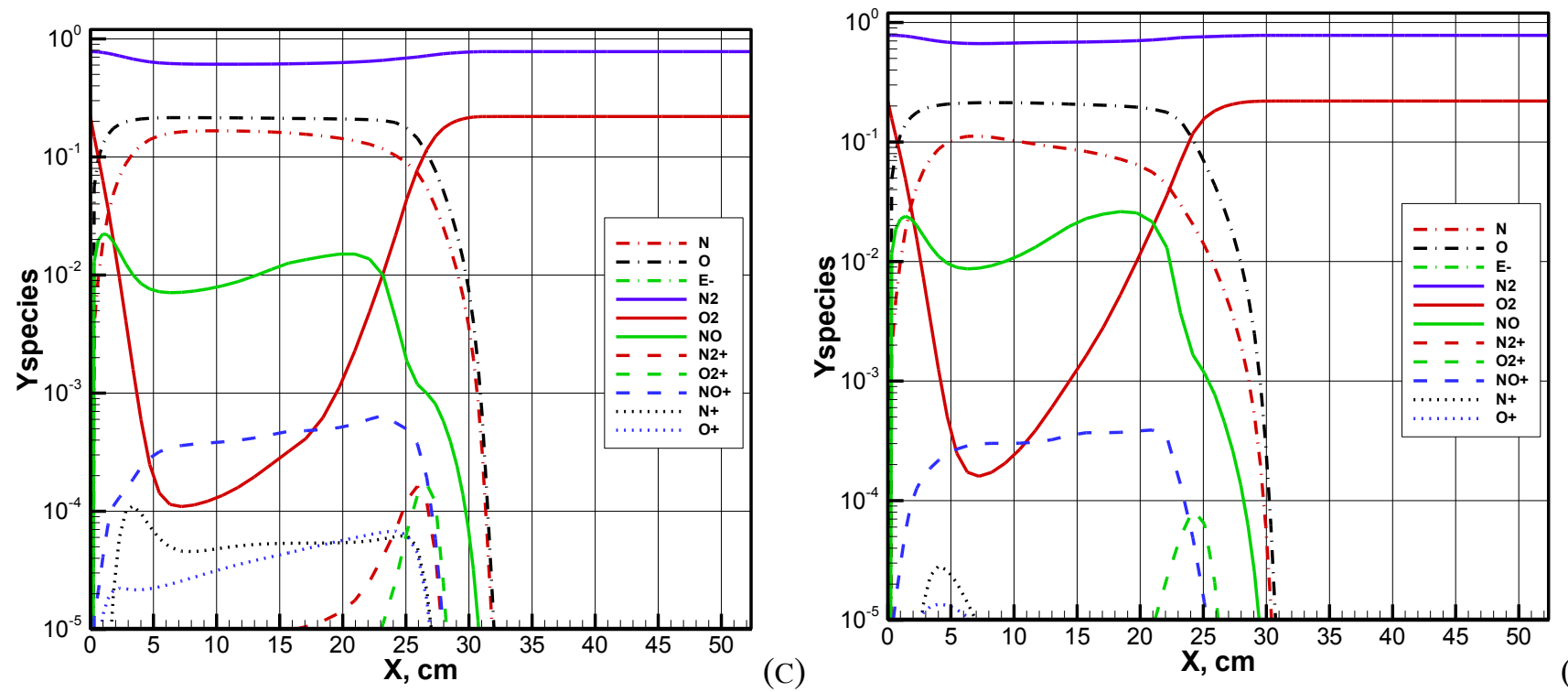

(D)

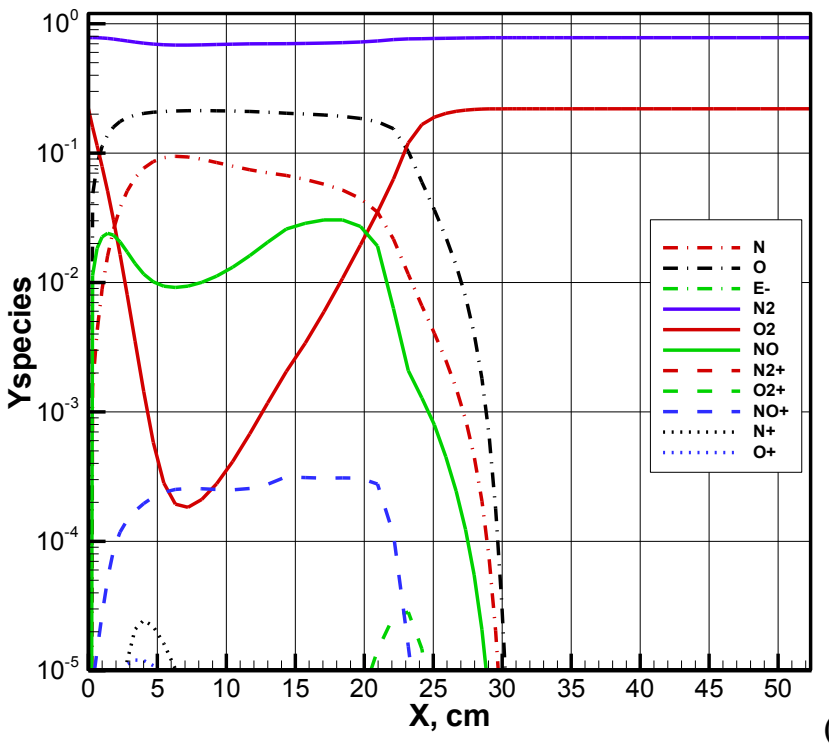

(E)

Fig. (4). Molar fractions of species along forward stagnation line at $t=150 \mathrm{~s}$. Catalytic surface. $\boldsymbol{a}$ - LTE model; $\boldsymbol{b}$ - the Park model of CVD [11]; $\boldsymbol{c}$ - the Treanor-Marrone model [9]; $\boldsymbol{d}$ - the Marrone-Treanor model [10] with $\mathrm{U}=3$; $\boldsymbol{e}$ - the Marrone-Treanor model [10] with $\mathrm{U}=6$. 
Wrad, $W * \mathrm{~cm} /(\mathrm{cm} * * 2)$
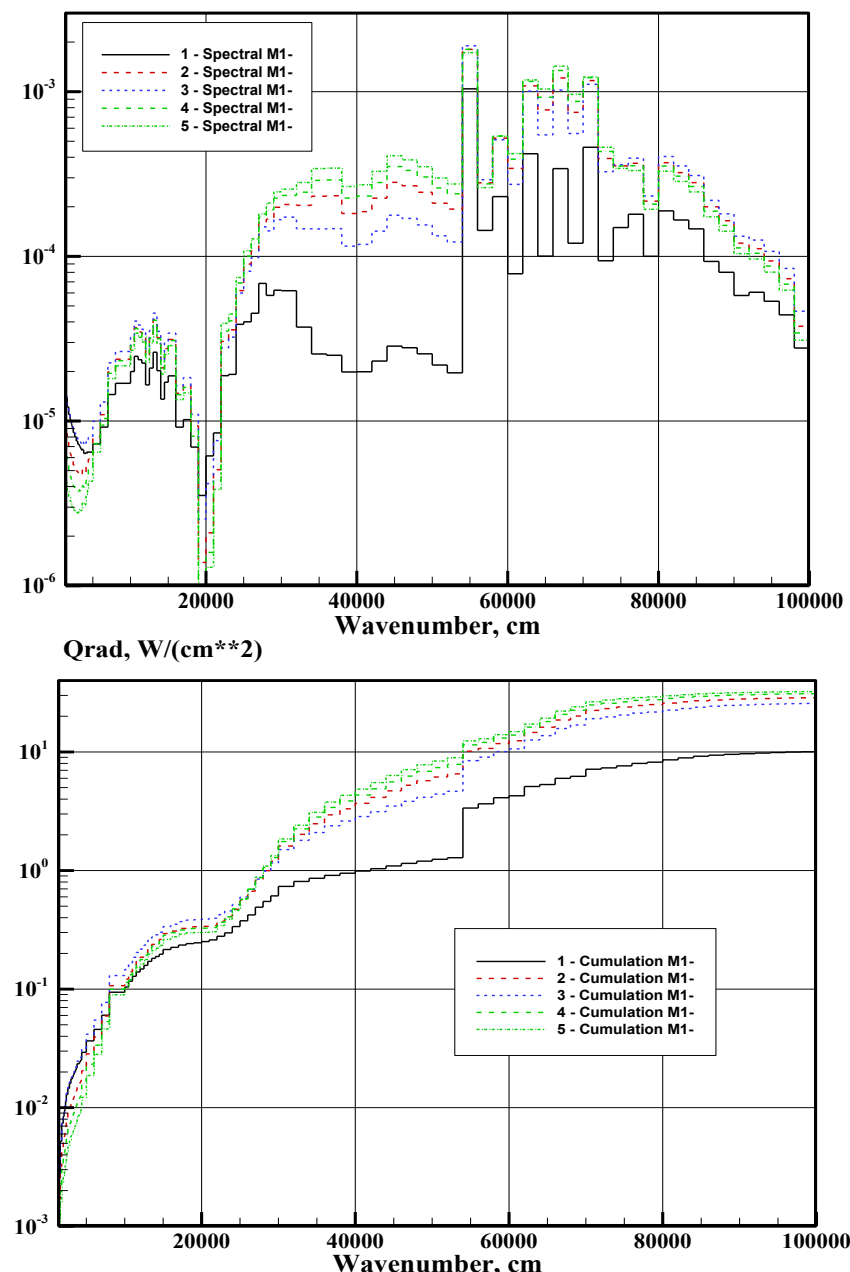

Fig. (5). Spectral radiation heat fluxes to stagnation point and corresponding cumulative functions at $\mathrm{t}=150 \mathrm{~s}$ : 1 - LTE model; 2 - the Park model of CVD [11]; 3 - the Treanor-Marrone model [9], 4 - the Marrone-Treanor model [10] with $U=3 ; 5$ - the Marrone-Treanor model [10] with $\mathrm{U}=6$.

General ways for verification and validation all of such models and codes are the comparison with available experimental and flight data such as [36, 39-42]. Unfortunately, the list of the data, is utterly small. Therefore comparative investigations of aerothermodynamic data obtained with the use of different computational models and codes are also of much current interest.

This part presents results obtained with the use of the three-dimensional (3D) multi-physics radiative gas dynamic model of Martian descent space vehicles, which is realized in NERAT-ASTEROID computer platform. Gas dynamic code NERAT-3D included unto the computing platform uses the time-relaxation method on structured multi-blocks curvilinear calculation grids. On the each time step the following groups of governing equations are integrated successively: the Navier - Stokes (or Reynolds averaged N-S equations, with several turbulence models) and continuity equations, the equations of mass conservation of chemical species, the equation of energy conservation together with equations for vibrational energy conservation for separate vibrational modes, the electron energy conservation, and the radiation heat transfer equation (in multi-group approximation). The energy conservation equation is integrated in the form of the Fourier-Kirchhoff equation, which is formulated relative to translational temperature.

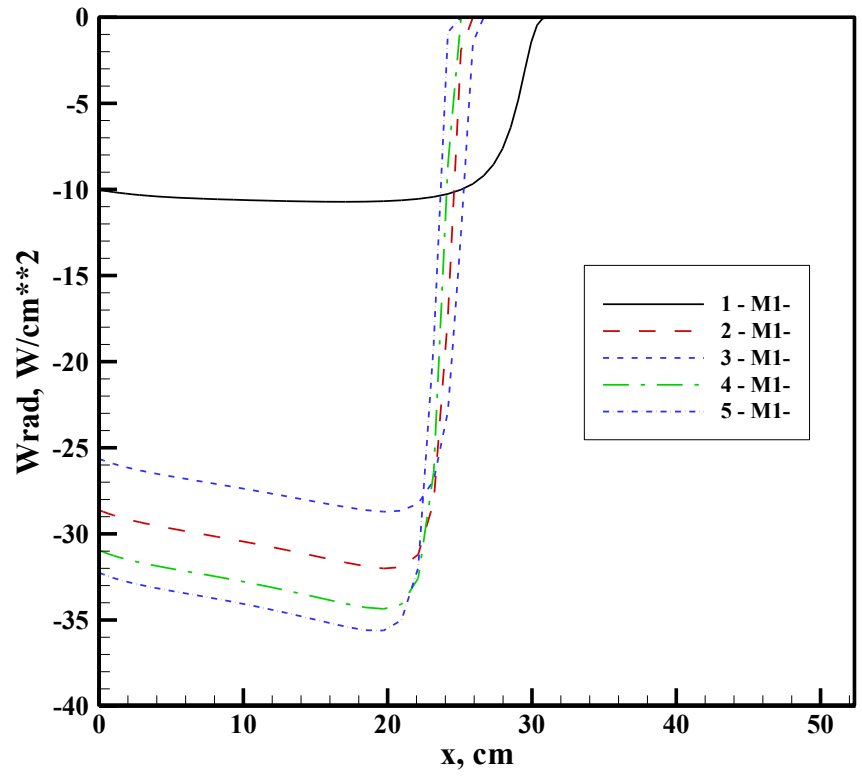

Fig. (6). Integral radiation heat fluxes directed to surface along stagnation line in shock layer at $\mathrm{t}=150 \mathrm{~s}$ : 1 - LTE model; 2 - the Park model of CVD [11]; 3 - the Treanor-Marrone model [9]; 4 - the Marrone-Treanor model [10] with $U=3 ; 5$ - the MarroneTreanor model [10] with $U=6$.

Some computing models, intended for determination of integrated radiative characteristics are included into the codes. These are: the multi-group (line-by-line) models of spectrum, the ray-tracing method for radiative heating prediction of space vehicle surface, the half-moment method for description radiation heat transfer inside inhomogeneous shock layers in multi-group approximation in view of random models of molecular lines [50]. To create different multi-group spectral models of gases of complex chemical composition a computing code ASTEROID [51] is used. Due to relatively small entry velocities of Martian space vehicles the interaction of gas dynamic and radiation heat transfer processes are considered in the frame of the model of weak radiation gas dynamic coupling. Nevertheless, it will be shown that the radiative heating of Martian space vehicles gives significant contribution to total heating of entry capsule.

\subsubsection{Initial Conditions for Numerical Simulation}

Preliminary results of systematic computational fluid dynamics (CFD) investigations of radiation aerothermodynamics of Martian entry probes were presented in [43-49]. Different kinds of entry probes and different freestream conditions were analyzed with the purpose of determination of intensity of convective and radiative heating along entry trajectories. Investigated freestream conditions are presented in Tables 2-4. The first reference for each the table shows original source for the parameters, while others indicate papers were corresponding calculations were performed.

Detailed description of the base aero-physical model is presented in [43, 49]. Numerical simulation results obtained 

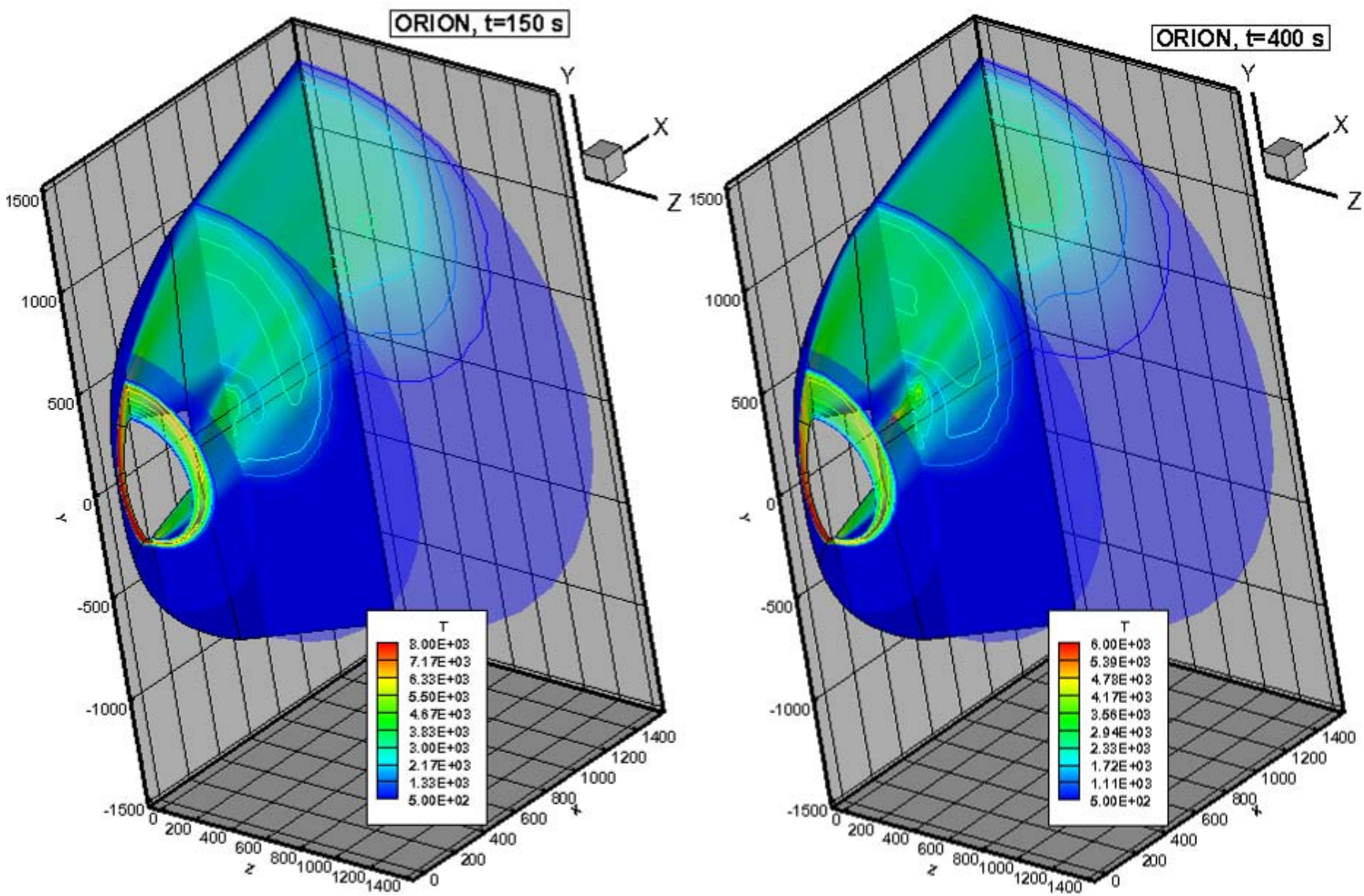

Fig. (7). Translational temperature at consecutive trajectory points. Angle of attack $\alpha=25^{0}$.

with two-dimensional code NERAT-2D for four trajectory points of Pathfinder $(t=42 \mathrm{~s}, 52 \mathrm{~s}, 66 \mathrm{~s}$, and $80 \mathrm{~s})$ are presented in [43]. It was demonstrated that front aerodynamic shield is heated generally by ultra-violet radiation with flux $q_{R} \sim 100 \mathrm{~W} / \mathrm{cm}^{2}$, while Pathfinder's leeward surface is heated by infrared radiation due to emissivity of vibrational bands $\mathrm{CO}_{2}\left(q_{R} \sim 2-5 \mathrm{~W} / \mathrm{cm}^{2}\right)$. Spectral radiation heat fluxes are presented in that paper in six points along Pathfinder's surface in meridional plane from the forward up to back stagnation points.

Three Exomars' trajectory points were studied also with NERAT-2D code (SC.1, SD.1, SD.2 [43]). It was shown that due to relatively low entry velocities a windward surface of Exomars is subjected by relatively small radiative heating $\left(q_{R} \sim 50-60 \mathrm{~W} / \mathrm{cm}^{2}\right)$. But radiative heating of its leeward surface remain as for Pathfinder $\left(q_{R} \sim 2-5 \mathrm{~W} / \mathrm{cm}^{2}\right)$. Also it was demonstrated that radiation heat flux on the front shield increases in 2-3 times from the stagnation point in the direction of its edge.

Results of some three-dimensional calculations are presented also in [43]. Only one Exomars' trajectory points (SC.1) was analyzed there. Convective and radiative heating of Exomars at angle of attack $\alpha=15^{\circ}$ were calculated for non-catalytic and catalytic surface. It was demonstrated that catalytic properties of space vehicle surfaces are extremely significant for predicted convective heating but not very significant for radiative heating.
Investigation of radiative aerothermodynamics of the two mentioned space vehicles was continued in $[55,56]$. Extremely non-equilibrium conditions for Pathfinder entry $(t=40 \mathrm{~s})$ and two quasi-"equilibrium" Exomars' trajectory points were analyzed in [43]. The paper contains also estimations of turbulent heating of front shield of Exomars.

Comparative analysis of three kinds of Martian descent vehicles (Pathfinder, Exomars and some model representation of the Mars Sample Return Orbiter (MSRO)) is presented in [55]. Studied trajectory points are presented in Table 4. This paper contains numerical prediction of radiative and convective heating of MSRO at angle of attack $\alpha=15^{\circ}$ and $V_{\alpha}=5.2 \mathrm{~km} / \mathrm{s}$. Calculated data for MSRO are compared with predictions for Pathfinder $\left(t=52 \mathrm{~s}, \alpha=0^{0}\right.$ and $V_{\alpha}=7.49 \mathrm{~km} / \mathrm{s}$ ), and for Exomars (point SC.1, $\alpha=15^{0}$ and $V_{\alpha}=4.22 \mathrm{~km} / \mathrm{s}$ ). All these calculations confirm high level of radiative heating of leeward surface due to $\mathrm{CO}_{2}$ emissivity $\left(q_{R} \sim 1-5 \mathrm{~W} / \mathrm{cm}^{2}\right)$.

Numerous results of methodological investigations concerned to development of computing models of Martian entry probes are presented in $[43,44]$. Different topologies of computing meshes are considered there, as well as comparison of two-dimensional and three-dimensional calculations for Exomars at trajectory point SC.1 [43].

First comparison for three-dimensional radiative and convective heating of Pathfinder (trajectory point $t=66 \mathrm{~s}$ ) and MSL (trajectory point $t=89 \mathrm{~s}$ ) are presented in [56]. As 

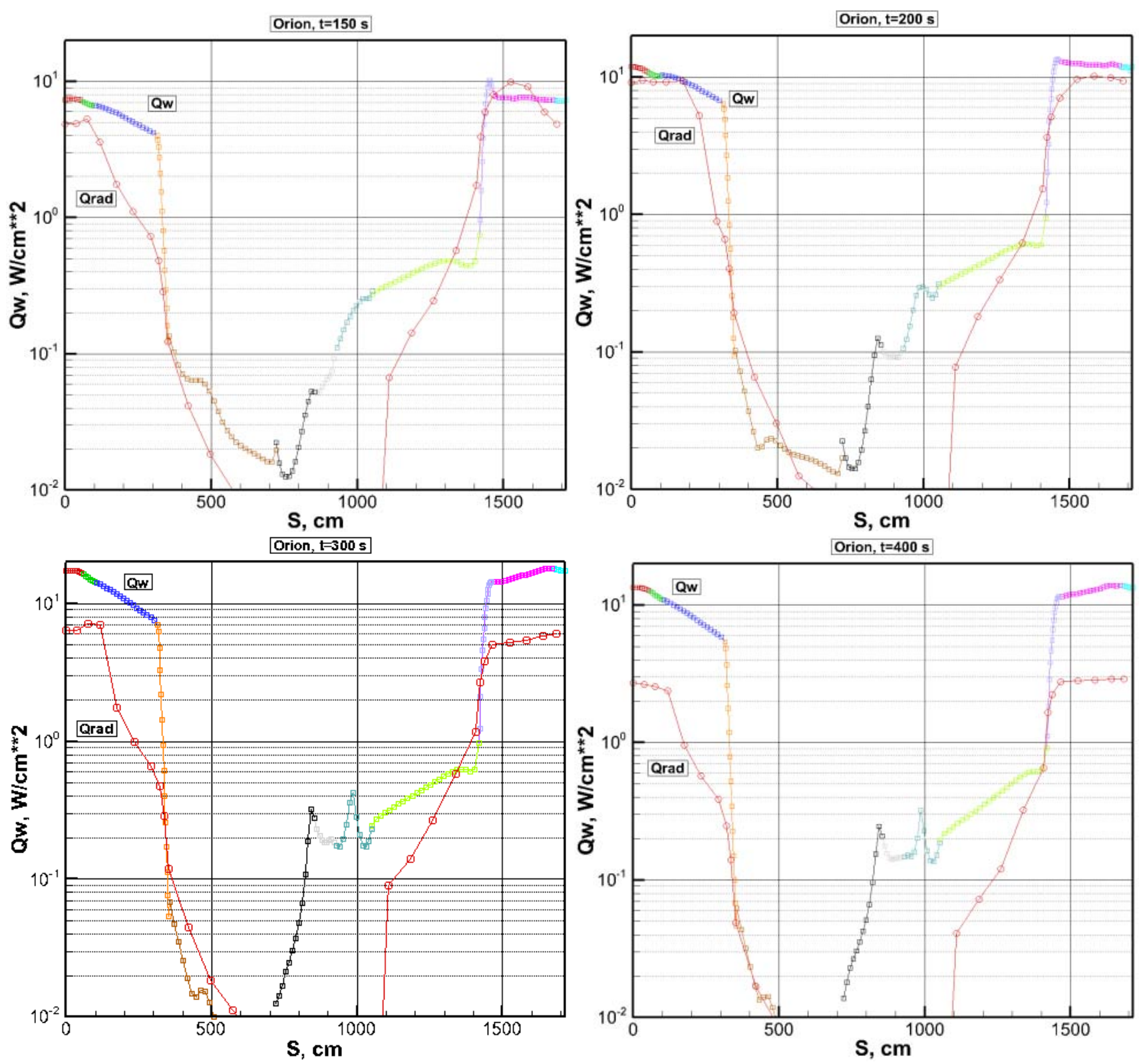

Fig. (8). Convective (squares) and integral radiation (circles) heat fluxes on spacecraft surface at $t=150(\boldsymbol{a}), 200(\boldsymbol{b}), 300(\boldsymbol{c})$ and $400(\boldsymbol{d})$ s. $\alpha=25^{0}$.

before, convective and radiative heat fluxes were calculated along surface, including windward and leeward surfaces. It was shown that the radiative heating of leeward surface of these space vehicles exceed ones convective heating.

Below we will consider typical general results of CFD research which were not demonstrated before, and formulate general conclusion of the numerical modeling.

\subsubsection{Radiative Gas Dynamics of Pathfinder}

Fig. (10) shows flow field about space vehicle Pathfinder under angle of attack $\alpha=15^{\circ}$. These calculations were performed for catalytic surface. The distinctive features of the flow field are the following:

Flow field asymmetry in distributions of longitudinal velocity $(a)$, mole fractions of $\mathrm{CO}(b)$ and $\mathrm{CO}_{2}(c)$, translational temperature $(d)$ and anti-symmetric vibrational temperature $\mathrm{CO}_{2}(e)$ is observed due to angle of attack $\alpha=15^{\circ}$;

Shock layer expansion above windward surface from the direction of incident flow is observed, as well as the vortex structure above the top piece of leeward surface;

- $\quad$ The catalytic surface is characterised by high mass fractions of $\mathrm{CO}_{2}$ and low mass fractions of $\mathrm{CO}$ in the vicinity of the surface (Fig. 10c). But behind bow shock wave high concentration of molecules $\mathrm{CO}$ is observed due to intensive dissociation of molecules $\mathrm{CO}_{2}$;

- It is not observed significant influence of catalytic properties of Pathfinder's surface on its integral and spectral radiative heating. At the same time, 
convective heating of catalytic surface is about two times higher than for non-catalytic one;

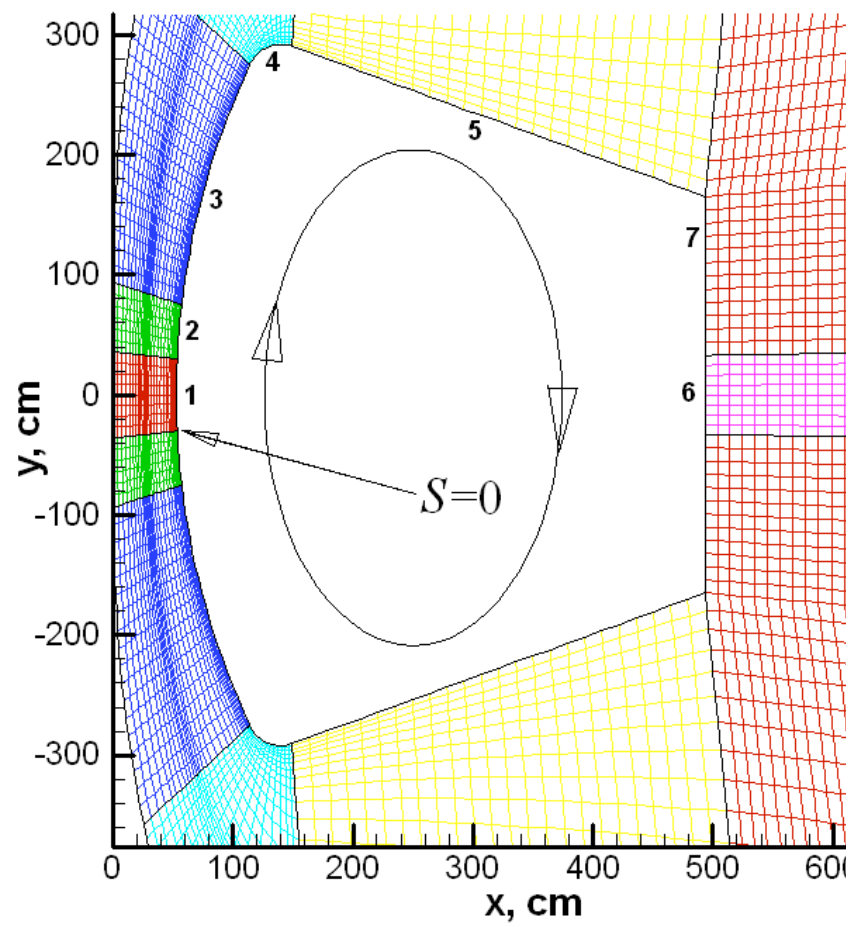

Fig. (9). Calculation grid near to space vehicle in three-dimensional case.

Table 2. Trajectory points for MSRO [42, 45, 47].

\begin{tabular}{|c|c|c|c|c|c|}
\hline No. & Time, $\mathbf{s}$ & $\boldsymbol{\rho}_{\infty}, \mathbf{g} / \mathbf{c m}^{3}$ & $\boldsymbol{p}_{\infty}, \mathbf{e r g} / \mathbf{c m}^{3}$ & $\boldsymbol{V}_{\infty}, \mathbf{m} / \mathbf{s}$ & $\boldsymbol{T}_{\infty}, \mathbf{K}$ \\
\hline \hline 1 & 70 & $3.14 \times 10^{-8}$ & 8.4 & 5687 & 140 \\
\hline 2 & 115 & $2.93 \times 10^{-7}$ & 78.7 & 5223 & 140 \\
\hline 3 & 175 & $3.07 \times 10^{-7}$ & 82.3 & 3998 & 140 \\
\hline 4 & 270 & $2.82 \times 10^{-8}$ & 7.6 & 3536 & 140 \\
\hline
\end{tabular}

Radiative heating of Pathfinder's surface should be taken into account at the leeward part (Fig. 11a), because it is exposed by infrared radiation in vibrational bands $\mathrm{CO}_{2}$ and $\mathrm{CO}$ from large volume of heated gas in the wake region. Integral radiation heat fluxes achieve here value about $1 \mathrm{~W} / \mathrm{cm}^{2}$. Emissivity of vibrational bands of $\mathrm{CO}_{2}$ and $\mathrm{CO}$ is easily observable in Fig. (11b, c);

Cumulative functions which are shown in Fig. (11c) indicate two spectral regions only give general contribution into total radiation heat fluxes. These are: $\Delta \omega=2000 \div 3000 \mathrm{~cm}^{-1}$ and $50000 \div 70000 \mathrm{~cm}^{-1}$. Vibrational molecular bands of $\mathrm{CO}_{2}$ are located in the first one, while the electronic bands of $\mathrm{CO}$ are located in the second spectral region. To determine the locations of grid nodes in equatorial cross section of the space vehicle, where spectral radiation heat fluxes were calculated, one can use Fig. (10f) (see \# 1, 36, $71,106,141,171)$.

\subsubsection{Radiative Gas Dynamics of Exomars}

This part presents three-dimensional numerical simulation results on spectral and integral radiative heating of Exomars' surface in Martian atmosphere for trajectory point SC.1 (see Table 3). Comparison of calculated data for other trajectory points are presented for non-axisymmetric and axisymmetric cases in [43, 44]. Current calculations were performed for trajectory point SC.1 at angle of attack $\alpha=15^{0}$. Figs. (12) show fields of longitudinal velocity, translational and one of vibrational temperature (for antisymmetric vibrational mode of $\mathrm{CO}_{2}$ ), as well as mass fractions of $\mathrm{CO}_{2}$ and $\mathrm{CO}$ in calculation domain.

The following significant peculiarities are observed in the flow field structure:

- General deceleration of incident flow is observed above the lower part of the windward surface. A thickening of the shock layer is also observed here;

Large scale vortex attached to leeward surface is shifted in the direction of flow. Obviously that spatial structure of the flow becomes more complex, because the vortex structure exists above curvilinear (conical) part of the surface;

Fluctuations of velocity field are observed in wake region. Calculation field in this part of flow is unsteady, while above the windward surface the full convergence of numerical solution is observed. Fig. (12d, e) illustrate degree of temperature nonequilibr-ium in the case under consideration. Only one of vibrational modes is characterised here. Other vibrati-onal temperatures also differ significantly from the translational temperature. This fact should be taken into account at prediction of radiative heating of spacecraft surfaces in Martian atmosphere. Fig. $(\mathbf{1 2 b}, \mathbf{c})$ show distributions of mass fractions of $\mathrm{CO}_{2}$ and $\mathrm{CO}$ in the calculation domain. One can see, as before, high level of $\mathrm{CO}_{2}$ mass fractions and low level of CO mass fraction in the vicinity of the surface. Such behaviour of mass fractions is in full agreement with used assumption concerning catalytic properties of the surface.

Investigation of influence of catalytic properties of streamlining surface on its radiative heating should be performed in future. Here we present some numerical simulation results on convective and radiative heating of Exomars under angle of attack, which were obtained for catalytic surface.

Fig. (13a) shows distribution of convective and integral radiation heat fluxes along over all Exomars' surface in the plane $z=0$. Coordinate along the surface in equatorial plane is counted out from the point \# 1 showed in Fig. (12f). This point is located on the bottom boundary of the first grid block. Presented data demonstrate significant fact of convective heating domination on the windward part of the surface, and of the radiative heating domination on the leeward part of the surface. Note, that such a ratio of levels of convective and radiative heating is very sensitive to initial conditions.

In the case under consideration general contribution into radiation heat flux provides infrared radiative energy. 

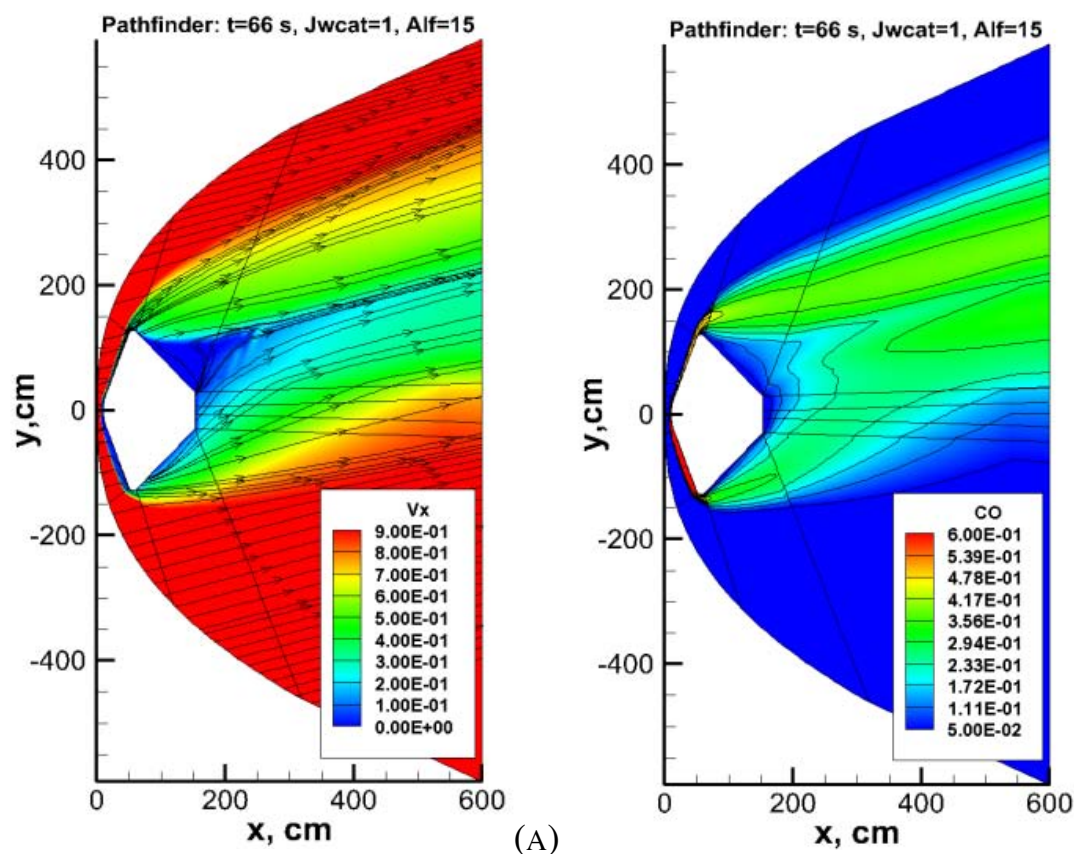

(A)
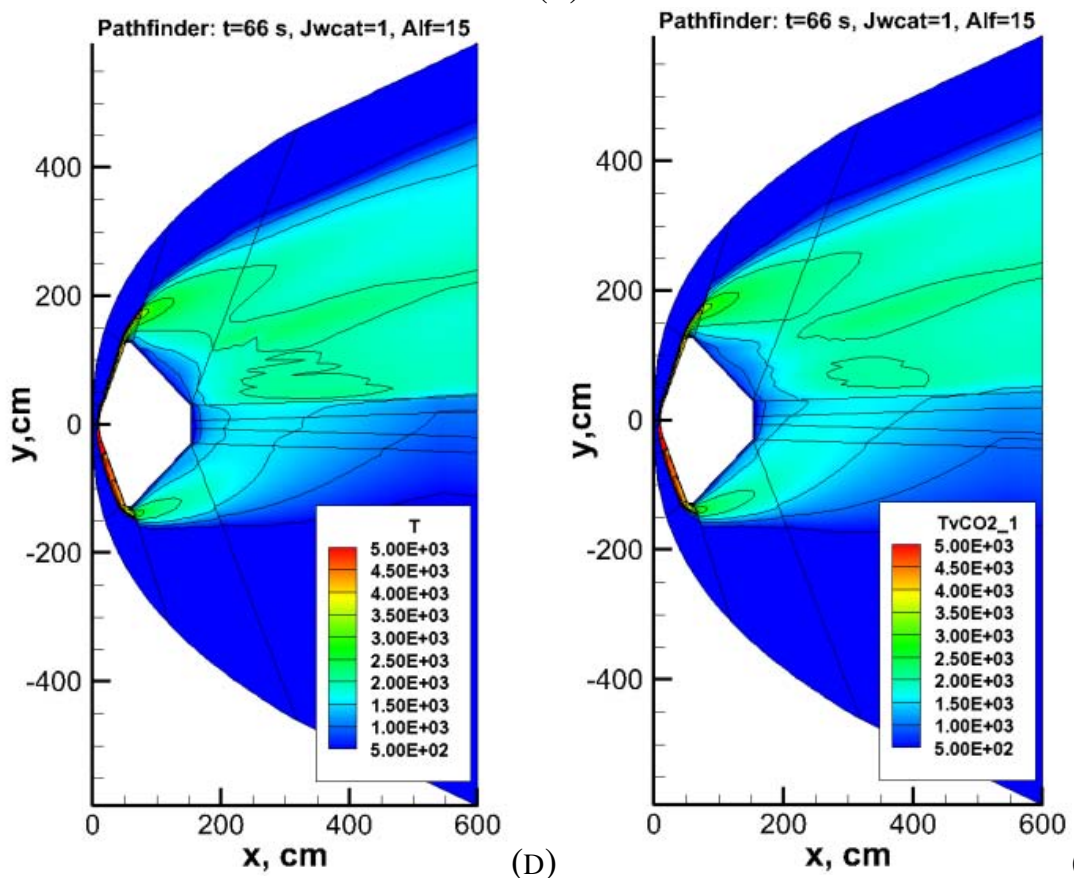

(B)

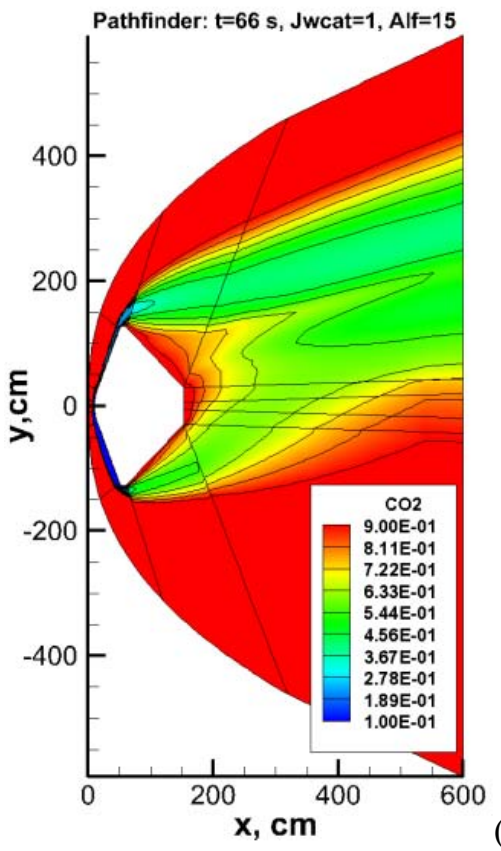

(C)

(D)

(E)

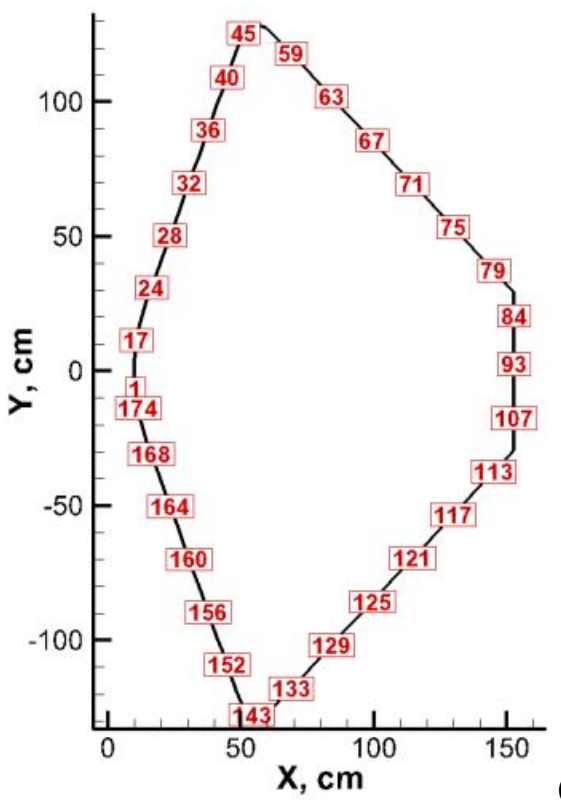

(F)

Fig. (10). Flow field about Pathfinder at angle of attack $\alpha=15^{\circ}$ (trajectory point $t=66 \mathrm{~s}$ ): $\boldsymbol{a}$ - longitudinal velocity, molar fractions of CO (b) and $\mathrm{CO}_{2}(\boldsymbol{c})$ for catalytic surface, $\boldsymbol{d}$ - translational temperature, $\boldsymbol{e}$ - vibrational temperature of $\mathrm{CO}_{2}$ anti-symmetric mode; $\boldsymbol{f}$ - location of grid nodes in equatorial cross section.

Fig. (13b) shows spectral heat fluxes traceable at different points along surface. Locations of the points on the surface are elucidated in Fig. (12f). It is clearly seen from Fig. (13b) that infrared radiation emitted by vibrational bands of $\mathrm{CO}_{2}$ and $\mathrm{CO}$ is really dominant in the spectrum of heat radiation. Some insignificant contribution into integral heat flux one can observe in the visible and near-ultraviolet part of the spectrum for the points location on the windward surface.

\subsubsection{Radiative Gas Dynamics of MSL}

Detail investigation of convective heating of MSL is presented in [38]. Non-axisymmetric non-equilibrium full
Navier-Stokes equation solver LAURA (Langley Aerothermodynamic Upwind Relaxation Algorithm) [52] was used in [38]. For Mars flight conditions, LAURA models an 8-species Mars gas $\left(\mathrm{CO}_{2}, \mathrm{CO}, \mathrm{N}_{2}, \mathrm{O}_{2}, \mathrm{NO}, \mathrm{C}, \mathrm{N}, \mathrm{O}\right)$ in chemical and thermal non-equilibrium using the Park'94 reaction rates [53]. A finite-volume approach was used on a structured grid to solve the full Navier-Stokes flowfield equations. The code uses Roe's averaging for inviscid fluxes with second-order corrections using Yee's symmetric total variation diminishing scheme.

A super-catalytic wall boundary condition fixes the species mass fractions for $\mathrm{CO}_{2}$ and $\mathrm{N}_{2}$ at their freestream 
values of 0.97 and 0.03 , respectively. This boundary condition results in conservative heating rate predictions in flight. A radiative-equilibrium wall temperature was specified as $q_{w}=\varepsilon \sigma T_{w, \text { rad-eq }}^{4}$, where $\varepsilon=0.9$ is the surface emissivity.

It was stressed in [38] that all heating results reported there are convective only, and the heat radiation contribution was expected to be small and was therefore excluded from the analysis. Calculation data obtained in [26] were successfully used for verification of 3D flow fields predicted in the given paper. Nevertheless predictions of the given paper show that the radiative heating of MSL's surface should be taken into account.

Fig. (14) show flow field about space vehicle MSL with catalytic surface under angle of attack $\alpha=11^{\circ}$. As before, a snaking was assumed to be zero therefore the calculations were performed in half of the whole calculation domain (i.e. YOX is the plane of symmetry). The distinctive features of the flow field are the following:

- $\quad$ Predicted asymmetry of the flow field (longitudinal velocity $(a)$, mass fractions $(b, c)$, translational and vibrational temperatures $(d, e))$ is formed due to angle of attack $\alpha=11^{\circ}$;

- $\quad$ As well for other entry probes, an expansion of shock layer above windward surface from the direction of incident flow is observed. The vortex structure above top piece of leeward surface is also observed;

- $\quad$ Significant differences in distributions of mass fractions of molecules $\mathrm{CO}_{2}$ and $\mathrm{CO}$ are observed for non-catalytic and catalytic surface. The non-catalytic

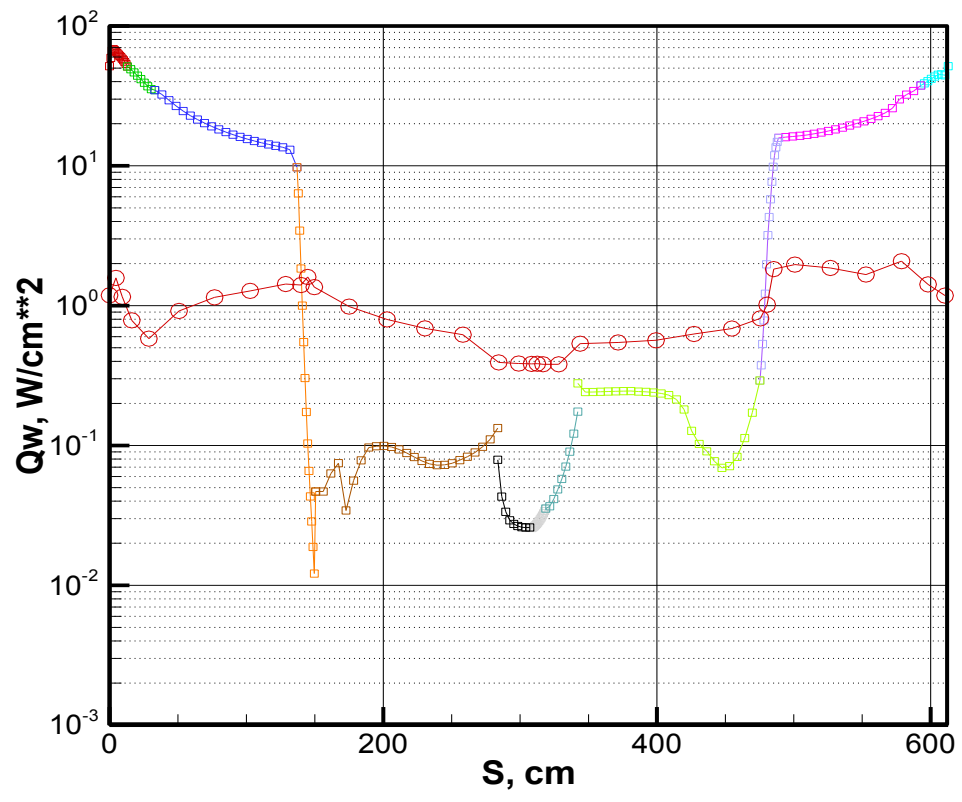

(A)
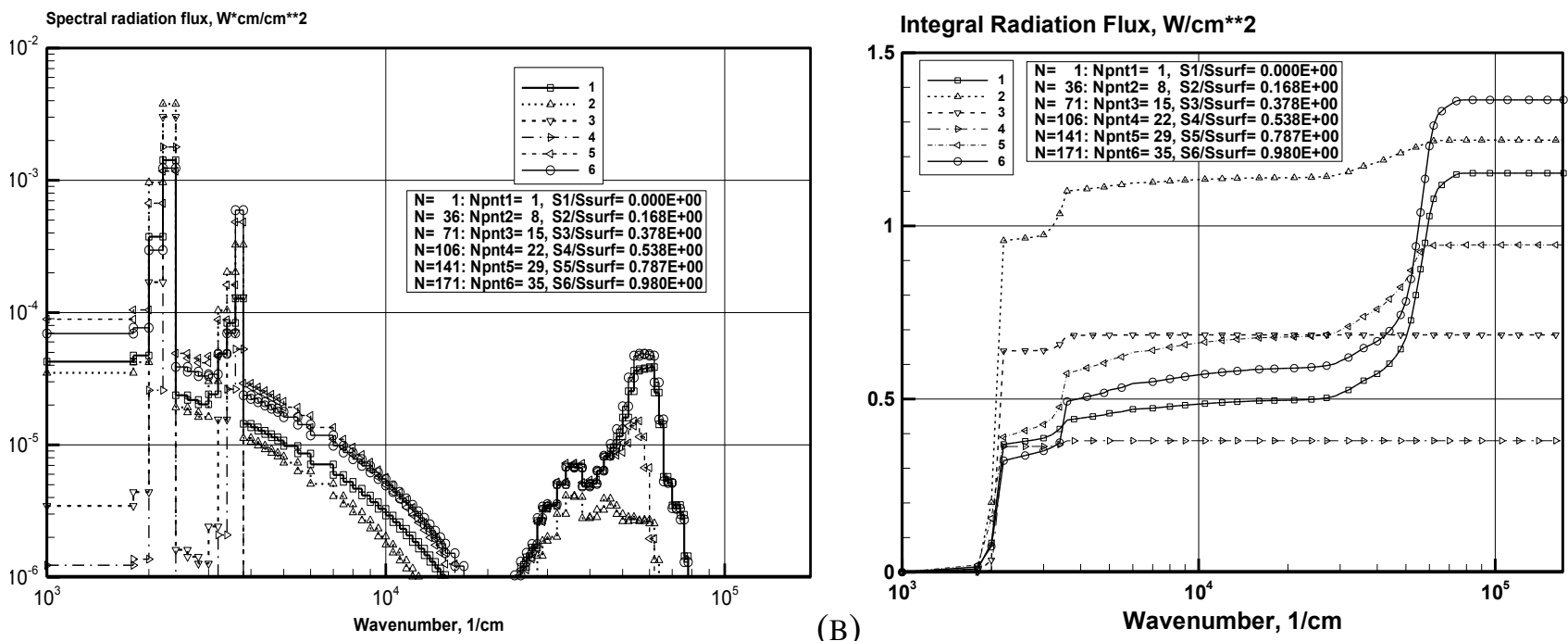

(C)

Fig. (11). Convective (squares) and radiative heating (circles) of Pathfinder's catalytic surface (trajectory point $t=66 \mathrm{~s})(\boldsymbol{a})$; spectral heat fluxes $(\boldsymbol{b})$ and cumulative function $(\boldsymbol{c})$ for six points on the non-catalytic surface. Angle of attack $\alpha=15^{\circ}$. 

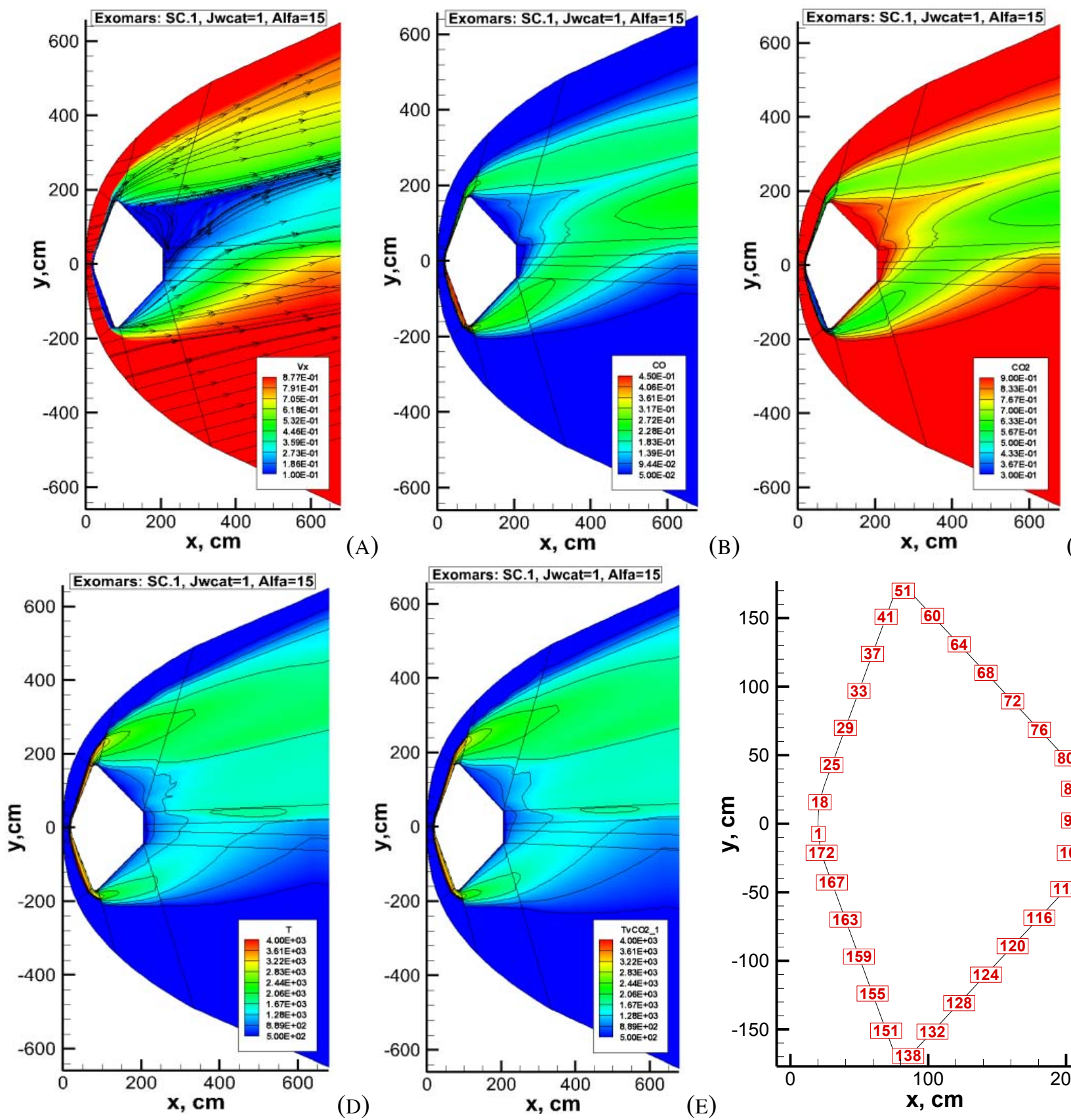

(B)

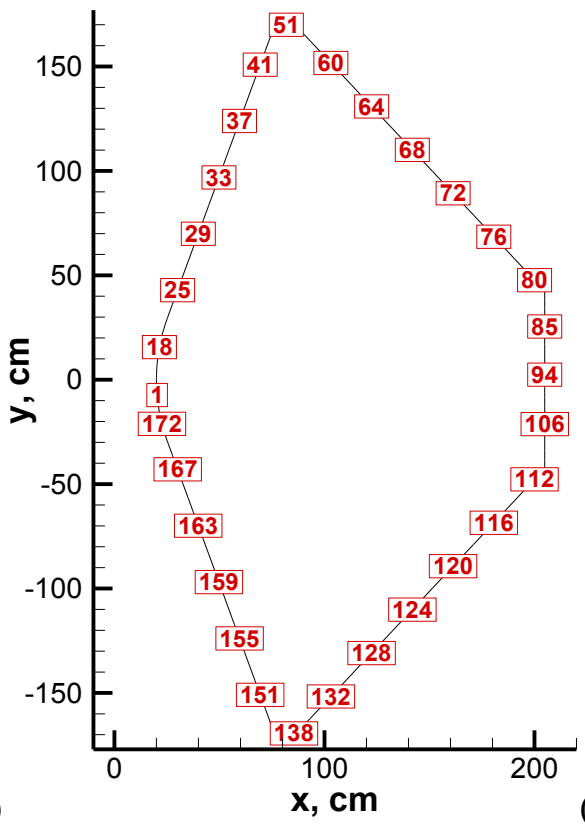

Fig. (12). Flow field about Exomars at angle of attack $\alpha=15^{\circ}$ (trajectory point SC.1): $\boldsymbol{a}$ - longitudinal velocity, molar fractions of CO (b) and $\mathrm{CO}_{2}(\boldsymbol{c})$ for catalytic surface, $\boldsymbol{d}$ - translational temperature, $\boldsymbol{e}$ - vibrational temperature of $\mathrm{CO}_{2}$ anti-symmetric mode; $\boldsymbol{f}$ - location of grid nodes in equatorial cross section.

surface is characterised by increased mass fraction of $\mathrm{CO}$ and decreased mass fraction of $\mathrm{CO}_{2}$ in the vicinity of streamlined surface, while high mass fractions of $\mathrm{CO}_{2}$ and low mass fractions of $\mathrm{CO}$ are characterised for catalytic surface (Figs. 14b, c);

Convective heating of catalytic surface is about two times higher than for non-catalytic one;

It is not observed significant influence of catalytic properties of MSL's surface on its integral and spectral radiative heating.

The radiative heating of MSL's surface, as is observed, higher than for Pathfinder, and also should be taken into account at the leeward part, where integral radiation heat fluxes achieve values about $2-3 \mathrm{~W} / \mathrm{cm}^{2}$. This part of the surface is exposed by infrared radiation in vibrational bands $\mathrm{CO}_{2}$ and $\mathrm{CO}$ from large volume of heated gas in the wake region. Emissivity of vibrational bands of $\mathrm{CO}_{2}$ and $\mathrm{CO}$ is easily observable in Fig. $(\mathbf{1 5 b}, \mathbf{c})$.

\subsection{Partial Conclusion: The Challenging Problems of the Martian Entry Aerothermodynamics}

Three-dimensional laminar convective and radiative heating predictions have been performed for three Martian entry probes. These are: Pathfinder, Exomars and Mars Science Laboratory. Presented numerical simulation results 


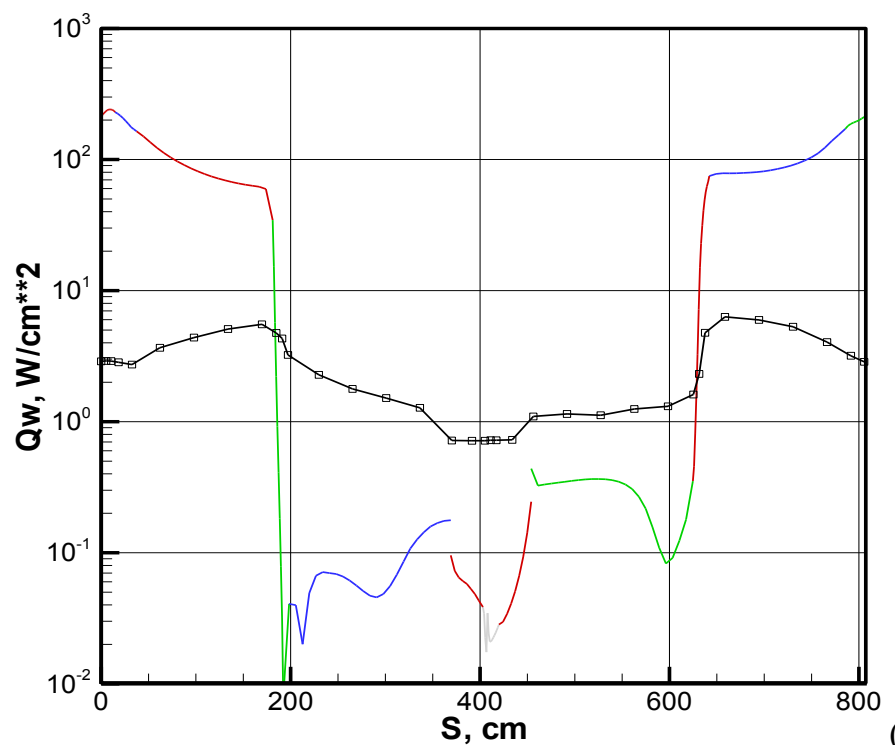

(A)
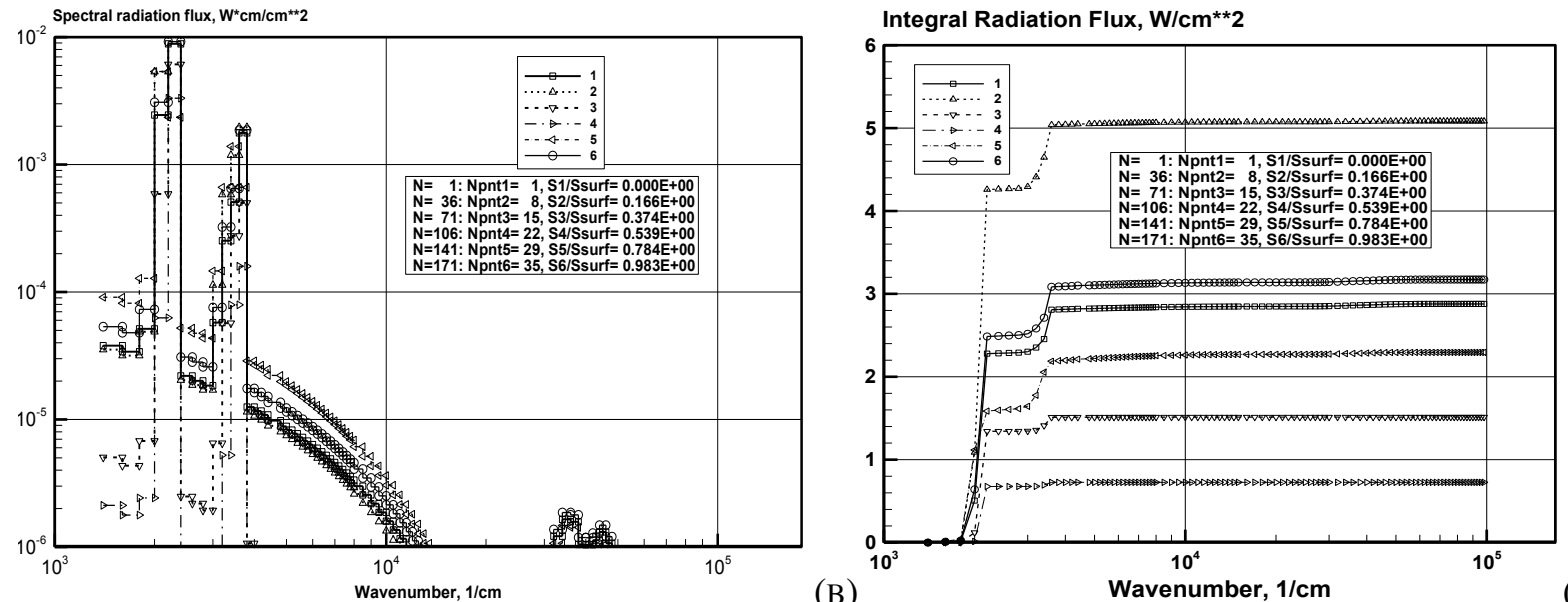

(B)

(C)

Fig. (13). Convective (squares) and radiative heating (circles) of Exomars' catalytic surface (trajectory point SC.1) (a); spectral heat fluxes (b) and cumulative function (c) for six points on the non-catalytic surface. Angle of attack $\alpha=15^{\circ}$.

for convective heating were successfully compared with available calculation data for Pathfinder [24, 25] and Mars Science Laboratory [37]. Presented calculation data on radiative heating predict significant contribution of the heat radiation into total heating of leeward surface of the space vehicles. Afterbody radiative heating rates are predicted to be generally one order higher than the laminar convective heating.

Table 3. Trajectory points for pathfinder [35].

\begin{tabular}{|c|c|c|c|c|}
\hline $\boldsymbol{t}, \mathbf{s}$ & $\rho_{\infty}, \mathbf{g} / \mathbf{c m}^{3}$ & $p_{\infty}, \mathbf{e r g} / \mathbf{c m}^{3}$ & $\boldsymbol{V}_{\infty}, \mathbf{k m} / \mathbf{s}$ & $\boldsymbol{T}_{\infty}, \mathbf{K}$ \\
\hline \hline 40 & $0.724 \times 10^{-8}$ & 1.660 & 7.496 & 122 \\
\hline 42 & $1.01 \times 10^{-8}$ & 2.462 & 7.490 & 129 \\
\hline 52 & $5.76 \times 10^{-8}$ & 15.56 & 7.364 & 143 \\
\hline 66 & $2.80 \times 10^{-7}$ & 89.41 & 6.596 & 169 \\
\hline 80 & $8.54 \times 10^{-7}$ & 282.0 & 4.717 & 175 \\
\hline
\end{tabular}

Table 4. Trajectory points for Exomars [54].

\begin{tabular}{|c|c|c|c|c|}
\hline & $\rho_{\infty}, \mathbf{g} / \mathbf{c m}^{3}$ & $p_{\infty}, \mathbf{e r g} / \mathbf{c m}^{3}$ & $V_{\infty}, \mathbf{~ k m} / \mathbf{s}$ & $\boldsymbol{T}_{\infty}, \mathbf{K}$ \\
\hline \hline SC.1 & $6.838 \times 10^{-7}$ & 200.3 & 4.922 & 195 \\
\hline SC.2 & $1.069 \times 10^{-6}$ & 324.6 & 4.474 & 194 \\
\hline SD.1 & $3.708 \times 10^{-7}$ & 137.4 & 4.878 & 158 \\
\hline SD.2 & $5.534 \times 10^{-7}$ & 205.9 & 4.489 & 153 \\
\hline Cold94.1 & $1.186 \times 10^{-6}$ & 352.8 & 3.842 & 155 \\
\hline Storm90.1 & $1.911 \times 10^{-7}$ & 77.3 & 5.268 & 211 \\
\hline
\end{tabular}

It should be taken into account that in this part we analyzed preliminary numerical simulation results which were obtained with assumption of local thermodynamic equilibrium of dissociated mixture of $\mathrm{CO}_{2}$ and $\mathrm{N}_{2}$ in nearby and far regions of wake. But, at the same time, our calculation data demonstrate significant differences between translational and vibrational temperatures just in the wake. It 


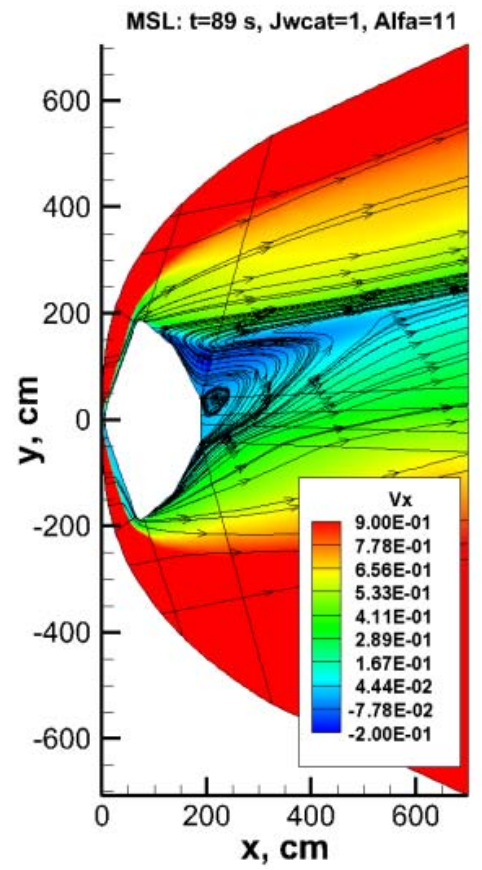

(A)

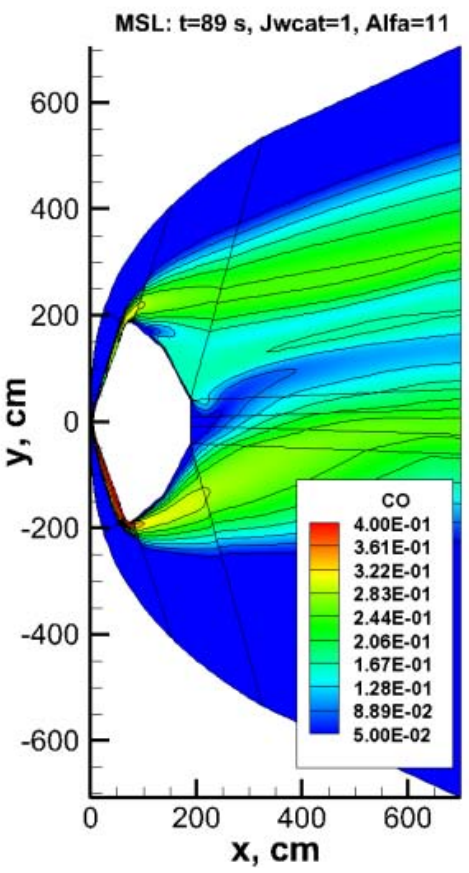

(B)

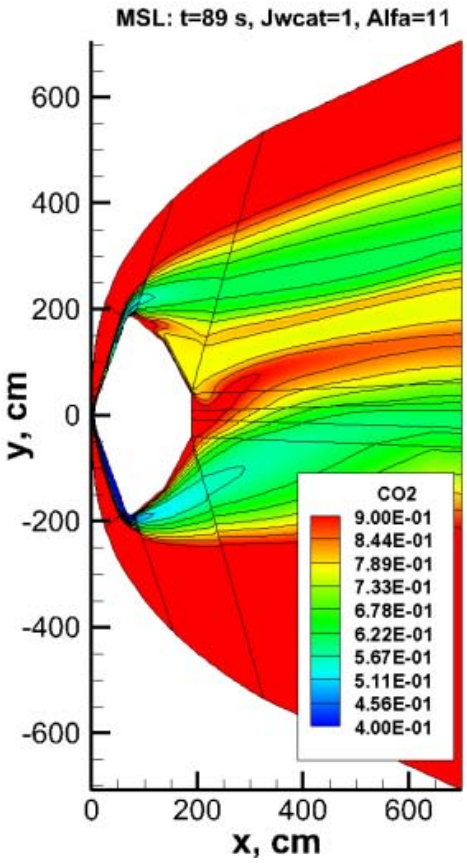

(C)

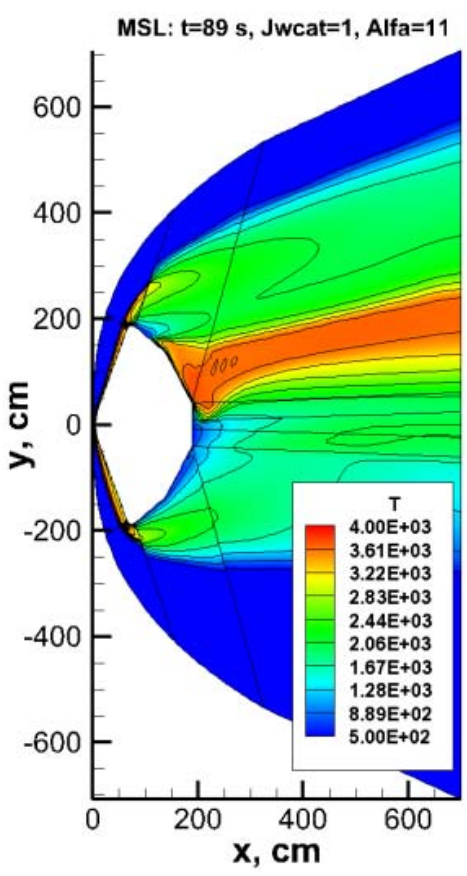

(D)

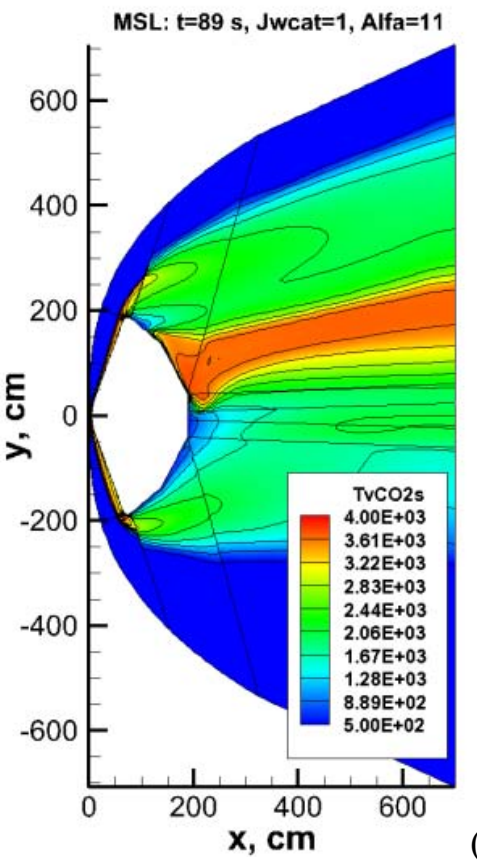

(E)

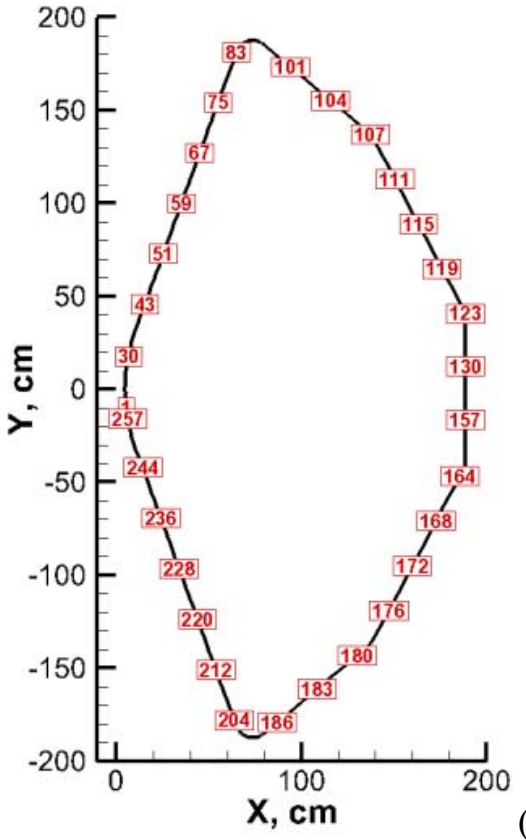

(F)

Fig. (14). Flow field about MSL at angle of attack $\alpha=11^{\circ}$ (trajectory point $t=80 \mathrm{~s}$ ): $\boldsymbol{a}$ - longitudinal velocity, molar fractions of CO (b) and $\mathrm{CO}_{2}(\boldsymbol{c})$ for catalytic surface, $\boldsymbol{d}$ - translational temperature, $\boldsymbol{e}$ - vibrational temperature of $\mathrm{CO}_{2}$ anti-symmetric mode; $\boldsymbol{f}$ - location of grid nodes in equatorial cross section.

means that to receive more reliable data concerning radiative heating of leeward surfaces of Martian space vehicles fully non-equilibrium radiative gas dynamic problem should be solved in the future.

\section{RADIATIVE AEROTHERMODYNAMICS OF THE JUPITER}

\subsection{Introduction}

Many studies have been focused on thermal analysis and aerothermodynamics of Galileo probe (shown in Fig. 16) from the mid-seventies to the early eighties for the mission preparation [57-60] and more recently for the post-flight analyses [61-64]. Due to very high radiative and convective heat-fluxes characterizing a Jupiter entry, the dominant uncertainty factor associated to the heat-shield recession calculations was the radiation absorption within the ablation layer. As a consequence, for this mission, the evaluation of the blockage (convective and radiative) was a major issue and a thorough effort was carried out for its estimate [65]. Among the different studies, several contributions have provided some estimate of the blockage factors and blowing rates for a Jupiter 


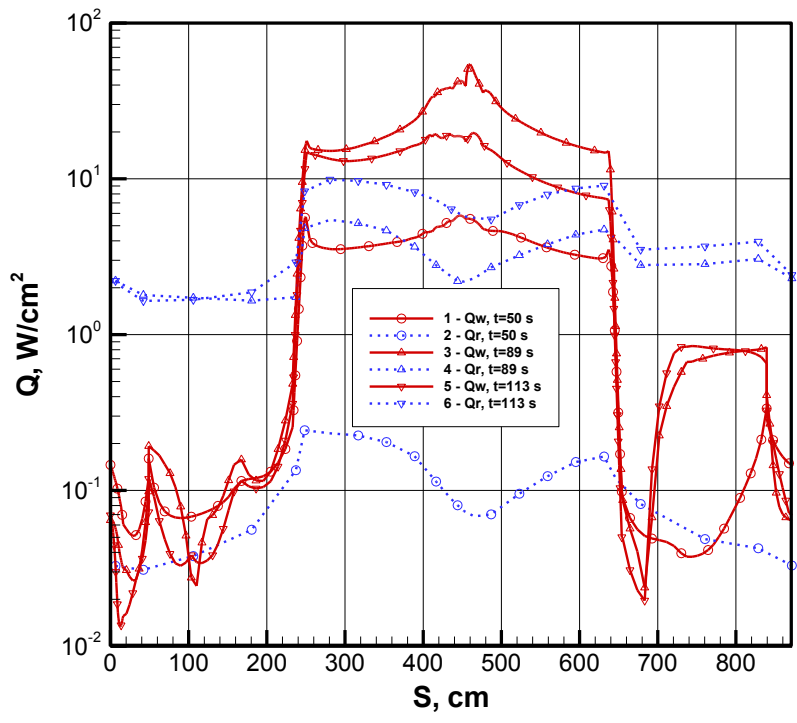

(A)
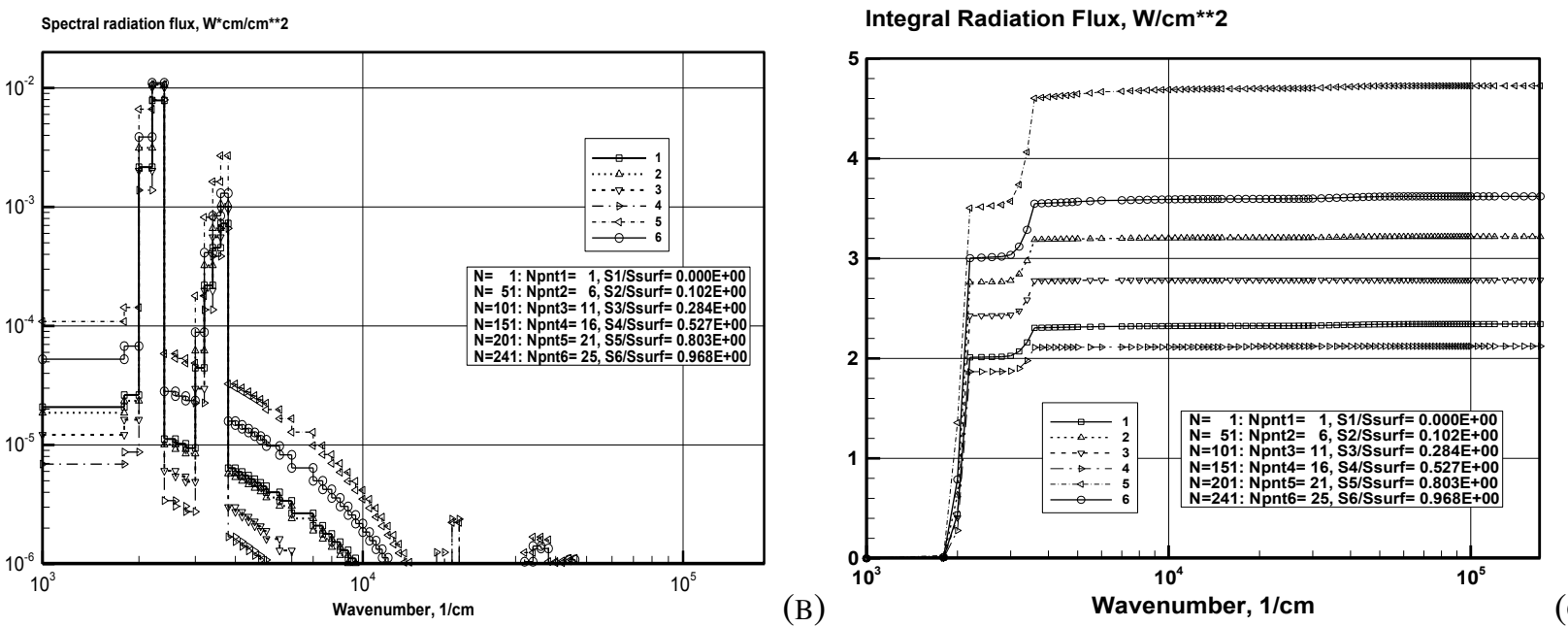

(B)

(C)

Fig. (15). Convective (squares) and radiative (circles) heating of MSL's surface at $t=80$ s for catalytic surface (a); (b)- spectral heat fluxes, and cumulative function $(\boldsymbol{c})$ for six points on the non-catalytic surface. Angle of attack $\alpha=11^{\circ}$.

entry [57, 66, 67]. Another issue was the turbulence that has been extensively investigated [57, 59, 66, 67]. Rarefied effects were also investigated for the mission preparation [68].

Table 5. Freestream conditions for CFD analysis of MSL [37].

\begin{tabular}{|c|c|c|c|c|c|}
\hline Time, $\mathbf{s}$ & $\mathbf{h}, \mathbf{k m}$ & $\rho_{\infty}, \mathbf{g} / \mathbf{c m}^{\mathbf{3}}$ & $\boldsymbol{p}_{\infty}, \mathbf{e r g} / \mathbf{c m}^{\mathbf{3}}$ & $\boldsymbol{V}_{\infty}, \mathbf{k m} / \mathbf{s}$ & $\boldsymbol{T}_{\infty}, \mathbf{K}$ \\
\hline \hline 50 & 68.3 & $4.71 \times 10^{-9}$ & 1.29 & 5.54 & 145 \\
\hline 70 & 47.7 & $7.63 \times 10^{-8}$ & 21.5 & 5.48 & 149 \\
\hline 80 & 38.3 & $2.10 \times 10^{-7}$ & 64.3 & 5.31 & 162 \\
\hline 89 & 31.0 & $4.74 \times 10^{-7}$ & 150. & 4.98 & 179 \\
\hline 103 & 22.3 & $1.05 \times 10^{-6}$ & 377. & 4.10 & 189 \\
\hline 109 & 19.6 & $1.44 \times 10^{-6}$ & 517. & 3.63 & 190 \\
\hline 113 & 18.0 & $1.48 \times 10^{-6}$ & 534. & 3.32 & 191 \\
\hline 137 & 14.2 & $2.43 \times 10^{-6}$ & 886. & 1.95 & 193 \\
\hline
\end{tabular}

Galileo probe was equipped with ablation detector sensors (ARAD) for collecting flight data during entry. The in-flight experiments have been well detailed by Milos [70]. Ten ablation sensors were included in the TPS, at 6 different locations, as shown in Fig. (17). The descent module was also containing an instrument for measuring temperature, density and pressure profiles along the trajectory. Four resistance thermometers were also bonded inside the aluminium structure as shown in Fig. (17). Data from the heat-shield experiments were transmitted from Galileo orbiter to Earth and then analysed [70, 71].

The different post-flight analysis carried out to reconstruct the thermal protection system (TPS) recession have highlighted different points:

- There are large discrepancies between most of the numerical rebuilding and the flight data;

- Accuracy of chemical kinetics and thermodynamic data for $\mathrm{H}$ and $\mathrm{H}^{+}$species; 
- VUV absorption mechanisms such as photoionization and radiation from spalled particles should be considered;

- Since the ionization level is high, the validity of existing models is questionable.

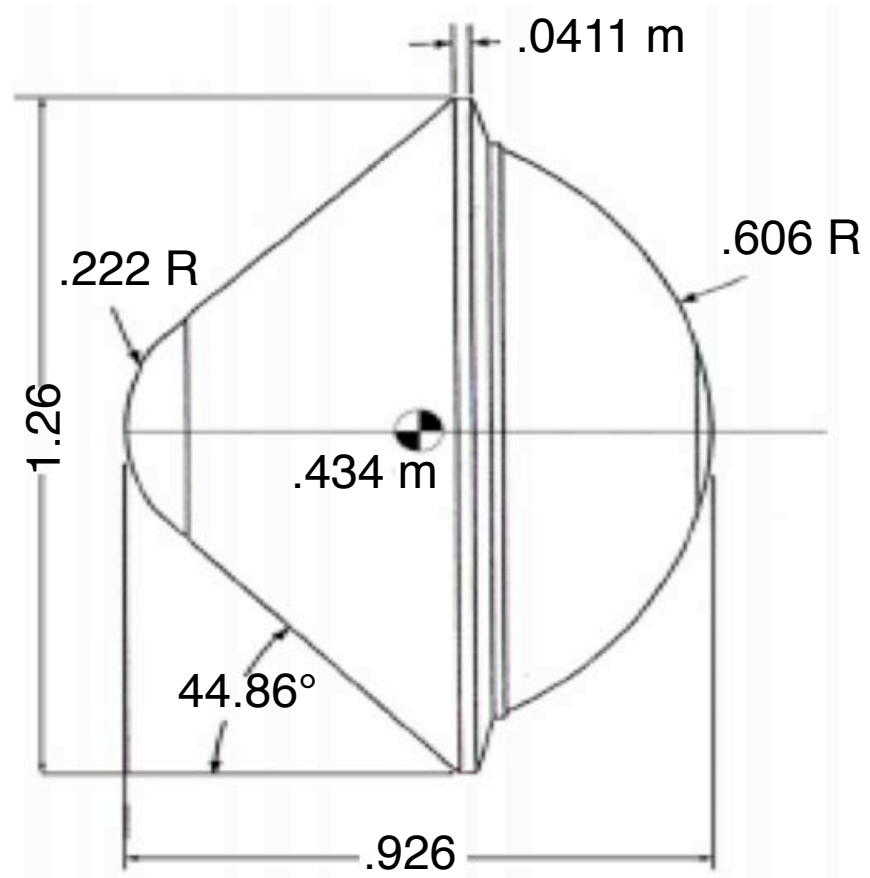

Fig. (16). Scheme of Galileo probe [69].

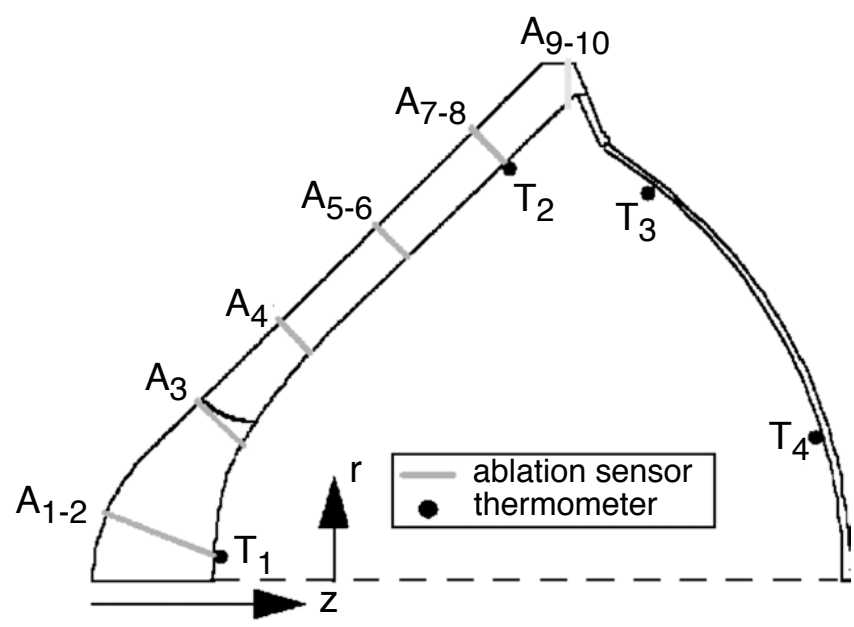

Fig. (17). Location of ablation sensors $\left(A_{1-10}\right)$ and thermometers $\left(\mathrm{T}_{1-4}\right)$ on Galileo probe [70].

The last point is a key issue since for such entry conditions, ionization can be strong. Additionally, most of the chemical kinetics models have been built for low or moderate levels of ionization and their reliability for such high-enthalpy flows has not been fully established.

In the frame of this study a computational test matrix for the numerical simulations has been selected, based on the numerical, experimental and flight results obtained for Galileo. Then, a chemical kinetics model has been set up accounting from previous efforts. Finally, numerical computations of Galileo flow-field have been performed and comparisons with other data are presented with a focus on the results obtained with some non-equilibrium at high altitude.

\subsection{Survey and Computational Matrix}

For the mission preparation, numerical predictions have not only been done using engineering correlations [57] but flow-field solutions have been also computed. First numerical simulations have been done for shock-layer solutions at chemical equilibrium [67, 72], later on NavierStokes solutions have been calculated $[58,60]$ still at chemical equilibrium.

Most of the available numerical data focused on the evolution during entry of stagnation point heat-flux. Radiative surface heat-flux distributions with and without blowing are available in $[57,59,60,67]$. These results have been obtained at chemical equilibrium for laminar and turbulent flow conditions. Forebody distributions of radiative heat-flux at different entry times are shown in Fig. (18).

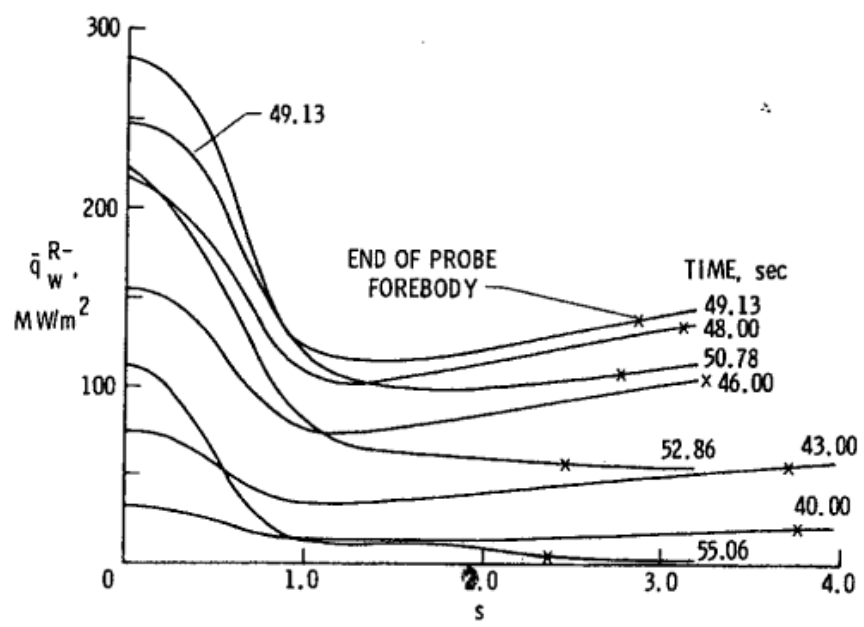

Fig. (18). Forebody distributions of radiative heating at different trajectory locations [58].

Table 6. Entry trajectory and reconstructed atmosphere [70].

\begin{tabular}{|c|c|c|c|c|c|}
\hline $\begin{array}{c}\text { Time, } \\
\text { s }\end{array}$ & $\begin{array}{c}\text { Altitude, } \\
\text { km }\end{array}$ & $\begin{array}{c}\text { Velocity, } \\
\text { km/s }\end{array}$ & $\begin{array}{c}\text { Density, } \\
\mathrm{km} / \mathrm{m}^{3}\end{array}$ & $\begin{array}{l}\text { Pressure, } \\
\text { bars }\end{array}$ & $\begin{array}{c}\text { Temperature, } \\
\mathbf{K}\end{array}$ \\
\hline 0.00 & 450 & 47.406 & $3.47 \mathrm{E}-09$ & $7.21 \mathrm{E}-08$ & 527.8 \\
\hline 7.30 & 400 & 47.429 & $9.92 \mathrm{E}-09$ & $1.45 \mathrm{E}-07$ & 381.9 \\
\hline 14.80 & 350 & 47.451 & $5.65 \mathrm{E}-08$ & $4.35 \mathrm{E}-07$ & 210.8 \\
\hline 22.50 & 300 & 47.468 & $3.05 \mathrm{E}-07$ & $2.13 \mathrm{E}-06$ & 195.9 \\
\hline 30.44 & 250 & 47.446 & $2.77 \mathrm{E}-06$ & $1.60 \mathrm{E}-05$ & 163.2 \\
\hline 34.51 & 225 & 47.368 & 7.73E-06 & $4.45 \mathrm{E}-05$ & 162.8 \\
\hline 38.67 & 200 & 47.135 & $2.16 \mathrm{E}-05$ & $1.23 \mathrm{E}-04$ & 160.4 \\
\hline 40.35 & 190 & 46.951 & $3.16 \mathrm{E}-05$ & $1.84 \mathrm{E}-04$ & 165.0 \\
\hline 42.06 & 180 & 46.674 & 4.81E-05 & $2.75 \mathrm{E}-04$ & 161.9 \\
\hline 43.79 & 170 & 46.256 & 7.03E-05 & $4.12 \mathrm{E}-04$ & 165.8 \\
\hline 45.55 & 160 & 45.667 & $1.00 \mathrm{E}-04$ & $6.06 \mathrm{E}-04$ & 170.6 \\
\hline 47.36 & 150 & 44.813 & $1.49 \mathrm{E}-04$ & $8.90 \mathrm{E}-04$ & 168.9 \\
\hline 49.21 & 140 & 43.531 & $2.27 \mathrm{E}-04$ & $1.32 \mathrm{E}-03$ & 164.3 \\
\hline 51.16 & 130 & 41.591 & $3.49 \mathrm{E}-04$ & $1.99 \mathrm{E}-03$ & 160.8 \\
\hline 53.23 & 120 & 38.617 & $5.56 \mathrm{E}-04$ & $3.02 \mathrm{E}-03$ & 153.6 \\
\hline 55.52 & 110 & 34.296 & 8.34E-04 & $4.62 \mathrm{E}-03$ & 156.6 \\
\hline 58.19 & 100 & 28.440 & $1.23 \mathrm{E}-03$ & $7.00 \mathrm{E}-03$ & 160.6 \\
\hline 61.57 & 90 & 21.342 & $1.85 \mathrm{E}-03$ & $1.05 \mathrm{E}-02$ & 160.1 \\
\hline 66.35 & 80 & 13.544 & $3.06 \mathrm{E}-03$ & $1.60 \mathrm{E}-02$ & 147.8 \\
\hline 74.55 & 70 & 6.352 & $5.30 \mathrm{E}-03$ & $2.57 \mathrm{E}-02$ & 136.9 \\
\hline 89.77 & 60 & 2.261 & $9.48 \mathrm{E}-03$ & 4.23E-02 & 126.3 \\
\hline 111.02 & 50 & 0.833 & $1.89 \mathrm{E}-02$ & $7.51 \mathrm{E}-02$ & 112.4 \\
\hline
\end{tabular}


The flight data have been analysed [70, 71] and the entry trajectory, as well as the atmospheric properties have been determined. They are all reported in Table 6. Using the determined trajectory, post-flight analyses have been carried out to reconstruct the TPS recession using numerical simulations. Some of these results are reported in Fig. (19). They highlight the point [74] that for Galileo, when comparing the predicted surface recession and the flight data, the measured recession is around half of the calculated value at the stagnation point and twice as large on the frustum. Fig. (19) shows that the predicted recession overestimates the flight data by $30 \%$ in the stagnation region, while it substantially underestimates the flight data by $50 \%$ in the frustum region.

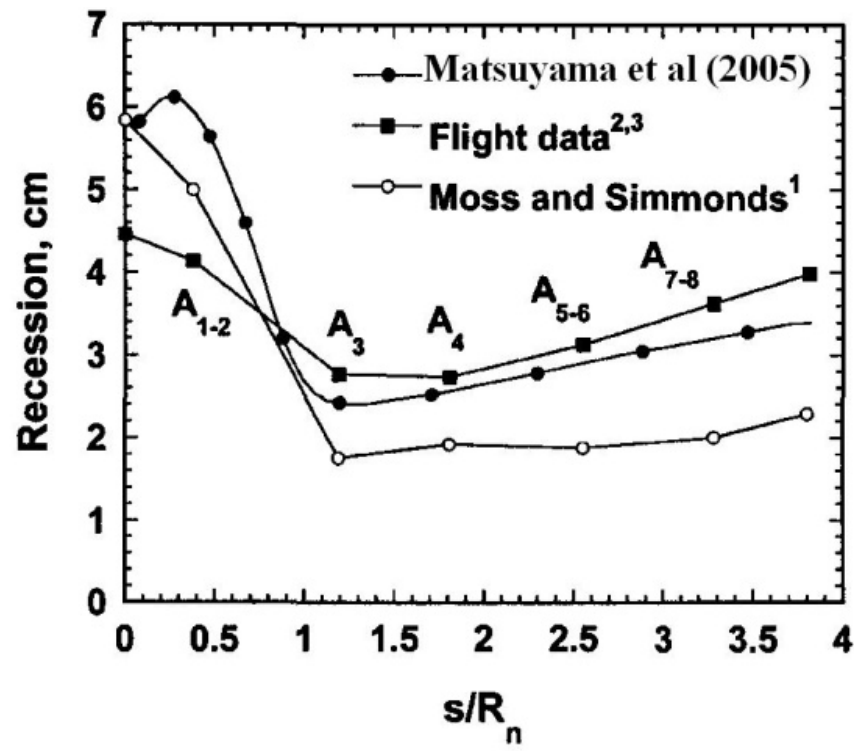

Fig. (19). Predicted surface recession and flight data.

The discrepancy in the stagnation region might be due to issues related to radiation and high temperature thermodynamic [64]. Concerning the frustum, the standard turbulence models failed to reproduce the anomalously high heating rate in the frustum at the origin of the higher recession. It has been pointed out $[73,74]$ that the promotion

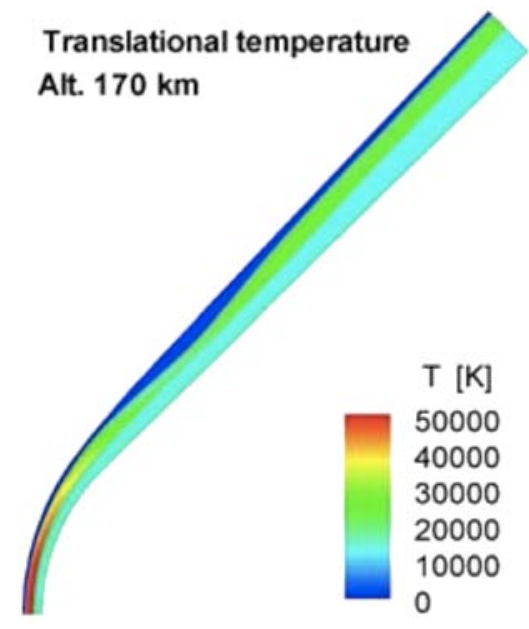

of boundary layer turbulence due to injection of pyrolysis gas, not accounted for in standard turbulence models, was the potential source of discrepancy. Accounting for these phenomena leads to a much better agreement between predictions of recession and flight data as reported in [64].

Recently, several contributions have been published focusing on Galileo post-flight reconstruction. Matsuyama et al. [61] have performed a set of calculations ( 8 trajectory points) for computing the gas mixture and the ablation products with an assumption of thermochemical equilibrium. Seven species were considered for the atmosphere model: $\mathrm{H}_{2}, \mathrm{H}, \mathrm{He}, \mathrm{H}_{2}{ }^{+}, \mathrm{H}^{+}, \mathrm{He}^{+}$, e ${ }^{-}$and 18 additional species, $\mathrm{C}, \mathrm{C}_{2}$, $\mathrm{C}_{3}, \mathrm{C}_{4}, \mathrm{C}_{5}, \mathrm{C}^{+}, \mathrm{CH}, \mathrm{C}_{2} \mathrm{H}, \mathrm{C}_{3} \mathrm{H}, \mathrm{C}_{4} \mathrm{H}, \mathrm{C}_{5} \mathrm{H}, \mathrm{CH}_{2}, \mathrm{C}_{2} \mathrm{H}_{2}, \mathrm{O}, \mathrm{O}_{2}$, $\mathrm{O}^{+}, \mathrm{CO}$ and $\mathrm{CO}_{2}$ for the ablation products.

The most recent contributions for rebuilding Galileo data have been carried out by Furudate et al. [63] and Park [64]. In the first study, the non-equilibrium influence has been investigated using Euler solutions and a 7 species model, $\mathrm{H}_{2}$, $\mathrm{He}, \mathrm{H}, \mathrm{H}^{+}, \mathrm{H}_{2}{ }^{+}, \mathrm{He}^{+}, \mathrm{e}^{-}$, for the trajectory points (the same as in [61]). The contours of translational and vibrational temperatures predicted by Furudate et al. [63] for an altitude of $170 \mathrm{~km}$ are plotted in Fig. (20), while Fig. (21) shows the contours of mole fractions of atomic hydrogen and electrons. Apparently, the translational temperature reaches $50,000 \mathrm{~K}$ in the stagnation region, the non-equilibrium region is one $\mathrm{cm}$ width covering half of the shock-layer. If the simulations for $170 \mathrm{~km}$ exhibit some non-equilibrium behaviour, at $130 \mathrm{~km}$ the equilibrium is nearly reached.

In the literature, the most computed point is the peak heating location. Calculations at this trajectory point have been carried out in $[58,61,63,64,75]$. Calculations carried out in [61] and $[63,64]$ were performed for the same trajectory points.

A test matrix has been selected based on the different numerical predictions. The velocity and atmosphere parameters along the entry trajectory are available in Table $\mathbf{6}$. This gives the advantage to have all necessary variables requested for the calculations: velocity, pressure, density and temperature. Since there are contours of variables available for the points at 170 and $130 \mathrm{~km}$, it is useful for future

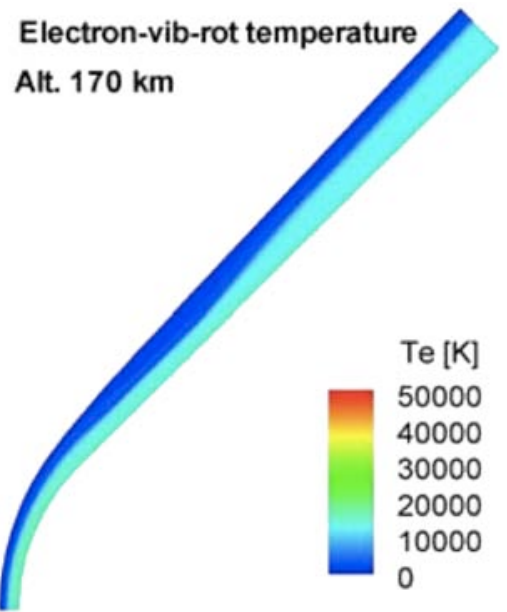

Fig. (20). Temperature contours at 130 and $170 \mathrm{~km}$ predicted in [63]. 


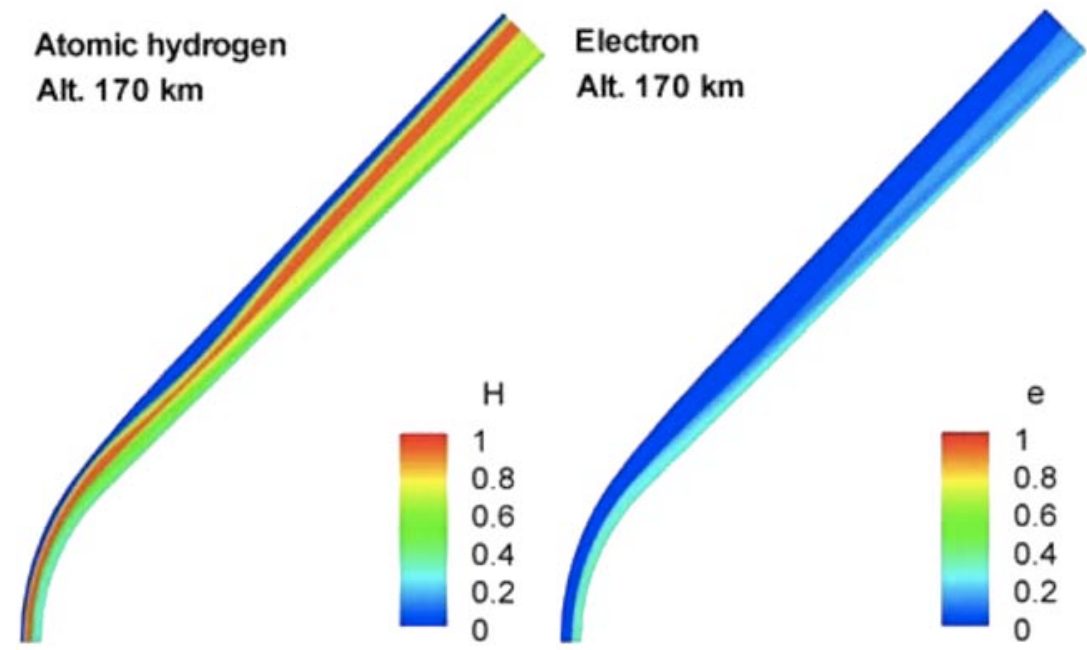

Fig. (21). Mole fraction contours of atomic hydrogen and electrons [63].

comparisons to have them in the matrix. This is also the case for the trajectory point at $180 \mathrm{~km}$ of altitude [75] that has been included (even if the density retained for the calculations does not fit the flight data of Table 6). To these three points, the point at $120 \mathrm{~km}$, considered to be the peak heating in [63] while peak heating is located at $130 \mathrm{~km}$ in [74], has been added. A last point included in this list, is the location of the maximum of convective flux occurring at $100 \mathrm{~km}$ of altitude according to [64]. The final matrix for the numerical simulations with velocity and atmosphere parameters is shown in Table 7.

\subsection{Kinetic Scheme and Transport Properties}

First computations [76] have been carried out to assess the code capabilities [77] for Jovian entry conditions, the computations have been carried out for all trajectory conditions of Table 7. For this purpose, the thermodynamic and kinetic models already used for ESA internal studies [75, 78] have been selected. Numerical results have been obtained [76] but they have highlighted the need to perform additional effort for the kinetic model.

Table 7. Test matrix for numerical simulations.

\begin{tabular}{|c|c|c|c|c|c|}
\hline $\begin{array}{c}\text { Entry } \\
\text { Time (s) }\end{array}$ & $\begin{array}{c}\text { Altitude } \\
(\mathbf{k m})\end{array}$ & $\begin{array}{c}\text { Velocity } \\
(\mathbf{k m} / \mathbf{s})\end{array}$ & $\begin{array}{c}\text { Density } \\
\mathbf{k g} / \mathbf{m}^{\mathbf{3}}\end{array}$ & $\begin{array}{c}\text { Pres., } \\
\mathbf{P a}\end{array}$ & $\begin{array}{c}\mathbf{T}, \\
\mathbf{K}\end{array}$ \\
\hline \hline 42.06 & 180 & 46.674 & $4.81 \mathrm{e}^{-5}$ & 27.5 & 161.9 \\
\hline 43.79 & 170 & 46.256 & $7.03 \mathrm{e}^{-5}$ & 41.2 & 165.8 \\
\hline 51.16 & 130 & 41.591 & $3.49 \mathrm{e}^{-4}$ & 199.0 & 160.8 \\
\hline 53.23 & 120 & 38.617 & $5.56 \mathrm{e}^{-4}$ & 302.0 & 153.6 \\
\hline 58.19 & 100 & 28.44 & $1.23 \mathrm{e}^{-3}$ & 700.0 & 160.6 \\
\hline
\end{tabular}

As a consequence, a kinetic model has been set up accounting for previous efforts carried out for simulating Jupiter entry. Several chemical kinetics models can be found in the literature related to entry into giant planet atmospheres [79]. Most of them have been developed and used for the Galileo mission [80]. Other models retained for recent studies carried out for Jovian entry $[63,75]$ or Neptune entry $[81,82]$, have been also considered.
Among, the different models, those proposed by Tiwari \& Szema [80] and Furudate et al. [63] are the most detailed. Tiwari \& Szema [80] have proposed a model with 6 species $\mathrm{H}_{2}, \mathrm{He}, \mathrm{H}, \mathrm{H}^{+}, \mathrm{He}^{+}, \mathrm{e}^{-}$, and 11 reactions. Furudate et al. [63] have published a recent contribution for rebuilding Galileo entry. In this study, the non-equilibrium influence has been investigated using Euler solutions and a 7 species model, $\mathrm{H}_{2}$, $\mathrm{He}, \mathrm{H}, \mathrm{H}^{+}, \mathrm{H}_{2}^{+}, \mathrm{He}^{+}$, e , accounting for the non-equilibrium ionization of $\mathrm{H}$ and the photo-ionization of $\mathrm{H}_{2}$. In both models the reaction schemes are based on the measurements of Leibowitz [83]. The different reactions describe the dissociation of molecular hydrogen, excitation of electronic states of hydrogen and helium, and ionization of atomic species by collisions with atoms and electrons.

Using these two models, a chemical kinetics model has been set up by selecting some of the reactions and related chemical rates. The photo-ionization has not been retained since this phenomenon cannot be yet accounted for radiation calculations using PARADE [84]. The discrimination of the rates has been carried out for ensuring the model consistency (from a numerical point of view) and an easy incorporation in TINA [77]. Using this approach a 6 species model $\mathrm{H}_{2}, \mathrm{He}$, $\mathrm{H}, \mathrm{H}^{+}, \mathrm{He}^{+}, \mathrm{e}^{-}$, has been set up with 9 reactions. A variation of this model, with 7 species $\left(\mathrm{H}_{2}, \mathrm{He}, \mathrm{H}, \mathrm{H}^{+}, \mathrm{H}_{2}^{+}, \mathrm{He}^{+}, \mathrm{e}^{-}\right)$ and 10 reactions, has been also used for the calculations. The chemical reactions retained for the computations are:

$$
\begin{aligned}
& \mathrm{H}+\mathrm{e}^{-}=\mathrm{H}^{+}+\mathrm{e}^{-}+\mathrm{e}^{-} \\
& \mathrm{He}+\mathrm{e}^{-}=\mathrm{He}^{+}+\mathrm{e}^{-}+\mathrm{e}^{-} \\
& \mathrm{H}+\mathrm{H}=\mathrm{H}^{+}+\mathrm{e}^{-}+\mathrm{H} \\
& \mathrm{H}+\mathrm{He}=\mathrm{H}^{+}+\mathrm{e}^{-}+\mathrm{He} \\
& \mathrm{H}_{2}+\mathrm{He}=\mathrm{H}+\mathrm{H}+\mathrm{He} \\
& \mathrm{H}_{2}+\mathrm{H}_{2}=\mathrm{H}+\mathrm{H}+\mathrm{H}_{2} \\
& \mathrm{H}_{2}+\mathrm{H}=\mathrm{H}+\mathrm{H}+\mathrm{H}^{+} \\
& \mathrm{H}_{2}+\mathrm{H}^{+}=\mathrm{H}+\mathrm{H}+\mathrm{H}^{+} \\
& \mathrm{H}_{2}+\mathrm{e}^{-}=\mathrm{H}+\mathrm{H}+\mathrm{e}^{-} \\
& \mathrm{H}_{2}{ }^{+}+\mathrm{e}^{-}=\mathrm{H}+\mathrm{H}
\end{aligned}
$$


Table 8. Constants and controlling temperature for the kinetic rates.

\begin{tabular}{|c|c|c|c|c|}
\hline Reaction & $A\left(\mathrm{~cm}^{3} / \mathrm{mol} / \mathrm{s}\right)$ & $b$ & $E_{f}(\mathbf{J})$ & $T_{r}$ \\
\hline $\mathrm{R} 1$ & $2.27 \mathrm{e} 13$ & 0.5 & 157800.0 & $\mathrm{Te}$ \\
\hline $\mathrm{R} 2$ & $1.33 \mathrm{e} 13$ & 0.5 & 285200.0 & $\mathrm{Te}$ \\
\hline R3 & $6.20 \mathrm{e} 10$ & 0.5 & 116000.0 & $\mathrm{Te}$ \\
\hline $\mathrm{R} 4$ & $4.89 \mathrm{e} 10$ & 0.5 & 116000.0 & $\mathrm{~T}$ \\
\hline R5 & $4.17 \mathrm{e} 18$ & -1.0 & 52340.0 & $\mathrm{~T}$ \\
\hline R6 & $1.04 \mathrm{e} 19$ & -1.0 & 52340.0 & $\mathrm{~T}$ \\
\hline R7 & $8.346 \mathrm{e} 19$ & -1.0 & 52340.0 & $\mathrm{~T}$ \\
\hline $\mathrm{R} 8$ & $8.346 \mathrm{e} 19$ & -1.0 & 52340.0 & $\mathrm{~T}$ \\
\hline R9 & $8.346 \mathrm{e} 19$ & -1.0 & 52340.0 & $\mathrm{~T}$ \\
\hline R10 & $6.604 \mathrm{e} 14$ & -0.4 & 0.0 & $\mathrm{~T}$ \\
\hline
\end{tabular}

The forward reaction rates are described using the following Arrhenius law,

$$
k_{f}=A T_{r}^{n} \exp \left(-\frac{E_{f}}{R T}\right)
$$

The values for the different constants are reported in Table 8. The rates for reaction R1 to R4 are from [80] while those for reaction R5 to R10 are taken from [63]. Concerning the controlling temperature, for the calculations a twotemperature model is used with the assumption that the electronic temperature is equal to the vibrational temperature.

The thermodynamic and transport properties for the chemical species have been taken from CEA [85] (Chemical Equilibrium with Application), as an in-depth study of the model at high temperature, typical of a Jovian entry, has not been yet undertaken but such a task is planed in future efforts.

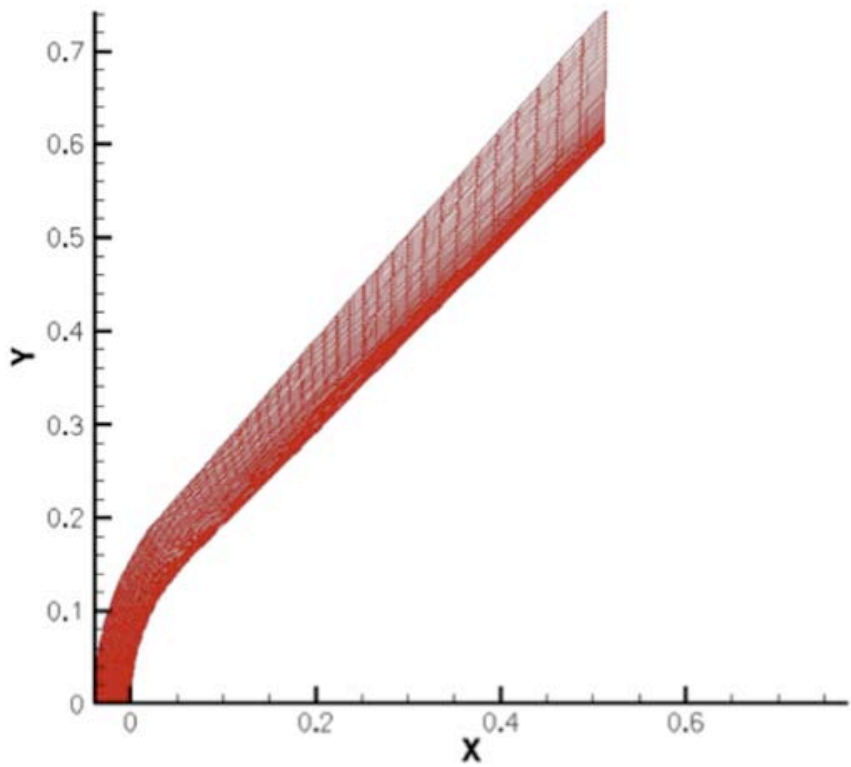

Fig. (22). Final mesh used for the calculations.

\subsection{A Jupiter Entry: Numerical Simulation Results}

Calculations have been carried out using TINA [77], a Navier-Stokes solver, accounting for chemical and vibrational non-equilibrium. It is adapted to the simulation of hypersonic flows encountered in high enthalpy nozzles or during entries, where enthalpies and local Mach numbers are high enough to allow non-equilibrium effects. The solver uses a time marching algorithm with the approximate RoeRiemann solver and the flux limiters proposed by Yee [86] for inviscid flows. The thermo-chemistry is implicitly coupled to the flow-field for computing the non-equilibrium effects.

The computations have been performed for the trajectory points reported in Table 7. However, most of the figures are related to the results obtained for the trajectory point with the highest altitude since it is the point with the highest nonequilibrium effects due to the high velocity and low pressure. Several meshes have been used for the calculations to assess the grid dependence of the results.

The final mesh is $80 \times 80$ cells, it is shown in Fig. (22). The first cell along the axis is $10 \mu \mathrm{m}$, special care has also been given to densify the cells at the shock location. The domain extends over $4 \mathrm{~cm}$ along the stagnation line and $15 \mathrm{~cm}$ at the leading edge. For the calculations, an isothermal wall at 3,000 K, the temperature of carbon sublimation, has been retained. Calculations with a wall temperature of $4,000 \mathrm{~K}$ did not show some influence on the flow-field. A noncatalytic wall has been retained for the simulations, at the exception of the ionic species, which recombine at the wall.

The free-stream was the nominal Jupiter atmosphere with $76 \%$ of $\mathrm{H}_{2}$ and $24 \%$ of $\mathrm{He}$ in volume fractions. Calculations have been carried out with a CFL of 0.5 , one order of magnitude larger than in previous computations [76]. Numerical simulations have been carried out for laminar flows using the 6 and 7 species models presented in the previous section. The convergence was reached after 200,000 iterations and the residual was around $10^{-4}$.

The predicted Mach number and pressure distributions are shown in Fig. (23), the translational and vibrational temperatures in Fig. (24). The simulations with the 6 and 7 

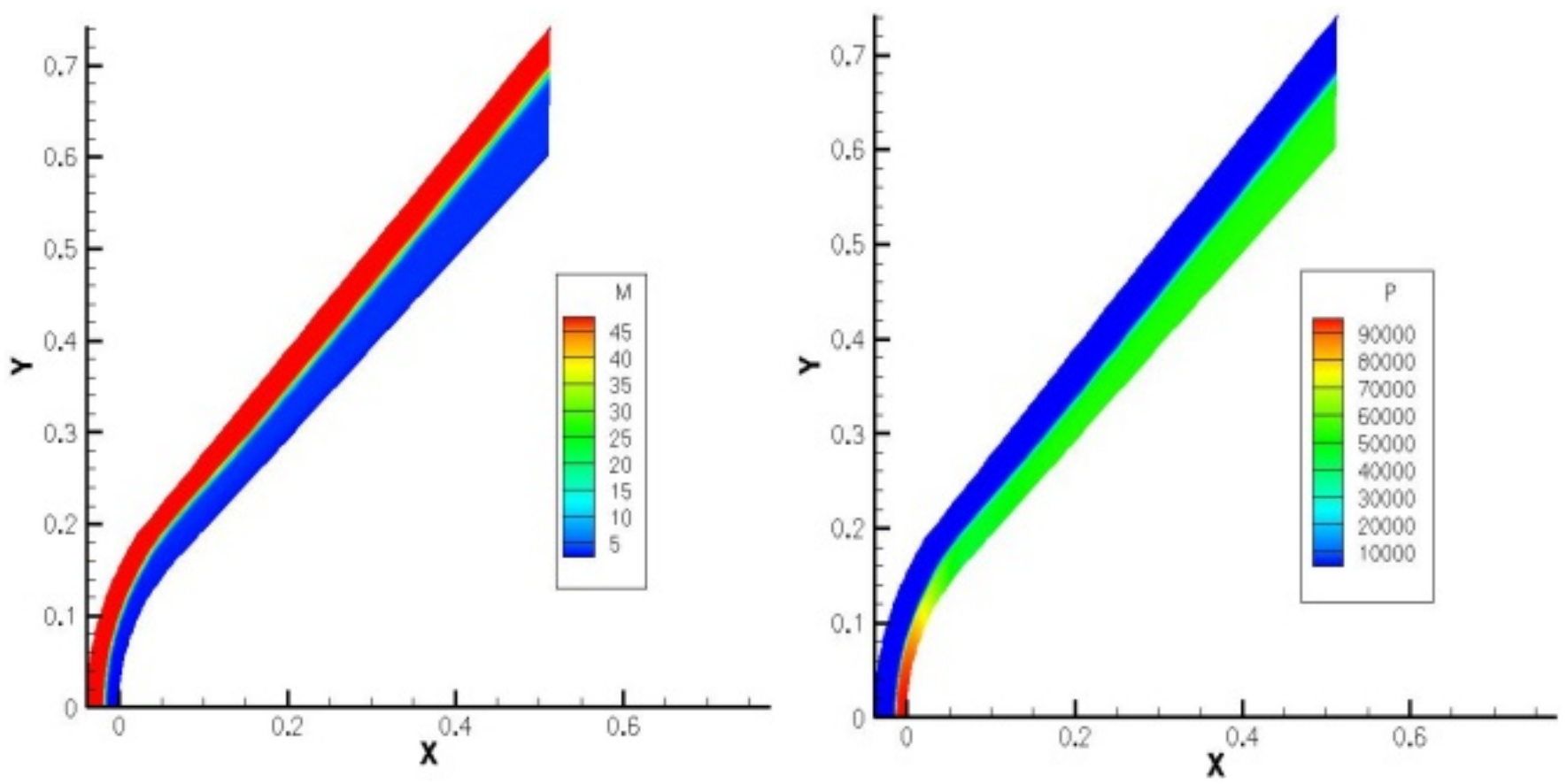

Fig. (23). Mach number (left) and pressure (right) distributions obtained with the 6 species model at $180 \mathrm{~km}$ of altitude.
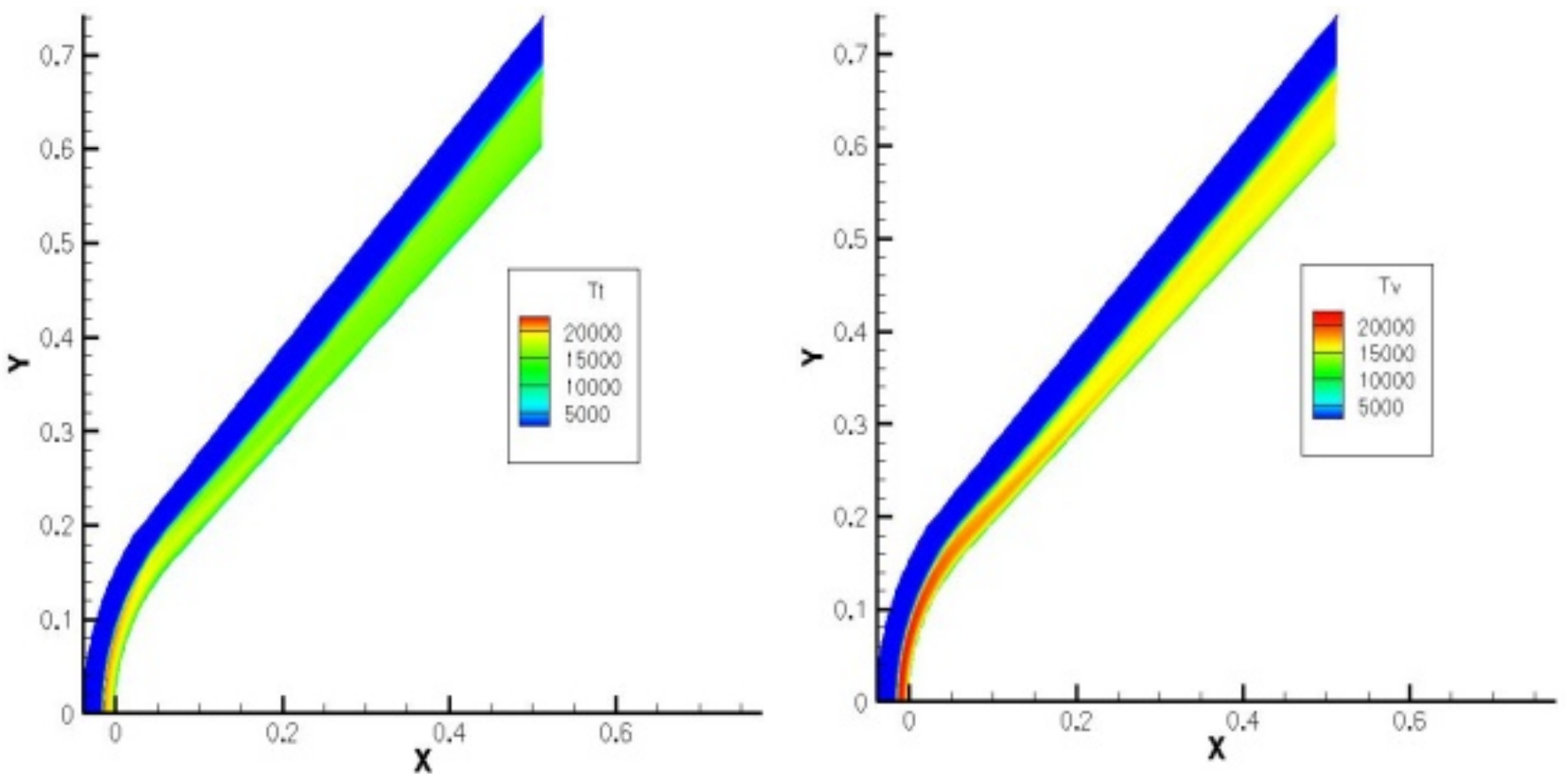

Fig. (24). Translational and vibrational temperature distributions predicted with the 6 species model at $180 \mathrm{~km}$ of altitude.

species models did not show some influence on the flowfield topology and flow variables such as the Mach number, the pressure, and the temperature. The shock standoff predicted numerically is $1.5 \mathrm{~cm}$ at the stagnation point for the altitude of $180 \mathrm{~km}$. This value is very close to the predictions obtained by Savajano [75] for the same altitude but with atmosphere conditions slightly different. For the stagnation pressure, its maximum is close to 1 bar at the stagnation point, lower than the value of 1.2 bar obtained in [75]. However, in this last study the free-stream density was $20 \%$ higher, with a value of $6.610^{-5} \mathrm{~kg} / \mathrm{m}^{3}$ instead of 4.81 $10^{-5} \mathrm{~kg} / \mathrm{m}^{3}$ in the current simulations.
The temperature distributions along the stagnation line predicted with 6 species at $180 \mathrm{~km}$ of altitude are plotted in Fig. (25). The figure puts in evidence a small region of nonequilibrium just behind the shock, according to the calculations this zone extends over $3 \mathrm{~mm}$ approximately. The maximum of the vibrational temperature is $20,000 \mathrm{~K}$ in the stagnation region while the translational temperature reaches a value of $25,000 \mathrm{~K}$. This is in good agreement with the value predicted for the translational temperature at the same location (also 25,000 K) in [75].

When comparing with the results obtained by Furudate et al. [63] shown in Fig. (20), the agreement is apparently 
good for the vibrational temperature but not for the translational one. The results obtained for the same altitude exhibits the same differences. As a consequence the reason of this discrepancy does not come from the trajectory location but more certainly from the different chemical kinetics and transport properties used in the two studies.

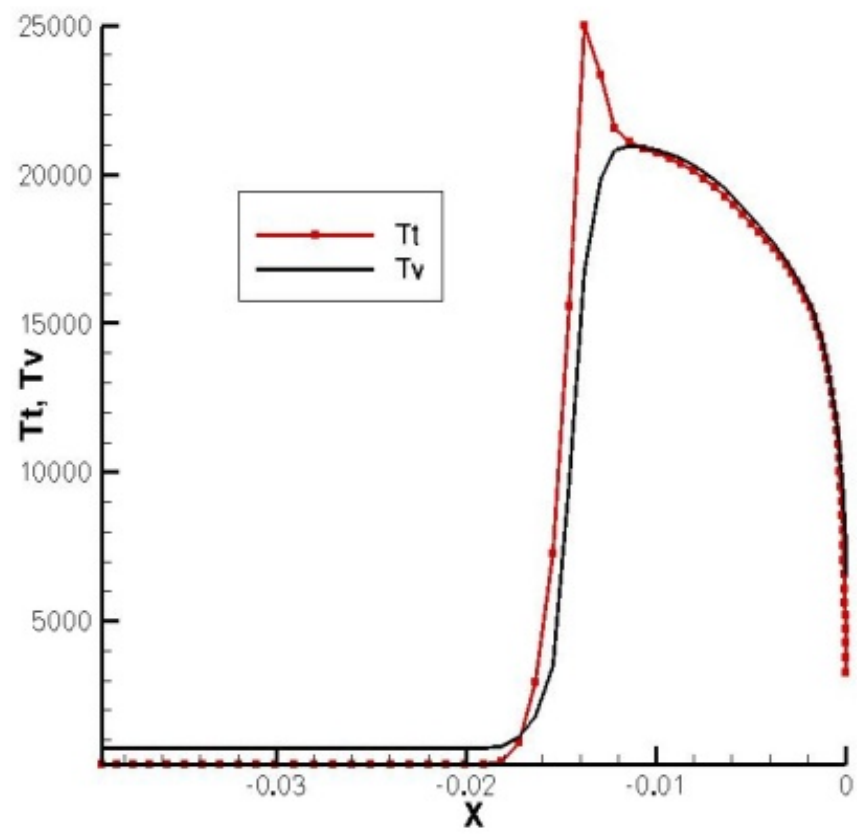

Fig. (25). Translational and vibrational temperatures along the stagnation line predicted with the 6 species model at $180 \mathrm{~km}$ of altitude.

The species mole fraction distributions along the stagnation line and at the leading edge predicted with the 7 species model are plotted in Fig. (26). The mole fraction flow-field of molecular and atomic hydrogen, as well as electrons and protons are plotted in Figs. $(\mathbf{2 7}, \mathbf{2 8})$. These

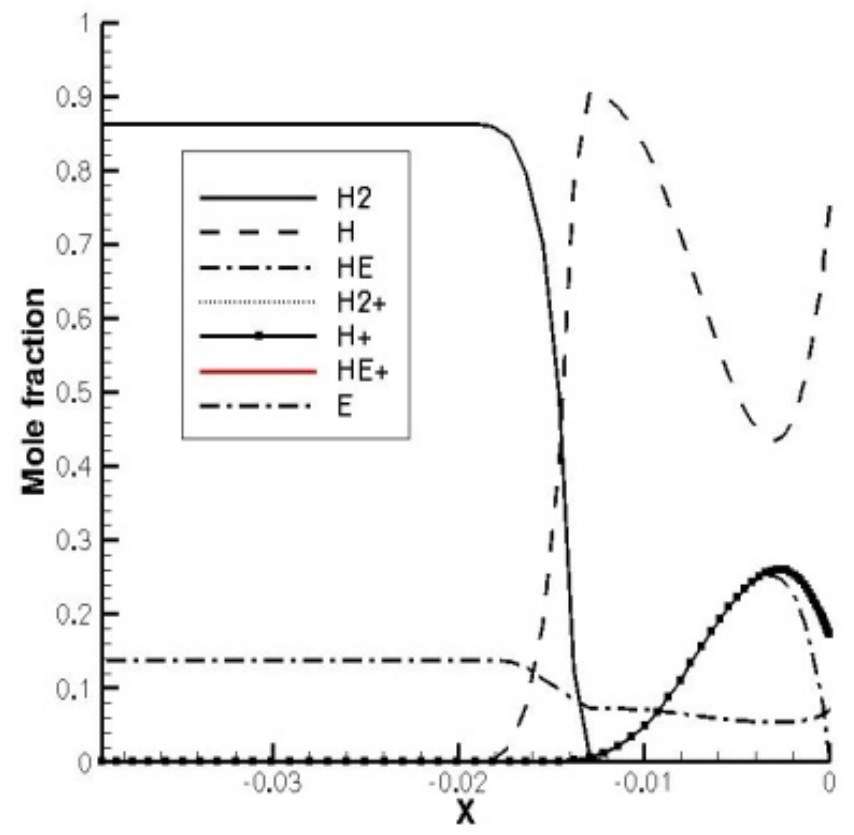

distributions show that most of the hydrogen is dissociated in the shock-layer. In the same figure, the distribution of atomic hydrogen shows the presence of a high fraction of atomic hydrogen in the shock-layer that decreases in a thin band at the vicinity of the wall. This flow-field topology agrees qualitatively with the results shown in Fig. (21) where a similar thin band with a lower level of mole fraction of atomic hydrogen. This thin band corresponds of the maximum of hydrogen ionization that can be observed in Fig. (28). In this thin band, the level of protons is high since it reaches a local maximum of 0.25 in the stagnation region.

The mole fraction of electrons is plotted in Fig. (28). The distribution of electrons is similar to the distribution of protons since the level of ionization of helium is very low. The maximum of ionized helium is of the order of $10^{-5}$ (in mole fraction) in the stagnation region as shown in Fig. (29). The electron mole fraction reaches a maximum of 0.25 in the stagnation region that can be observed in Fig. (28). These predictions seem to be close to those obtained by Furudate et al. [63] shown in Fig. (21).

The distribution of the mole fraction of $\mathrm{He}$ is displayed in Fig. (29). The higher values in the shock-layer are due to the massive ionization there that increases the number of species. The mole fraction distribution of $\mathrm{H}_{2}{ }^{+}$predicted using the 7 species model is plotted in Fig. (30). However, this specie is not very abundant as demonstrated in Fig. (26). The maximum of $\mathrm{H}_{2}^{+}$distributions is located in a band of the shock-layer located over the frustum of the capsule. Apparently, the molecular hydrogen is there ionized and this is the ion $\mathrm{H}_{2}{ }^{+}$, which is dissociated in the vicinity of the wall by the collisions with electrons. So far, no element of comparison has been found in the literature and it is difficult to conclude on this point.

The last point concerns the convective heat-flux. Its value is equal to $105 \mathrm{MW} / \mathrm{m}^{2}$ at the stagnation point, this for both 6 and 7 species models. In a previous communication [87] this

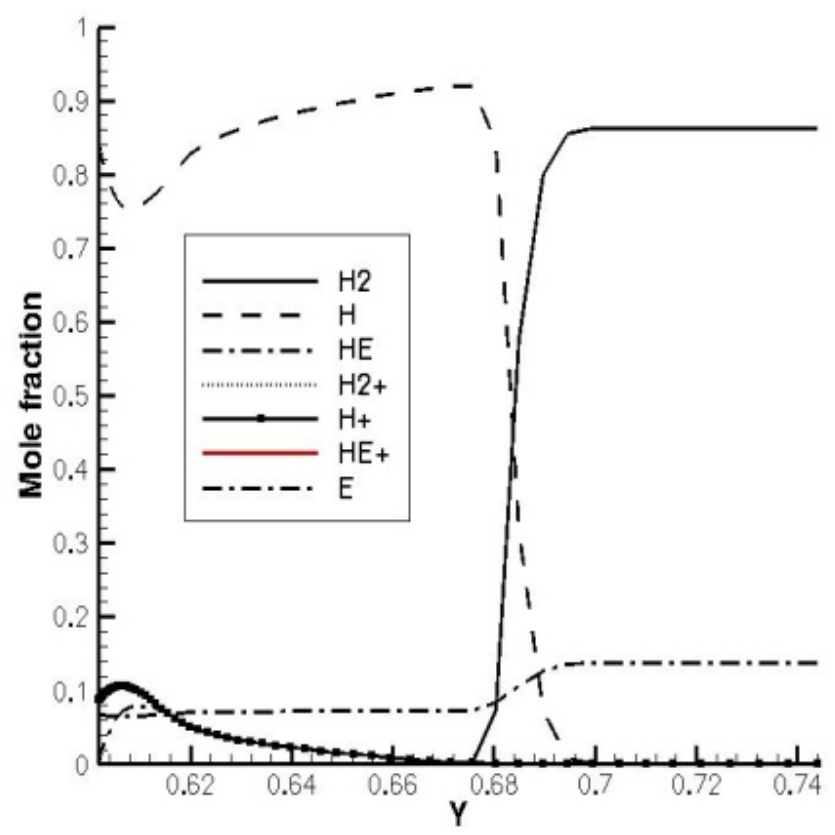

Fig. (26). Mole fraction distributions of species along the stagnation line (top) and at the leading edge (bottom) predicted with the 7 species model at $180 \mathrm{~km}$ of altitude. 

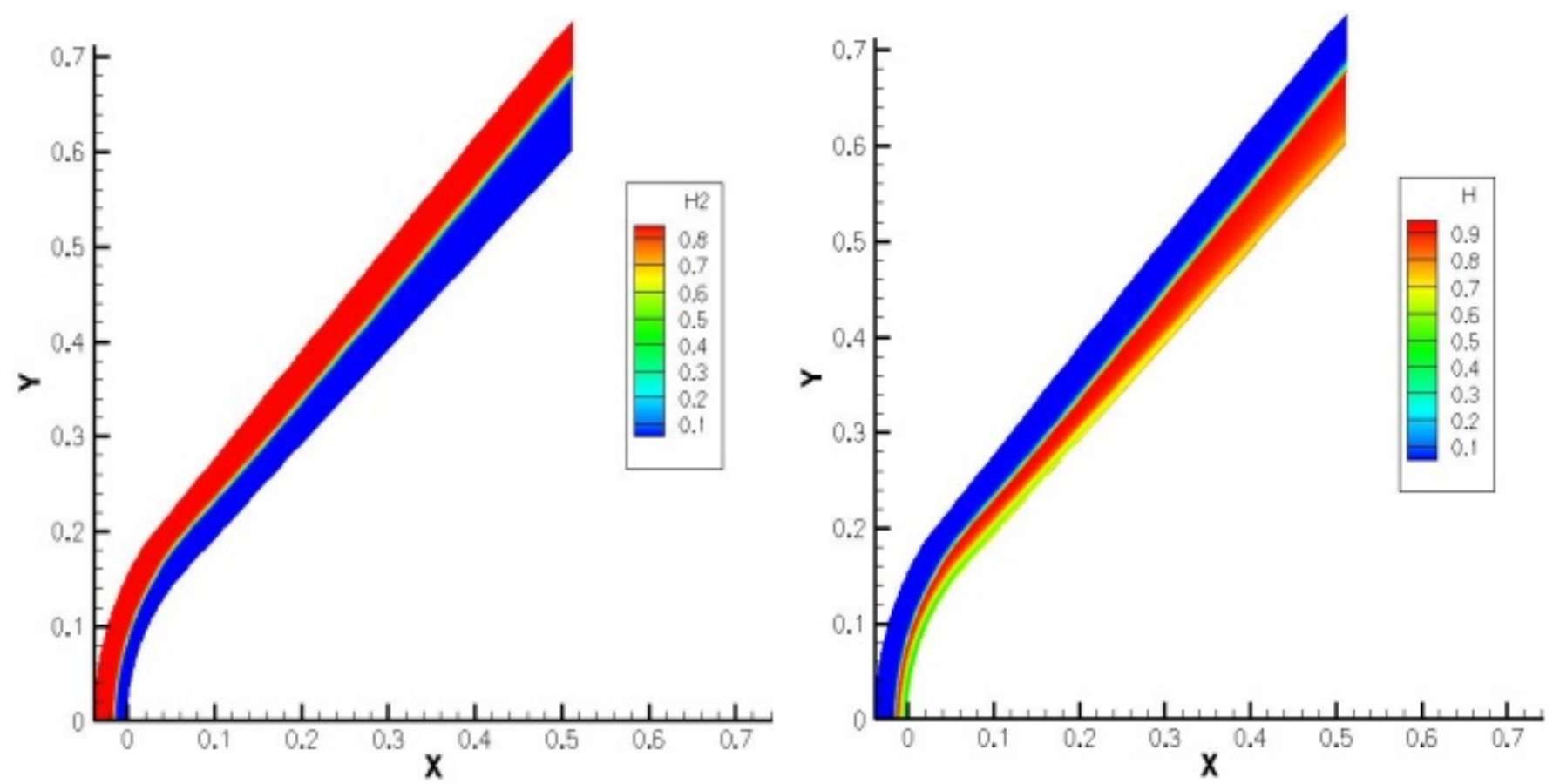

Fig. (27). Mole fraction distributions of molecular hydrogen (left) and atomic hydrogen (right) predicted with the 6 species model at $180 \mathrm{~km}$ of altitude.
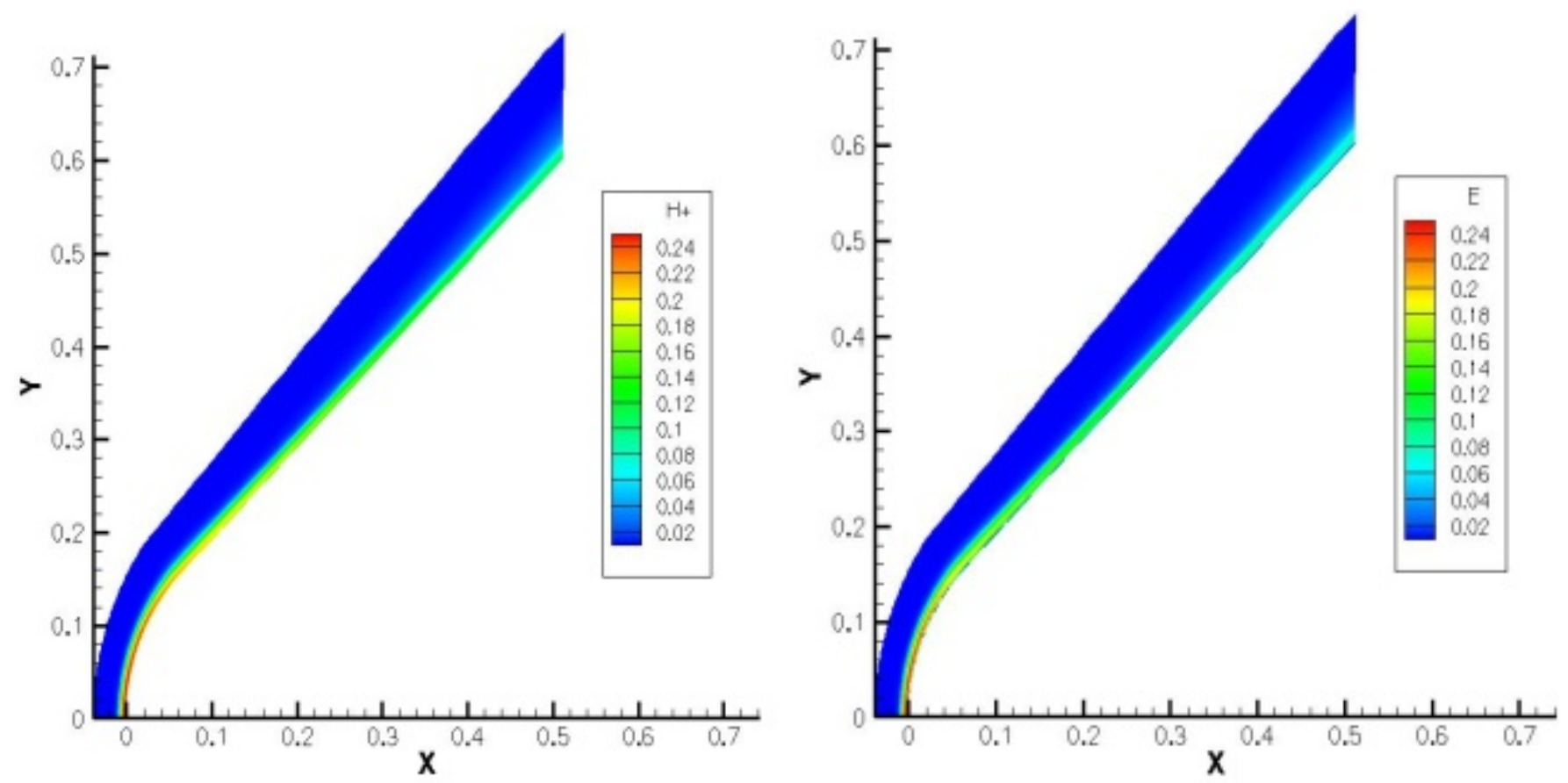

Fig. (28). Mole fraction distribution of protons (left) and electrons (right) predicted with the 6 species model at $180 \mathrm{~km}$ of altitude.

value was compared to those predicted in [63] for 170 and $190 \mathrm{~km}$ of altitude, unfortunately this was a mistake since these values concerned a radiative flux. However, comparisons with pre-flight predictions [57-59] and with the results of Savajano [75] are possible. This value is in between the predictions of 79 and $114 \mathrm{MW} / \mathrm{m}^{2}$ done by Moss [59] for altitudes of 195 and $170 \mathrm{~km}$ respectively; it is higher than other predictions $[57,58]$. Comparisons with the results of Savajano [75] are interesting since this author obtains a convective stagnation point heat-flux in between 74 and $158 \mathrm{MW} / \mathrm{m}^{2}$ as function of the models retained for the thermodynamic and transport properties. This confirms that a certain effort is needed for investigating the chemistry of Jupiter atmosphere at high temperature.

\subsection{Partial Conclusion: The Challenging Problems of the Jupiter Entry Aerothermodynamics}

The available data related to Jupiter entry have been gathered and analysed. Using the flight data and the CFD activities performed for the mission preparation and post- 


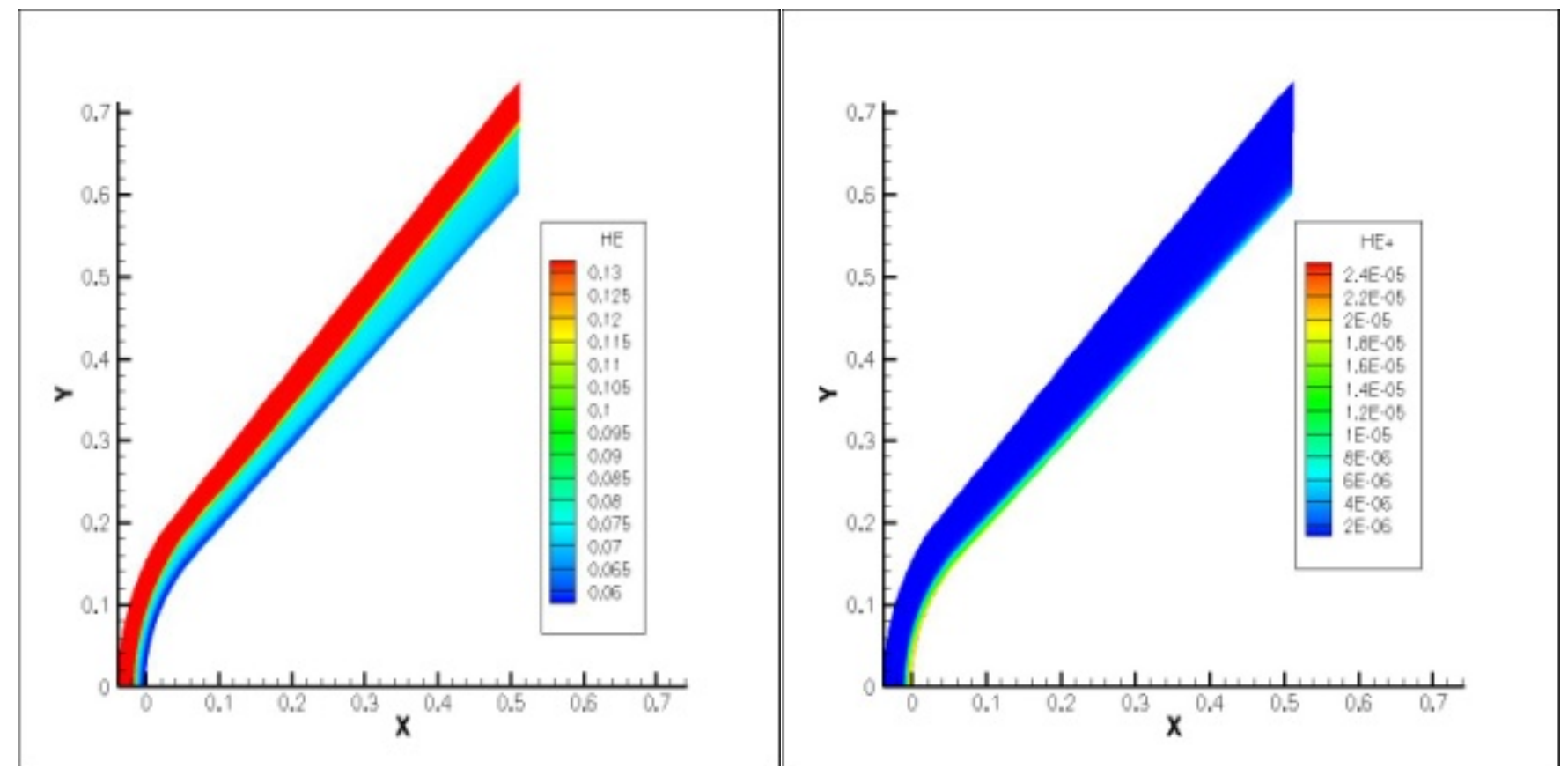

Fig. (29). Mole fraction distribution of $\mathrm{He}$ (left) and $\mathrm{He}^{+}$(right) obtained with the 7 species model at $180 \mathrm{~km}$ of altitude.

flight analyses, a computational matrix has been selected. In a second phase, a chemical kinetic model has been set up based on previous efforts.

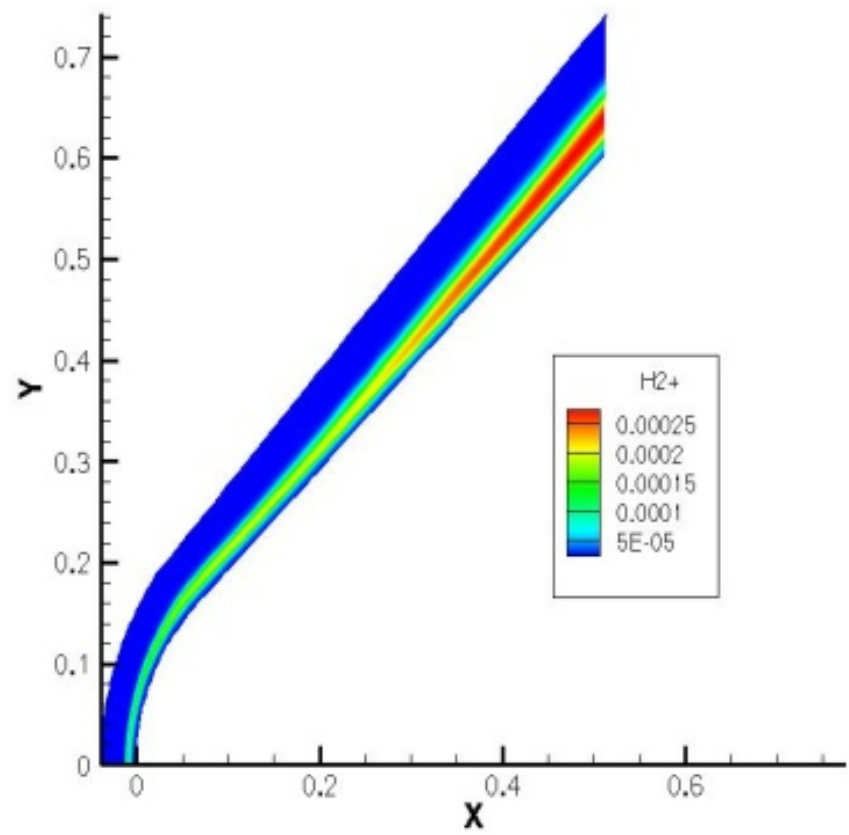

Fig. (30). Mole fraction distribution of $\mathrm{H}_{2}{ }^{+}$ions obtained with the 7 species model at $180 \mathrm{~km}$ of altitude.

Then, the computational matrix has been computed, and the effort of analysis concentrated on the trajectory point with the highest non-equilibrium. The numerical results obtained for $180 \mathrm{~km}$ of altitudes how generally a good agreement with other studies. Comparisons have also highlighted some discrepancies for the temperatures and heat-flux that underlines that some additional efforts are necessary for transport properties and thermodynamic. Future efforts will be concentrated for the prediction of radiative heat-flux and computations with a chemical kinetic model based on a state-to-state approach.

\section{MHD EFFECTS ON CHEMICAL REACTING FLOW PAST A BLUNT-BODY}

\subsection{Introduction}

Many aerospace applications are characterized by low magnetic Reynolds number $R_{m}(\sim 1)$ and the aircraft re-entry problem is one of them. In fact, in the flight regime of interest, static temperature is too low $(5,000 \mathrm{~K})$ for thermal ionization of air and it does not allow the electrical conductivity $\sigma$ in hypersonic magneto-hydrodynamics (MHD) devices to be very high $\left[\sigma<10^{3}(\Omega m)^{-1}\right]$. Up to now, only few works using upwind methods with a self-consistent, finite and non-homogeneous electrical conductivity have been afforded [88-92]. For this reason, in this work we have developed a two-dimensional MHD model describing a chemically reacting nitrogen hypersonic flow past a bluntbody. The electrical conductivity is obtained selfconsistently by transport calculations solving Boltzmann equation with the third-order approximation of the Chapman-Enskog method [93]. A four-species (N, $\mathrm{N}_{2}, \mathrm{~N}_{2}{ }^{+}$, e) reduced to three by plasma neutrality hypothesis, threereactions scheme for nitrogen chemistry has been used [94]: two gas-induced dissociation channels $\left(\mathrm{N}_{2}+\mathrm{N}_{2} \leftrightarrow \mathrm{N}+\mathrm{N}+\mathrm{N}_{2}\right.$ and $\left.\mathrm{N}_{2}+\mathrm{N} \leftrightarrow \mathrm{N}+\mathrm{N}+\mathrm{N}\right)$ and the ionizing recombination $\left(\mathrm{N}+\mathrm{N} \leftrightarrow \mathrm{N}_{2}^{+}+\mathrm{e}\right)$. The system is considered ideal as regards the gas phase (Euler representation) but not ideal as regards the plasma-magnetic field interaction.

\subsection{Numerical Analysis}

Free stream conditions used are density $\rho_{x}=1.48 \mathrm{gm}^{-3}$, pressure $p_{x}=132 \mathrm{~Pa}$ and temperature $T_{\infty}=300 \mathrm{~K}$, corresponding to air properties of atmosphere at an altitude of $40 \mathrm{~km}$ [88]. A blunt-body diameter $D=1.6 \mathrm{~m}$ has been taken into consideration and in all the cases the imposed initial magnetic 


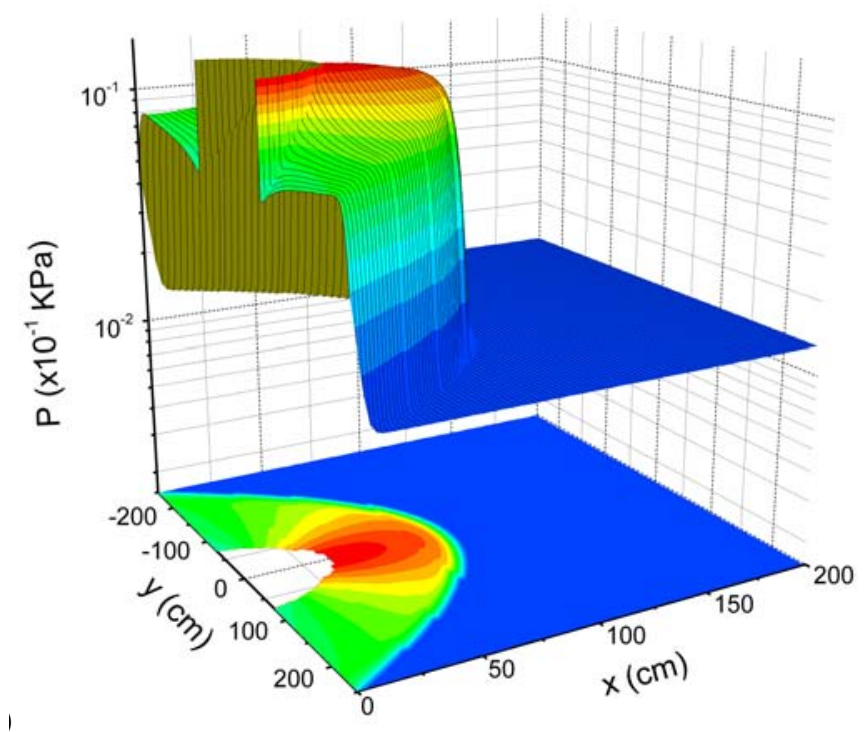

(B)

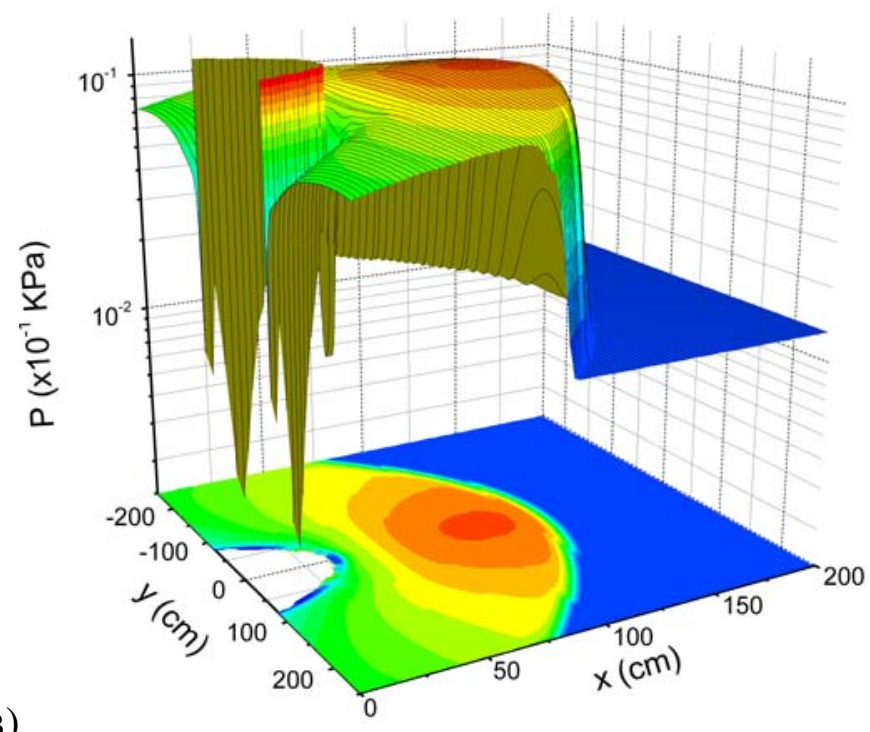

Fig. (31). Two-dimensional distribution of pressure for (a) acoustic $(B=0)$ and $(\mathbf{b})$ plasma $\left(B=5.2 \times 10^{-3} \mathrm{~T}\right)$ flow field using a fixed electrical conductivity $\sigma=4.9 \times 10^{5}(\Omega \mathrm{m})^{-1}$ for $M_{\star}=3.05$.

field is uniform and perpendicular to the flow direction. Free stream conditions used are density $\rho_{x}=1.48 \mathrm{gm}^{-3}$, pressure $p_{s}=132 \mathrm{~Pa}$ and temperature $T_{x}=300 \mathrm{~K}$, corresponding to air properties of atmosphere at an altitude of $40 \mathrm{~km} \mathrm{[88].} \mathrm{A} \mathrm{blunt-}$ body diameter $D=1.6 \mathrm{~m}$ has been taken into consideration and in all the cases the imposed initial magnetic field is uniform and perpendicular to the flow direction.

\subsection{MHD Effect on a Chemical Frozen Gas}

First effects of magnetic field on the plasma flow with a fixed uniform electrical conductivity over the entire simulation domain have been studied. Fig. (31) show the two-dimensional pressure contour distributions in acoustic

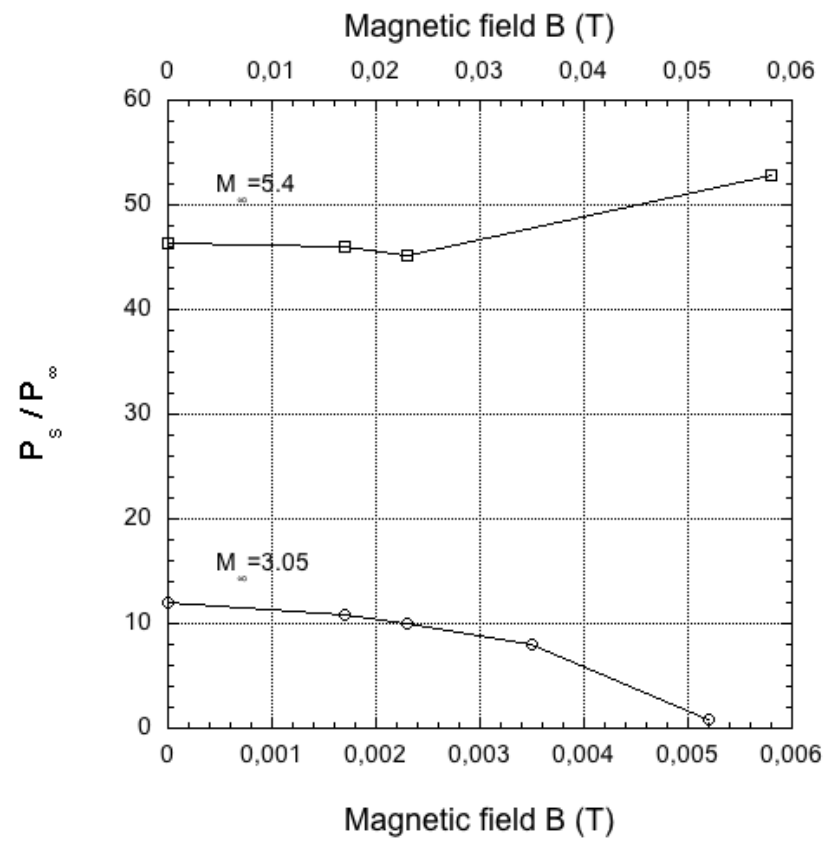

(A)
$\left(B=0\right.$ in Fig. 31a) and plasma $\left(B=5.2 \times 10^{-3} \mathrm{~T}\right.$ in Fig. 31b $)$ fields at Mach number $M_{*}=3.05$ using an electrical conductivity $\sigma=4.9 \times 10^{5}(\Omega \mathrm{m})^{-1}$. Results reveal that the magnetic field effectively pushes the bow shock wave further away from the blunt-body as already observed by different authors [91, 92, 95]. For this case, the shock envelope in the plasma field exhibits an outward displacement compared to the gas dynamic shock by a factor 2 in stand-off distance $\Delta$ (see Fig. 32b).

Numerical results for the acoustic field $(B=0)$ show that pressure jump across the shock wave according to the RankineHugoniot condition. Subsequently, pressure rises monotonically

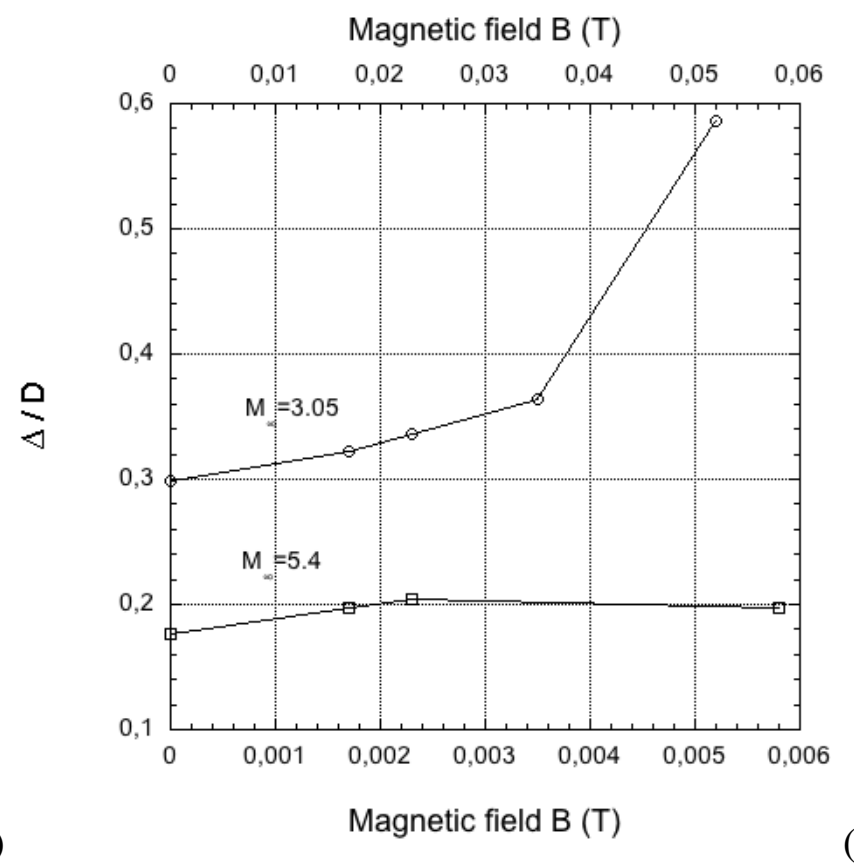

Fig. (32). (a) Surface pressure and (b) shock stand-off distance $\Delta$ as a function of magnetic field for the two flow regimes analyzed, $M_{x}=3.05$ and $M_{\infty}=5.4$ in the case of chemical frozen gas. 

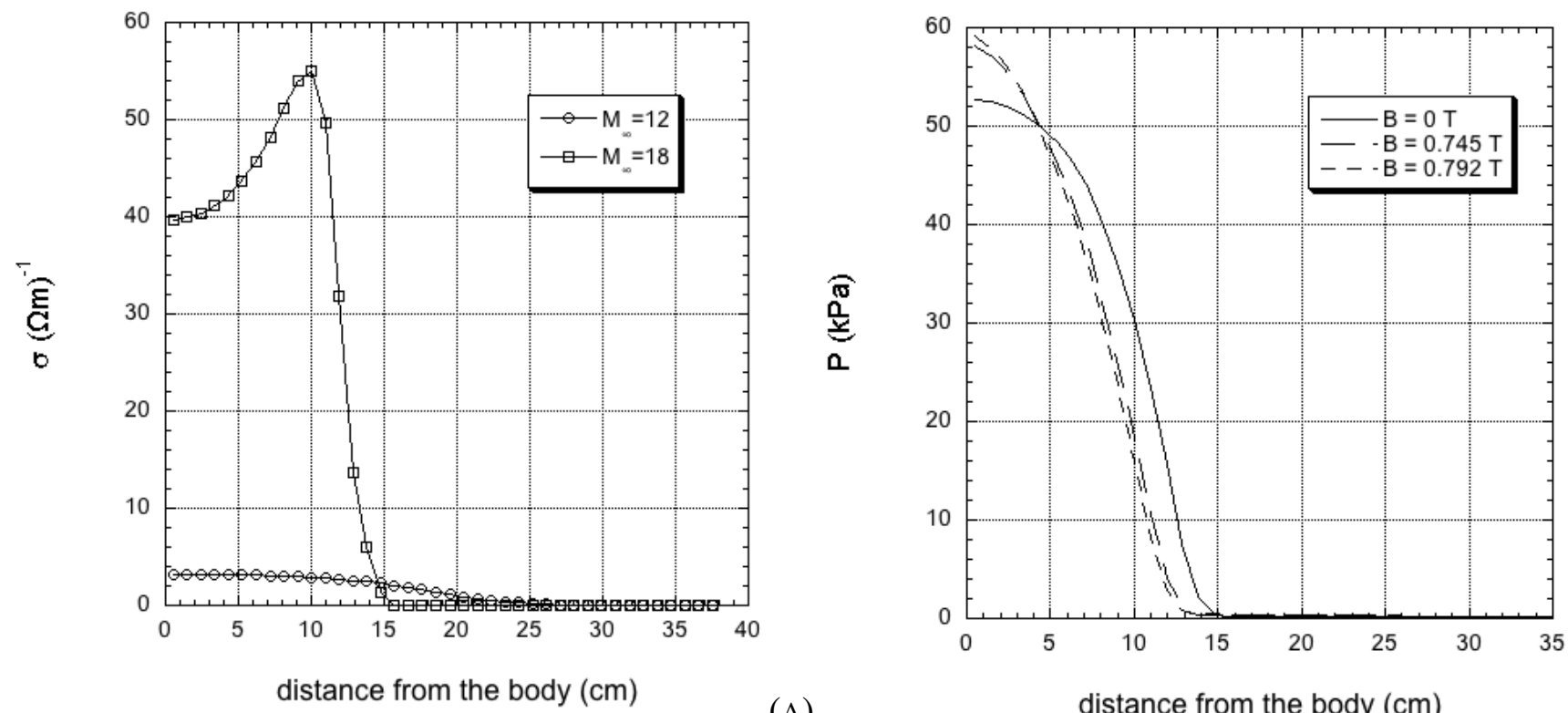

(A)

distance from the body $(\mathrm{cm})$

Fig. (33). (a) Electrical conductivity profile along the stagnation line for two flow regimes, $M_{\star}=12$ and $M_{\infty}=18$, in the case of chemical reacting gas. (b) Pressure profiles along the stagnation line calculated for three different magnetic fields in the case of chemical reacting gas for $M_{\infty}=18$.

as the flow further compresses to the stagnation point of the blunt-body nose. In contrast, the post-shock pressure distribution along the line of symmetry in the MHD case follows a non-monotonic variation. As the strength of the magnetic field increases, a new secondary wave appears in addition to the main shock wave. The compression across the bow shock is subsequently followed by an expansion across the secondary MHD wave. This wave develops at the body surface and it is the result of the magnetic force $\boldsymbol{F}_{\mathrm{m}}$ opposing to the flow velocity $\boldsymbol{u}$ and then tending to decelerate the flow. This can also explain the increased shock stand-off distance observed for the case of imposed magnetic field (see Fig. 32b). In fact, the shock wave location results from a balance between the aerodynamic pressure $P$ ahead of the shock and the total, aerodynamic plus magnetic pressure, behind the shock. The magnetic pressure increases as $B$ is increased, thus moving the shock wave away from the body. The gradients of the gas dynamic parameters decrease and the gas dynamic force exerted on the body also decreases, as shown by the surface pressure behaviour in Fig. (32a). This trend is completely reversed increasing the Mach number $M_{\infty}=5.4$ with $\sigma=1 \times 10^{3}(\Omega \mathrm{m})^{-1}$. In this case, the surface pressure (Fig. 32a) is an increasing function of the applied magnetic field, while the shock stand-off distance (Fig. 32b) is almost unchanged, as already observed by Hoffmann-Damevin-Dietiker [91]. The reason for the reduction of magnetic effectiveness on the plasma flow is ascribed to the fact that the retarding magnetic force $\boldsymbol{F}_{\mathrm{m}}$ is not more able to overcome the accelerating effect, which is larger due to the high Mach number value.

\subsection{MHD Effect on a Chemical Reacting Gas}

With self-consistent calculation of the electrical conductivity, as already observed in the boundary layer theory of Bush [96], the effectiveness of magnetic control is strongly reduced. MHD effects on plasma flow are almost absent for Mach number $M_{x}<16$. The reason is ascribed to a very low ionization degree; electrical conductivity is too small to couple magnetic field with plasma flow. Only for high-hypersonic $M_{*}>16$ conditions (corresponding to a specific enthalpy $H$ of $16.4 \mathrm{MJ} / \mathrm{kg}$ ), the ionization rate starts to became relevant and the conductivity acquires values enabling a coupling between plasma flow and magnetic field [97-99]. In Fig. (33a), profiles along the $x$-axis of $\sigma$ for two different Mach numbers, $M_{\infty}=12$ and $M_{\infty}=18$, are reported. Due to the fact that magnetic field effects are important only at high Mach numbers, the effect is an increasing of the surface pressure with applied magnetic field as already seen for the chemically frozen gas case at $M_{x}=5.4$. In Fig. (33b) pressure profiles along the $x$-axis are reported comparing the acoustic case with magnetic cases at $M_{\infty}=18$.

These results emphasize the usefulness of uncoupling the electrical conductivity (that is the ionization degree) from the flow dependent variables (such as the temperature). It is possible to achieve such as result with a system in which ionization is assisted by using electron beams or Caesium seeding [89, 100].

\subsection{Partial Conclusion: The Challenging Problems of Reactive MHD}

Computational studies of supersonic and hypersonic flows over a blunt-body were carried out by mean of a numerical tool for magneto-hydrodynamic simulation coupled with a chemical reacting gas though the selfconsistent calculation of electrical conductivity. The flow was studied in the low magnetic Reynolds regimes with an imposed uniform magnetic field perpendicular to the flow direction. Results indicate that the effect of magnetic field using a variable conductivity are visible only at high Mach number, where the accelerating effect of the pressure gradient is too strong to be balanced by the retarding magnetic force. This conclusion suggests the necessity of 
introducing extra electrons and superconducting magnets in order to make electromagnetic control effective.

Further developments will include different magnetic field configurations (dipolar, radial, etc.), oxygen chemistry and tensorial electrical conductivity with the evaluation of other transport variables (thermal conductivity and viscosity) with the implementation of Navier-Stokes equation coupled with Poisson equation to study anode-cathode configurations [101, 102].

\section{CONFLICT OF INTEREST}

The authors confirm that this article content has no conflict of interest.

\section{ACKNOWLEDGEMENTS}

The research leading to these results has received funding from the European Community's Seventh Framework Program (FP7/2007-2013) under grant agreement no. 242311.

The authors thank Professor M. Capitelli for valuable discussions of all problems presented in the paper.

\section{REFERENCES}

[1] NASA's Exploration Systems Architecture. Final Report. Report no.: NASA-TM-2005-214062; p. 758, November 2005.

[2] Surzhikov ST, Shang JS. Radiative and convective heating of ORION space vehicles at earth orbital entries. AIAA paper 2011$0251 ; 2011$.

Available from: http://arc.aiaa.org/doi/abs/10.2514/6. 2011-251

[3] Djadkin A, Beloshitsky A, Shuvalov M, Surzhikov S. Nonequilibrium radiative gas dynamics of segmental-conical space vehicle of large size. AIAA paper 2011-0453; 2011. Available from: http://arc.aiaa.org/doi/abs/10.2514/6.2011-453

[4] Colonna G, D'Ammando G, Perrin MY, et al. Radiation models and radiation transfer in hypersonics. Open Plasma Phys J 2013; In press.

[5] Surzhikov ST. A study of the influence of kinetic models on calculations of the radiation-convective heating of a space vehicle in fire-II flight experiment. Russian J Phys Chem 2008; 2(5): 81426.

[6] Park C, Jaffe RL, Partridge H. Chemical-kinetic parameters of hyperbolic earth entry. J Thermophys Heat Transf 1991; 15(1): 7690. Available from: http://arc.aiaa.org/doi/abs/10.2514/2.6582

[7] Dunn MG, Kang SW. Theoretical and experimental studies of reentry plasmas. NASA technical report. Report no. CR223; NASA 1973.

[8] Bond JW, Watson KM, Welch Jr JA. Atomic theory of gas dynamics. Massachusets: Addison-Wesley Reading 1964.

[9] Treanor CE, Marrone PV. Effect of dissociation on the rate of vibrational relaxation. Phys Fluids 1962; 5(9): 1022-6.

Available from:

http://scitation.aip.org/content/aip/journal/pof1/5/9/10.1063/1.17244 67

[10] Marrone PV, Treanor CE. Chemical relaxation with preferential dissociation from excited vibrational levels. Phys Fluids 1963; 6(9): 1215-21. Available from: http://dx.doi.org/10.1063/1.1706888

[11] Park C. Non-equilibrium hypersonic aerothermodynamics. NewYork: Wiley \& Sons 1990.

[12] Walter R. Recent advances in computational analysis of hypersonic vehicles. Combust Explos Shock Waves 1993; 29(3): 316-9. Available from: http://link.springer.com/article/10.1007\%2FB F00797649

[13] Schneider W. Effect of radiation on hypersonic stagnation flow at low density. Z Flugwiss 1970; 18(2/3): 50-8.

[14] Martin J. Atmospheric re-entry. An introduction to its science and engineering. Englewood Cliffs, New Jersey: Prentice-Hall, Inc1962.

[15] Gruszczynski JS, Warren Jr WR. Experimental heat-transfer studies of hypervelocity flight in planetary atmospheres. AIAA J 1964; 2(9): 1542-50.

Available from: http://arc.aiaa.org/doi/abs/10. 2514/3.2618
[16] James CS. Experimental study of radiative transport from hot gases simulating in composition the atmospheres of mars and venus. AIAA J 1964; 2(3): 470-5.

Available from: http://arc.aiaa.o rg/doi/abs/10.2514/3.2358

[17] Fairbairn AR. Spectrum of shock-heated gases simulating the venus atmosphere. AIAA J 1964; 2(6): 1004-7. Available from: http://arc.aiaa.org/doi/abs/10.2514/3.2487

[18] Thomas GM, Menard WA. Experimental measurements of nonequilibrium and equilibrium radiation from planetary atmospheres. AIAA J 1966; 4(2): 227-37.

Available from: http://arc.aiaa.org/doi/abs/10.2514/3.3423

[19] Freeman GN, Oliver CC. High-temperature thermodynamic and transport properties of planetary $\mathrm{CO}_{2}-\mathrm{N}_{2}$ atmospheres. AIAA J 1970; 8(9): 1687-93.

Available from: http://arc.aiaa.org/doi/abs/ 10.2514/3.5965

[20] Kirk DB, Intrieri PF, Seiff A. Aerodynamic behaviour of the viking entry vehicle: ground test and flight results. J Spacecr Rockets 1978; 15(4): 208-12.

Available from: http://arc.aiaa.org/ doi/abs/10.2514/3.57307

[21] Chen YK, Henline WD, Stewart DA, Candler GV. Navier-stokes solutions with surface catalysis for martian atmospheric entry. J Spacecr Rockets 1993; 30(1): 32-42. Available from: http://arc. aiaa.org/doi/abs/10.2514/3.25468

[22] Tauber ME, Yang L, Paterson J. Flat surface heat transfer correlations for martian entry. J Spacecr Rockets 1993; 30(2): 1649. Available from: http://arc.aiaa.org/doi/abs/10.2514/3.11524

[23] Mitcheletree RA. Aerothermodyamic methods for a mars environmental survey mars entry. J Spacecr Rockets 1994; 31(3): 516-23.

[24] Tauber M, Sutton K. Stagnation-point radiative heating relations for Earth and Mars entries. J Spacecr Rockets 1991; 28(1): 40-2. Available from: http://arc.aiaa.org/doi/abs/10.2514/3.26206

[25] Hassan B, Candler G, Olynick D. Thermo-chemical non-equilibrium effects on the aerothermodynamics of aerobraking vehicles. J Spacecr Rockets 1993; 30(6): 647-55. Available from: http://arc.aiaa.org/doi/abs/10.2514/3.26369

[26] Tauber ME, Palmer GE, Yang L. Earth atmospheric entry studies for manned mars mission. J Thermophys Heat Transf 1992; 6(2): 193-9. Available from: http://arc.aiaa.org/doi/abs/10.2514/3.345

[27] Chen YK, Henline WD, Tauber ME. Mars pathfinder trajectory based heating and ablation calculations. J Spacecr Rockets 1995; 32(2): 225-30.

Available from: http://arc.aiaa.org/doi/abs/10. 2514/3.26600

[28] Hartung LC. Development of a non-equilibrium radiative heating prediction method for coupled flowfield solutions. J Thermophys Heat Transf 1992; 6(6): 618-25.

Available from: http://arc.aiaa. Org/doi/abs/10.2514/3.11542

[29] Park C, Yoon S. Fully coupled implicit method for thermochemical non-equilibrium air at suborbital flight speeds. J Spacecr Rockets 1991; 28(1): 31-9.

Available from: http:// arc.aiaa.org/doi/abs/10.2514/3.26205

[30] Henline W, Tauber M. Trajectory-based heating analysis for the European Space Agency/Rosetta Earth return vehicle. J Spacecr Rockets 1994; 31(3): 421-8.

Available from: http://arc.aiaa.org/ doi/abs/10.2514/3.26455

[31] Greendyke RB, Gnoffo PA, Wes Lawrence R. Calculated electron number density profiles for aeroassist flight experiment. J Spacecr Rockets 1992; 29(5): 621-6.

Available from: http://arc.ai aa.org/doi/abs/10.2514/3.11501

[32] Gnoffo PA, Price JM, Braun RD. Computation of near-wake, aerobrake flowfields. J Spacecr Rockets 1992; 29(2): 182-9. Available from: http://arc.aiaa.org/doi/abs/10.2514/3.26333

[33] Gupta RN, Lee K-P, Moss JN, Sutton K. Viscous shock-layer solution with coupled radiation and ablation for Earth entry. J Spacecr Rockets 1992; 29(2): 173-81.

Available from: http://arc. Aiaa.org/doi/abs/10.2514/3.26332

[34] Mitcheltree RA, Gnoffo PA. Wake flow about the mars pathfinder entry vehicle. J Spacecr Rockets 1995; 32(5): 771-5. Available from: http://arc.aiaa.org/doi/abs/10.2514/3.26682

[35] Milos FS, Chen YK, Gongdon WM, Thornton JM. Mars pathfinder entry temperature data, aerothermal heating, and heatshield material response. J Spacecr Rockets 1999; 36(3): 380-91. Available from: http://arc.aiaa.org/doi/abs/10.2514/2.3457

[36] Paterna D, Monti R, Savino R, Esposito A. Experimental and numerical investigation of martian atmosphere entry. J Spacecr Rockets 2002; 39(2): 227-36. 
Available from: http://arc.aiaa.org/ doi/abs/10.2514/2.3804

[37] Edquist KT. Afterbody heating predictions for a mars science laboratory entry vehicle. AIAA paper 2005-4817; 2005. Available from: http://arc.aiaa.org/doi/abs/10.2514/6.2005-4817

[38] Bose D, Wright M. Uncertainty analysis of laminar aeroheating predictions for Mars entries. AIAA paper 2005-4682; 2005. Available from: http://arc.aiaa.org/doi/abs/10.2514/6.2005-4682

[39] Hollis BR, Collier AS. Turbulent aeroheating testing of mars science laboratory entry vehicle in perfect-gas nitrogen. AIAA paper 2007-1208; 2007.

Available from: http://arc.aiaa.org/doi/ abs/10.2514/6.2007-1208

[40] Hollis BR, Collier AS. Turbulent aeroheating testing of Mars science laboratory entry vehicle. J Spacecr Rockets 2008; 45(3): 417-27. Available from: http://arc.aiaa.org/doi/abs/10.2514/1.31798

[41] Grinstead JH, Wright MJ, Bogdanoff DW, Allen GA. Shock radiation measurements for Mars aerocapture radiative heating analysis. J Thermophys Heat Transf 2009; 23(2): 249-55. Available from: http://arc.aiaa.org/doi/abs/10.2514/1.37281

[42] Surzhikov ST, Omaly P. MSRO convective and radiative heating. AIAA paper 2008-1274; 2008.

Available from: http://arc.aiaa.org/ doi/abs/10.2514/6.2008-1274

[43] Surzhikov ST, Omaly P. Radiative gas dynamics of martian space vehicles. AIAA paper 2011-0452; 2011.

Available from: http://arc. Aiaa.org/doi/abs/10.2514/6.2011-452

[44] Surzhikov ST. Comparative analysis of radiative aerothermodynamics of martian entry probes. AIAA paper 2012-2867; 2012. Available from: http://arc.aiaa.org/doi/abs/10.2514/6.2012-2867

[45] Gromov VG, Surzhikov ST, Charbonnier JM. Convective and radiative heating of a martian space vehicle base surface. Conference Proceedings; 4th European Symp. On Aerothermodynamics for Space Vehicles 2002, Capua, Italy. 2002 ESA SP487: $265-9$.

[46] Surzhikov ST. 2D CFD/RGD Model of space vehicles. Conference Proceedings; Int. Workshop on Radiation of High Temperature Gases in Atmospheric Entry 2003, Lisbon, Portugal. 2003 ESA SP533: 95-102.

[47] Surzhikov ST. TC3: Convective and radiative heating of MSRO for simplest kinetic models. Conference Proceedings; HTGR Workshop, 2005 ESA SP-583: 55-62.

[48] Surzhikov ST. TC3: Convective and radiative heating of MSRO, predicted by different kinetic models. Conference Proceedings; 2nd HTGR Workshop, 2006 ESA SP-629 (CD-ROM).

[49] Surzhikov ST. Three-dimensional computer model of nonequilibrium aerophysics of the spacecraft entering in the martian atmosphere. Fluid Dyn 2011; 46(3): 490-503. Available from: http://link.springer.com/article/10.1134\%2FS001546281103015X

[50] Surzhikov ST. Random models of atomic lines for calculation of radiative heat transfer in laser supported waves. AIAA paper 97-2367; 1997.

Available from: http://arc.aiaa.org/doi/abs/10.2514/6.1997-2367

[51] Surzhikov ST. Computing system for mathematical simulation of selective radiation transfer. AIAA paper 00-2369; 2000. Available from: http://arc.aiaa.org/doi/abs/10.2514/6.2000-2369

[52] Chatwood FM, Gnoffo PA. User's manual for the langley aerothermodynamic upwind algorithm (LAURA). Report no.: TM4674. NASA; 1996. NASA Technical Report.

[53] Park C, Howe JT, Jaffe RL Candler GV. Review of chemicalkinetic problems of future NASA missions, II: Mars entries. J Thermophys Heat Transf 1994; 8(1): 9-23.

Available from: http://arc.aiaa.org/doi/abs/10.2514/3.496

[54] Surzhikov ST, Omaly P. Radiative gas dynamics of Exomars at angle of attack. Conference Proceedings; 4th European HTGR Workshop, Lausanne, Switzerland. Available on CD and wwwpage of European Space Agency.

[55] Surzhikov ST, Shang JS. Radiative aerothermodynamics of entry probes in martian and Earth atmospheres. Conference Proceedings; 7th European Aerothermodynamics Symposium on Space Vehicles, 2011 Bruges, Belgium.

[56] Surzhikov ST. Convective and radiative heating of martian space vehicles. Conference Proceedings; 4th European Conference for Aerospace Sciences (EUCASS) 2011; p. 8 (Proceedings on CD).

[57] Brewer RA, Brant DN. Thermal protection system for the Galileo mission atmospheric entry probe. AIAA paper 80-0358; 1980. Available from: http://arc.aiaa.org/doi/abs/10.2514/6.1980-358
[58] Moss JN, Simmonds AL. Galileo probe forebody flowfield predictions during Jupiter entry. AIAA paper 82-0874; 1982 Available from: http://arc.aiaa.org/doi/abs/10.2514/6.1982-874

[59] Moss JN. A study of the aerothermal entry environment for the Galileo probe. AIAA paper 79-1081; 1979.

Available from: http://arc.aiaa.org/doi/abs/10.2514/6.1979-1081

[60] Kumar A, Tiwari SN, Graves RA, Weilmuenster KJ. Laminar and turbulent flow solutions with radiation and ablation injection for jovian entry. AIAA paper $80-0288 ; 1980$.

Available from: http://arc.aiaa.org/doi/abs/10.2514/6.1980-288

[61] Matsuyama S, Ohnishi N, Sasoh A, Sawada K. Numerical simulation of Galileo probe entry flowfield with radiation and ablation. J Thermophys Heat Transf 2005; 19(1): 28-35.

Available from: http://arc.aiaa.org/doi/abs/10.2514/1.10264

[62] Matsuyama S, Shimogonya Y, Ohnishi N, Sasoh A, Sawada K. Multiband radiation model for simulation of Galileo probe entry flowfield. J Thermophys Heat Transf 2006; 20(3): 611-4. Available from: http://arc.aiaa.org/doi/abs/10.2514/1.16432

[63] Furudate M, Jeung I-S, Matsuyama S. Non-equilibrium calculation of flowfield over Galileo probe. AIAA paper 2006-383; 2006. Available from: http://arc.aiaa.org/doi/abs/10.2514/6.2006-383

[64] Park C. Stagnation-region heating environment of the Galileo probe. J Thermophys Heat Transf 2009; 23(3): 417-24. Available from: http://arc.aiaa.org/doi/abs/10.2514/1.38712

[65] Reynier PH. Survey of convective blockage for planetary entries. Acta Astronaut 2013; 83: 175-95. Available from: http://www.sci encedirect.com/science/article/pii/S0094576512002548

[66] Brewer RA, Brant DN, Fogaroli RP. Development of a steady-state shape change ablation code for the design of outer planet probes. AIAA paper 77-95; 1977.

Available from: http://arc.aiaa. org/doi/abs/10.2514/6.1977-95

[67] Moss JN, Simmonds AL, Anderson EC. Turbulent radiating shocklayers with coupled ablation injection. J Spacecr Rockets 1980; 17(3): 177-83.

Available from: http://arc.aiaa.org/doi/abs/10.2514/3.57726

[68] Haas BL, Milos FS. Simulated rarefied entry of the Galileo probe into the atmosphere of Jupiter. NASA Technical Report. Report no.: TM-110507; NASA 1993.

[69] Anon, Planetary mission entry vehicles: Quick reference guide. NASA SP-3401, Version 3; 2006.

[70] Milos FS. Galileo probe heat shield ablation experiment. J Spacecr Rockets 1997; 34(6): 705-13.

Available from: http://arc.aiaa.org/ doi/abs/10.2514/2.3293

[71] Milos FS, Chen YK, Squire TH, Brewer RA. Analysis of Galileo probe heatshield ablation and temperature data. J Spacecr Rockets 1999; 36(3): 298-306.

Available from: http://arc.aiaa.org/doi/ abs/10.2514/2.3465

[72] Moss JN, Jones JJ, Simmonds AL. Radiative flux penetration through a blown shock-layer for Jupiter entry. AIAA paper 78-908; 1978.

Available from: http://arc.aiaa.org/doi/abs/10.2514/6.1978-908

[73] Park C, Tauber ME. Heat shielding problems of planetary entries a review. AIAA paper 99-3415; 1999.

Available from: http://arc.aiaa. Org/doi/abs/10.2514/6.1999-3415

[74] Park C. Injection-induced turbulence in stagnation point boundary layers. AIAA J 1984; 22(2): 219-25.

Available from: http://arc.ai aa.org/doi/abs/10.2514/3.8371

[75] Savajano R. Modelling of hypersonic flows in Jupiter's atmospheric re-entry ESA-ESTEC. Projet de fin d'étude de l'ensma, Poitiers, France 2007.

[76] Reynier PH. CFD computations of Galileo entry. Conference Proceedings; 53rd Course on Molecular Physics and Plasma in Hypersonics, International School of Quantum Electronics, Erice, Italy, Sept 8-15; 2012.

[77] TINA Version 4: Theory and user manual. TN89/96 Issue 7; Fluid Gravity Engineering, Emsworth, UK, March 2008.

[78] ESA-ESTEC. Jupiter entry probe, concurrent design facility study. Noordwijk, The Netherlands; 2005. CDF-43(A).

[79] Park C. Frontiers of aerothermodynamics, non-equilibrium gas dynamics - from physical models to hypersonic flights. RTO-ENAVT-162-11; 2009.

[80] Tiwari SN, Szema KY. Effects of precursor heating on radiative and chemically reacting viscous flow around a jovian entry body. NASA Technical Report. Report no.: CR-3181. NASA; 1979. 
[81] Park C. Non-equilibrium ionization and radiation in hydrogenhelium mixtures. J Thermophys Heat Transf 2012; 26(2): 231-43. Available from: http://arc.aiaa.org/doi/abs/10.2514/1.T3689

[82] Park C. Non-equilibrium chemistry and radiation for Neptune entry. J Spacecr Rockets 2011; 48(6): 897-903.

Available from: http://arc.aiaa.org/doi/abs/10.2514/1.51810

[83] Leibowitz LP. Measurements of the structure of an ionizing shock wave in a hydrogen-helium mixture. Phys Fluids 1973; 16(1): 59-68. Available from: http://dx.doi.org/10.1063/1.1694174

[84] Smith AJ, Gogel T, Vandevelde P, Marraffa L. Plasma radiation database. Technical Report ESTEC. Contract No.: 11148/94/NL/ FG; Fluid Gravity Engineering, Emsworth, UK 1996.

[85] McBride BJ, Zehe MJ, Gordon S. NASA glenn coefficients for calculating thermodynamic properties of individual species. NASA Technical Report. Report no.: TP-2002-211556, NASA; 2002.

[86] Yee HC. Construction of explicit and implicit symmetric TVD schemes and their applications. J Comp Phys 1987; 68(1): 151-79. Available from: http://www.sciencedirect.com/science/article/pii/0 021999187900490

[87] Reynier PH. Numerical reconstruction of Galileo entry. Conference Proceedings; ESA SP-714, 5th International Workshop on Radiation and High Temperature Gases in Atmospheric Entry, Barcelona 2012.

[88] Fujino T, Ishikawa M. Numerical simulation of control of plasma flow with magnetic field for thermal protection in Earth re-entry flight. IEEE Trans Plasma Sci 2006; 34(2): 409-20.

[89] Maccormack RW. Numerical simulation of aerodynamic flow within a strong magnetic field with hall current and ion slip. AIAA paper 2007-4370; 2007

Available from: http://arc.aiaa.org/ doi/abs/10.2514/6.2007-4370

[90] Macheret SO, Shneider MN, Miles RB. Magneto-hydrodynamic control of hypersonic flows and scramjet inlets using electron beam ionization. AIAA J 2002; 40(1): 74-81.

Available from: http://arc.aiaa.org/doi/abs/10.2514/2.1616

[91] Hoffmann KA, Damevin HM, Dietiker JF. Numerical simulation of hypersonic magneto-fluid dynamic flows. AIAA paper 2000-2259; 2000.

Available from: http://arc.aiaa.org/doi/abs/10.2514/6. 2000-2259

[92] Poggie J, Gaitonde DV. Magnetic control of flow past a bluntbody: numerical validation and exploration. Phys Fluids 2002; 14(5): 1720-31.
Available from: http://dx.doi.org/10.1063/1.14654 24

[93] Capitelli M, Gorse C, Longo S, Giordano D. Collision integrals of high-temperature air species. J Thermophys Heat Transf 2000; 14(2): 259-68

Available from: http://arc.aiaa.org/doi/abs/10.2514/ 2.6517

[94] Sarma GSR. Physico-chemical modelling in hypersonic flow simulation. Prog Aerosp Sci 2000; 36(3-4): 281-349. Available from: http://www.sciencedirect.com/science/article/pii/S037604210000004X

[95] Bityurin VA, Bocharov AN. Magneto-hydrodynamic interaction in hypersonic air flow past a blunt-body. Fluid Dyn 2006; 41(5): 843-56. Available from:

http://link.springer.com/article/ 10.1007\%2Fs10697-006-0100-5

[96] Bush WB. Magneto-hydrodynamic hypersonic flow past a blunt nose. J Aero Sci 1958; 25(11): 685-90.

Available from: http://arc. Aiaa.org/doi/abs/10.2514/8.7845

[97] Cristofolini A, Borghi CA, Neretti G, et al. Experimental investigations on the MHD interaction around a blunt-body in a hypersonic unseeded air flows. AIAA paper 2012-2730; 2012. Available from: http://arc.aiaa.org/doi/abs/10.2514/6.2012-2730

[98] Cristofolini A, Borghi CA, Schettino A, Battista F. Numerica rebuilding of MHD tests in an unseeded mach 10 air flow around a blunt-body. AIAA paper 2012-2733; 2012.

Available from: http://arc.aiaa.org/doi/abs/10.2514/6.2012-2733

[99] Cristofolini A, Borghi CA, Neretti G, et al. Experimental investigations on the magneto-hydrodynamic interaction around a blunt-body in a hypersonic unseeded air flow. J Appl Phys 2012; 112: 093304. Available from: http://dx.doi.org/10.1063/1.4764105

[100] Maccormack RW. Solution of Maxwell's equations coupled to the Navier-Stokes equations. AIAA paper 2009-3911; 2009. Available from: http://arc.aiaa.org/doi/abs/10.2514/6.2009-3911

[101] Wan T, Candler GV, Macheret OS, Shneider MN. Three-dimensional simulation of the electric field and magneto-hydrodynamic power generation during re-entry. AIAA J 2009; 47(6): 1327-36. Available from: http://arc.aiaa.org/doi/abs/10.2514/1.32006

[102] Fujino T, Yoshino T, Ishikawa M. Aerodynamic heating of re-entry body equipped with onboard-surface hall magneto-hydrodynamic generator. J Prop Power 2010; 26(4): 638-48. Available from: http://arc.aiaa.org/doi/abs/10.2514/1.45080

(C) Surzhikov et al.; Licensee Bentham Open.

This is an open access article licensed under the terms of the Creative Commons Attribution Non-Commercial License (http://creativecommons.org/licenses/by-nc/3.0/) which permits unrestricted, non-commercial use, distribution and reproduction in any medium, provided the work is properly cited. 